\title{
Worlds Apart: Marx, Marcuse and Creative Engagement
}

\author{
by
}

Rebecca van der Post

B.A., Arts And Contemporary Studies (Ryerson University, 2014)

\author{
A Thesis \\ presented to Ryerson University \\ in partial fulfillment of \\ Master of Arts (M.A.) \\ in the Program of \\ Philosophy \\ Toronto, Ontario, Canada, 2017 \\ (C) Rebecca van der Post, 2017
}


AUTHOR'S DECLARATION FOR ELECTRONIC SUBMISSION OF A THESIS I hereby declare that I am the sole author of this thesis. This is a true copy of the thesis, including any required final revisions, as accepted by my examiners.

I authorize Ryerson University to lend this thesis to other institutions or individuals for the purpose of scholarly research.

I further authorize Ryerson University to reproduce this thesis by photocopying or by other means, in total or in part, at the request of other institutions or individuals for the purpose of scholarly research.

I understand that my thesis may be made electronically available to the public. 


\section{$\underline{\text { Abstract }}$ \\ Worlds Apart: Marx, Marcuse and Creative Engagement Rebecca van der Post Master of Arts (2017), Department of Philosophy, Ryerson University}

Marx's early account of socialism as the simultaneous liberation of mankind and nature holds creativity to be mankind's defining and trans-historical characteristic and the locus of human freedom. Yet, as I argue, Marx's creativity is predicated upon subject-object relations of domination that engender a pathological relationship between humans and nature, thereby militating against true freedom. This paper will explore Marcuse's attempt to rehabilitate Marx's account and will find that Marcuse fails to resolve the crucial tension between subject and object, while his model of freedom contains the possibility for an escalation in the very violations of nature that his account seeks to overcome. Finally, I argue that creative processes and creative engagement suggest a way to resolve the tension in Marx's account of human nature, while offering us a vantage point from which to critique and subvert the brutality of our own historical moment. 


\section{Acknowledgments}

I would like to give a huge and heartfelt thank you to my supervisor Dr. Paula Schwebel for the unlimited generosity of her time, her wisdom and her insight, and for the extraordinary kindness with which she has guided me through this process.

I would also like to give my warmest thanks to my committee members, Dr. John Caruana, Dr. Boris Hennig and Dr Glenn Parsons for their continued support and for their willingness to read this paper during their summer holidays at such considerably short notice.

To Dr James Cunningham, who first drew my attention to the rich potential of creative engagement as an area of philosophical investigation, and whose classroom was one of the happiest and most exciting experiences of my undergraduate days, I am forever indebted.

Finally I would like to thank Malu Maia without whom, I am quite certain, none of this could possibly have happened. 


\section{$\underline{\text { Dedication }}$}

To my husband Garnet and my daughter Francesca, whose love, good humour, and snack-making skills have kept me ever buoyant in the face of a project that has taken me far too long. 


\section{Table of Contents}

Introduction.......

Chapter 1

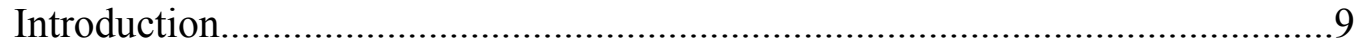

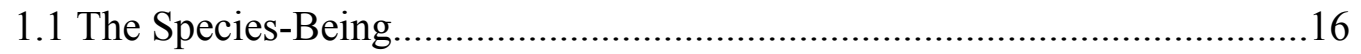

1.2 The Species-Being and Exchange Economy..............................................25

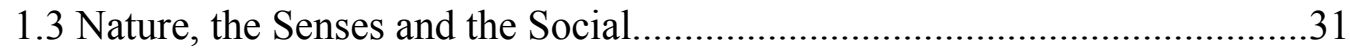

1.4 Humans and Everything Else.......................................................................

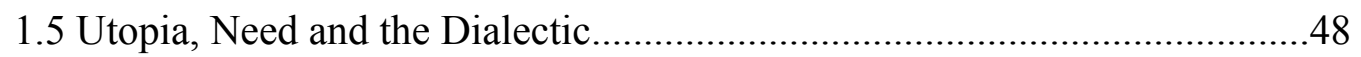

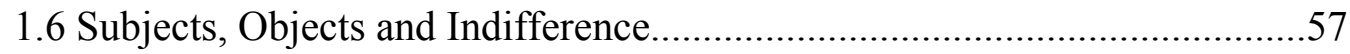

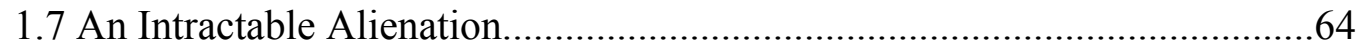

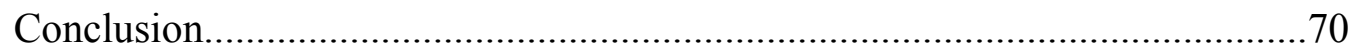

Chapter 2

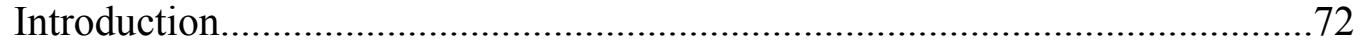

2.1 The Aesthetic Dimension and the Radical Sensibility...................................79

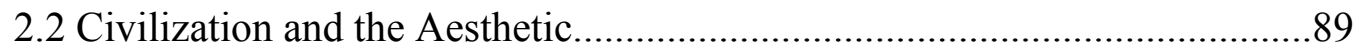

Chapter 3

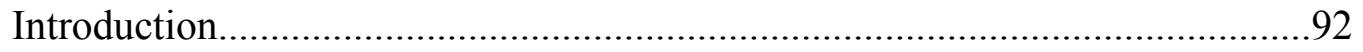

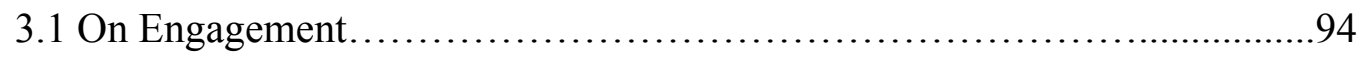

3.2 Marx, Marcuse and the Creative Process...................................................106

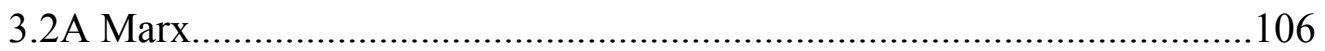

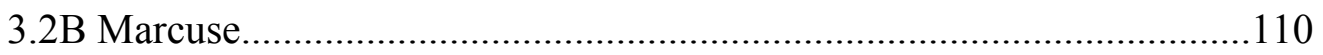

3.3 Some Problems with Engagement as a Way to Change the World.............114

3.4 Odysseus and the Brand New Shiny Motorboat........................................119

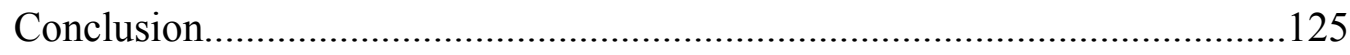

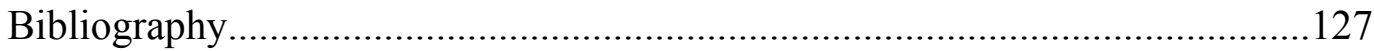




\section{$\underline{\text { Introduction }}$}

Any utopian vision seeking to pole-vault itself across the boundaries of wishful thinking, idle speculation or mere critique and into an active role in the realm of human experience must in some way furnish the foundational utopian commitment to another, better world with possibilities that are both actual and available to us within this world. Yet despite its violent, exploitative and ultimately self-destructive trajectory, our technologized mode of modernity is adept at sealing off those avenues and vistas that point us towards such possibilities. Presupposing its own terms and conditions, western market society preemptively undermines its own systemic transformation, dismissing explorations that point beyond its ideological boundaries as the dubious rumblings of futuristic fantasy or the unfeasible idealization of the past or the primitive. That it is sometimes justified in doing so should not, however, be taken to mean that the utopian project itself ought to be abandoned. Yet if we insist that the viability of any alternative social model depends upon its perpetuation and promulgation of the same principles and priorities as our own we are likely to find it populated by people like us doing the sorts of things that we do and propagating precisely the same sorts of problems.

As things currently stand the compulsion to live in a way that far outstrips our actual needs propels us through life in ways that would be laughable were they not also fully unsustainable, monstrously unethical, deeply irrational and increasingly self-defeating. Clearly, the human being is a creature for whom existence alone is not enough. One of our more contrary characteristics, perhaps, is our inability to feel fully alive when our lives are devoted fully to the processes of being alive. A life whose possibilities unfold within the narrow boundaries of subsistence alone does not feel to us like a truly human life. It remains to be seen, however, 
whether the insatiability of this particular character trait will enable us, eventually and universally, to flourish or whether it will in fact drive us to ever more violent and self-destructive patterns of behavior. The aggregated actions of 7 billion people today are giving rise to problems of such catastrophic magnitude and urgency that we have stripped the future before us of its own possibilities. The horizon that now confronts us does not surpass the present but is mired in its iniquities as the unintended but nonetheless all too foreseeable result of our way of being, and our own children will be left with the unenviable task of rendering fit for purpose the planet on which they must live. Far from moving the human experience beyond the constraints and impositions of need and towards freedom and self-actualization, our gift to posterity seems likely at best to be a globalised struggle to fulfill the basic needs of life and at worst a world in which life itself along with the means by which to sustain it turn out to have been an historical and statistical anomaly.

Our science and technology and the economic system with which it is symbiotically intertwined are themselves among the most sustained expressions of our needs while, at the same time, being instruments of our drive to live beyond them. They are central elements both of the given and of our drive to surpass and transform the circumstances in which we find ourselves, finding increasingly sophisticated ways to extract ever more from nature, human nature itself very much included; they are also, to a very great extent, the means by which we are able to visualize with such clarity the problems we bequeath to the decades ahead. Yet - and problematically - they fail to motivate or mobilize the radical, systemic transformation of our way of life that can surely be the only rational response to the insights they bring and to the knowledge they impart; for, emblematic of our refusal to identify ourselves with our needs even as they embed themselves within the very structures of our modern needs and their systems of 
fulfillment, science and technology have become a reflective surface that beams back at us primarily those needs that they promise to fulfill. Hence we are beguiled with all sorts of possibilities for increasingly technological solutions to the environmental collapse accelerating around us. A prime example is the recent proposal to re-freeze the arctic sea-ice with a system of wind-powered water pumps - an ingenious solution, no doubt, to one of the more urgent problems with which we are confronted, that, at the suggested price of 4 billion dollars, will make an important contribution to the global economic machinery to boot. But in its promise to continue to rescue us from ourselves and in its eagerness to mitigate the social and environmental devastations of our current way of life, our technologized capitalism is not only complicit in but dependant upon our stubborn refusal to consider a less destructive trajectory.

And so the reflective glare of our technological system further entrenches the understanding that our current way of life is as inevitable as it is necessary - that we must continue to expend our energy and ingenuity to support our technological systems, for only then can the systematic technological violations of nature upon which our economy depends be mitigated in such a way that our own continued survival can be ensured. In other words it has become increasingly tricky to differentiate between our own innate human needs and the needs of the technologized economic system upon which we have come to depend. Technocratic capitalism fulfills its totalizing potential at the point at which we believe our own needs to be fully identical with its own and when, dazzled by the manufactured surfaces of the world around us, we are blinded to the other possibilities, to the other ways in which our own potential and that of our world might unfold. It requires - and endlessly reproduces - not freedom but codependence. From within this existentially tautological position any exploration of better ways to go about the business of being human is required to navigate the rather slender terrain made up 
of those things we happen to like about ourselves and our current way of life, minus those that we don't. To the extent that change within the given order appears to be possible it thereby appears to be quantitative, and is restricted to tweaking the relative proportions and distribution of the current set of harms and goods: more of this, less of that - plenty for her, not so much for $\operatorname{him} . .$.

Thus one of the greatest triumphs of our technologized society is its systematic ability to render invisible its most pernicious effects, namely those problems that it not only cannot solve but that it must, in fact, perpetuate for its own continued survival. While many of the problems that beset late technologized capitalism are well-documented, such as gross economic inequality and the ongoing shift towards populism and extremism, it is by no means certain that capitalist society is incapable of resolving these problems on its own terms and within its own socioeconomic framework, should it muster the political will to do so. Resistance to the status quo that articulates itself in terms of such problems is therefore liable to re-enforce the very structures it seeks to overcome. True resistance must therefore identify central problems that industrialized civilization generates but cannot resolve without self-negation. In other words, the utopian longing for a better world must apply itself not to the task of constructing an unattainable fantasy, nor to the project of reform - of rendering palatable the unacceptable and the unviable but to the task of bringing to light what is already here but that we fail to notice. Above all, true resistance must confront the actual with the possible.

All of which brings me to the unabashedly utopian thread weaving back and forth between the early work of Karl Marx and the later work of Herbert Marcuse that is unwavering in its insistence upon the need for qualitative change, and in its commitment to the idea that we ourselves have the potential to be radically transformed and to experience ourselves and our 
world in ways that are entirely possible but that are obscured by the workings of the present social order and its structures.

Marcuse witnessed at first hand the remarkable events of the 1960's in California as the erupting counter-culture mobilized itself against war, racial and social inequality, consumerculture and the stifling repressions of the prevailing establishment. Some twenty years earlier Horkheimer and Adorno had argued persuasively that the infusion of mass culture into everyday experience that seamlessly and enjoyably aligned the perception of individual need with the appetites of the greater economic machinery effectively sounded the swan song for the revolution that Marxian theory had, initially assumed. ${ }^{1}$ But for Marcuse the nature and scope of the 60 's rebellions showed a chink in the armor of an otherwise totalizing system that was hidden from sight at the time that Horkheimer and Adorno were writing. The rebellions of the 1960's impressed Marcuse not only by their rejection of late capitalism and the systemic violence that it inflicts upon humans and nature, but by the spontaneous and creative forms that this rejection assumed, which, to Marcuse suggested that the human spirit itself was finding ways to break itself loose from centuries of repression and to reject the exploitative practices that fuel the advancement and expansion of western civilization. The revolutionary thrust towards a better world was no longer a theoretical model or philosophical construction but was showing itself to be centrally embedded in human nature itself, expressing itself through what Marcuse describes as a 'radical sensibility' and in ways that, for Marcuse, confirmed Marx's early adumbration of the relationship between nature, socialism and human self-actualization in the 1844 manuscripts.

In what follows I will be pursuing the two central strands of Marcuse's utopian thinking that are drawn from the early work of Marx, namely that it possible for us to enter into a

\footnotetext{
${ }^{1}$ Theodor W. Adorno and Max Horkheimer, "Culture Industry," in Dialectic of Enlightenment: Philosophical Fragments (Stanford University Press, 2002), 94-136.
} 
radically transformed relationship with nature - which for Marcuse, as for Marx, is not only nature as an externality but also human nature - and that our own well-being ultimately depends upon our doing so. Retrieving what he finds to be important but neglected themes in Marx's early manuscripts, Marcuse develops an account of the liberation of mankind and nature through the emancipation of the senses in the aesthetic dimension of human experience, where freedom and pleasure will repel the violence and repressions of reality in the pre-conscious and intuitive structures of our being. Like the early Marx, Marcuse finds that the experience of freedom is vital to the transformation of our material reality, yet - and this brings me to the central pillar of this paper - neither Marx nor Marcuse finds a way to resolve the tensions between freedom and necessity in a way that is ultimately to the benefit of the material realm. In the end freedom fails to break out of its own confines within the human experience and nature, ever and aggressively exploited in its supporting role, is left to muddle on as best it can.

Since Marx’s early account of human nature is foundational to everything else in this paper, it will be the focus of my first chapter. The chapter falls into several smaller sections, the first three devoted to an exegesis of Marx's account of the species-being and the last three to some of the ways in which it gets itself and nature into trouble. The second chapter explores ways in which Marcuse picks up Marx’s ideas and tries, albeit unsuccessfully as I will argue, to shake them loose from their underlying "hubris of domination."2 In particular I hope to bring into focus the underlying structures of domination that permeate the subject-object relation in both accounts. In the final chapter I will draw on my own work as a concert violinist, living and working among artists of every different stripe, to show that the creative processes and the state of engagement that they tend to engender show a way to rework some of Marx and Marcuse's

\footnotetext{
${ }^{2}$ Herbert Marcuse, Counter-Revolution and Revolt (Boston: Beacon Press, 1972), 69.
} 
ideas to the advantage of our dysfunctional subject-object relations and, therefore, to nature. Engagement, I will argue, is a locus of both freedom and subversion that furnishes a vantage point from which to critique and rehabilitate the pathological instrumentalizations which propel of our current mode of civilization and our brutalizing relationship with the natural world. 


\section{Chapter 1}

Instrumentalized subjective reason either eulogizes nature as pure vitality or disparages it as brute force, instead of treating it as a text to be interpreted by philosophy that, if rightly read, will unfold a tale of infinite suffering.

(Max Horkheimer, Eclipse of Reason)

\section{Introduction}

Marx firmly eschewed the construction of any kind of fictional Utopia, rejecting all such effort as worthless, ideological speculation that demonstrably fails to provide any useful insight either to the overall historical trajectory of the given reality or to those specific possibilities within the given that, when mobilized, will lead to its eventual transformation. ${ }^{3}$ Yet the early writings of Marx outline a euphoric account of an historical progression towards communism, and "the genuine resolution of the conflict between man and nature and between man and man," ${ }^{4}$ as society moves itself beyond exchange economy and the conditions of alienation, and mobilizes itself as a rational collective towards the conditions of freedom and universal self-actualization. For Marx, the crucial task was not to describe the new social order that would emerge from the struggles of our own but to demonstrate that an historical thrust towards a better world is itself an element of reality that can be brought to light by the systematic and scientific analysis of the dialectical motion of the given. Thus, as Andrew Feenberg once commented, "Marx presupposed the truth of the Utopian tradition - that a more perfect society was not only desirable but also entirely possible - without drawing a blueprint."5

${ }^{3}$ Alfred Schmidt, The Concept of Nature in Marx, (London, New York: Verso, 2014), 128.

${ }^{4}$ Karl Marx, Economic and Philosophic Manuscripts of 1844, trans. Martin Milligan (New York: Prometheus Books, 1988), 103.

${ }^{5}$ Feenberg and Leiss, "Introduction," the Essential Marcuse: Selected Writings, ed. Andrew Feenberg and William Leiss, (Boston: Beacon Press, 2007), xxv. 
Without deviating from the underlying principle of materialism - that our reality is a material reality that can unfold only in accordance with the given laws of nature - Marx undertook, in extraordinarily painstaking detail, to show that although the human being is an integral part of nature and is therefore beholden to the principles by which nature governs itself, the human is itself an active and determining factor of reality - a conscious and thoroughly vested agent of historical change rather than a passively determined happenstance.

Marx's early meditation on human nature, although brief, is the absolute fulcrum of his critique of capitalism. It is here that we find the untenable contradiction that is both the loadbearing beam of industrialized market society and the fault-line that will lead to its eventual and seismic collapse: that the production and accumulation of private property that is mankind's fundamental and natural activity within capitalist market society is an historical circumstance grounded in a brutalizing alienation of the human species from its true nature. It is in this rupture from the self, in this state of total self-estrangement rather than in mankind's economic circumstance, that we find both the imperative of and justification for the total and radical transformation of the given reality. Marcuse, responding in 1932 to the discovery of the 1844 Manuscripts, sees Marx's theory of human nature as an unmistakable call for revolution: "It is precisely the unerring contemplation of the essence of man that becomes the inexorable impulse for the initiation of radical revolution. The factual situation of capitalism is characterized not merely by economic or political crisis but by a catastrophe affecting the human essence; this insight condemns any mere economic or political reform from the outset, and unconditionally requires the cataclysmic transcendence of the actual situation through total revolution. ",

\footnotetext{
${ }^{6}$ Herbert Marcuse, "The Foundation of Historical Materialism," in the essential Marcuse: Selected Writings, ed. Andrew Feenberg and William Leiss, (Boston: Beacon Press, 2007), 96.
} 
In a life reduced to mere subsistence, human existence differs little from that of any other animal. In defining human nature Marx's purpose is to show that the human is, in its essence, fundamentally different to other creatures, and to show that a society that has developed a virtuoso capacity to live far beyond the confines of need but whose structures nonetheless entail a life of relentless and crushing struggle to fulfill basic need for the vast majority of its population, cannot, by any possible stretch, be a properly human society. But of course to do this he must also show that there is in fact society - he must show that, very far from our social condition being a random or incidental circumstance arising from the aggregated actions of atomized individuals as they pursue their enlightened but hermetically sealed self-interest, we are in fact social to our absolute core; and that while individualism under capitalism is indeed a manifestation of the social, the truly individuated and self-actualizing individual that is the purpose and achievement of a truly human society is supplanted in capitalist society by a reified effigy of a society that fails to recognize itself as such. He must show that while self-realization and true flourishing are simply not possible under present conditions, human beings are nonetheless endowed with the capacity to transform themselves and their world, and in fact must do so if a catastrophic collapse into barbarism is to be avoided and if anything remotely akin to their greater potential is to be realized. Finally, Marx must show not only that all of these characteristics - the productive, the social and the transformative - lie at the absolute heart of the human being but that they are corruptible and that capitalism is an expression of their corruption.

Marx's solution is breathtaking in its scope and its simplicity, boiling down both the central problem of capitalism and its resolution to this one essential distillate: the defining characteristic of the human being is the unquenchable thirst for productive activity beyond the 
fulfillment of need. ${ }^{7}$ In other words, we are creative. When emancipated, this essence of the human being is the driving force of total transformation and liberation; but, ensnared by the coercions of division of labour and the pursuit of private property, its radical and subversive potential is siphoned away into profit and surplus, domesticated by affluence and concealed within a system that appears natural, inevitable and beneficial to those that are able to render themselves fit for its purpose. A truly human society would be the springboard for universal selfactualization, propelled by creative productivity beyond need, but in industrialized market society the individual, if he or she is to survive, must apply their productive energies to becoming a product, with or without the appearance of material prosperity and the trappings of wealth, that meets the requirements of the market. Thus, in Marx's early writing we see that there is an inversion within exchange economy where "it is just because man is a conscious being that he makes his life-activity, his essential being a mere means to his existence." ${ }^{8}$ Or as Marcuse comments, “his (man's) existence is a 'means' to the realization of his essence, or - in estrangement - his essence is a means to his mere physical existence."9

We have to be extremely careful in broaching the matter of the essence of man when discussing Marx, for although he uses the term throughout the 1844 manuscripts the notion of an enduring a-historical essence of man is anathema to Marx's overarching views. As he tells us in the sixth of the Theses on Feuerbach: "The human essence is no abstraction inherent in each single individual. In its reality it is the ensemble of the social relations. ${ }^{, 10}$ Precisely because we are social creatures the human essence is socially mediated and therefore historically sensitive. Marcuse elaborates on Marx's views in the following short passage: "the historical experience

\footnotetext{
${ }^{7}$ Marx, 1844, 77.

${ }^{8}$ Ibid., 76.

${ }^{9}$ Marcuse, Foundation, 95.

${ }^{10}$ Marx, "Theses on Feuerbach" in Karl Marx: A Reader, ed. Jon Elster, (Cambridge: Cambridge University press, 1986), 22.
} 
of man is taken up into the definition of his essence. We are no longer dealing with an abstract human essence, which remains equally valid at every stage of concrete history, but with an essence which can be defined in history and only in history." Marx's account of the species-being we must keep in mind that to the extent that this can be read as an account of the essence of man it is an account of the essence of man as it can be extrapolated from the historical circumstances of capitalist society. This is not entirely unproblematic, however, since a very major part of Marx's project is to tease out the essence of man precisely in order to show that there is a genuine possibility for its realization in the future under entirely different social arrangements. So we are immediately confronted with the problem that if, as Marx maintains, the essence of the human being is historically and socially constituted then the exercise of extrapolating from our current social and economic circumstances to a future in which capitalism has been transcended is pointless. It seems that not only the state but, along with it, the essence of man as it appears in the 1844 manuscripts must wither under communism. This, of course, would be consonant with Marx's (sometimes frustrating) aversion to making concrete pronouncements about the details of life under true communism since the form and content of freedom can only, by their very nature, be known and arise from the free actions of the free individual. Yet the dialectical dynamic of historical progress in Marx's account swiftly collapses unless it can be assumed that aspects of the human being, if not fully a-historical, are persistent enough that we can use them to trace a plausible trajectory to a future grounded in some kind of real human possibility rather than in idle fantasy; thus, perhaps, the skeletal brevity of Marx's account, which is pared back to little more than those elements of the human essence that can account for there being any historical motion in the first place. But in fact, Marx himself seems to build upon and fortify his early insights into

\footnotetext{
${ }^{11}$ Marcuse, Foundation, 95.
} 
human nature in his account of the dialectical transformation of material reality, and so I am inclined to agree with Marcuse's further observation that Marx intends certain characteristics of the human being to be understood as trans-historical, in particular our drive to objectify: "Objectification as such belongs - like his participation in nature - to the essence of man, and can thus not be 'superseded'; according to revolutionary theory only a particular form of objectification - reification, "estrangement" - can and must be superseded." ${ }^{.12}$ In other words, and for the purposes of this paper, it seems that we can assume that Marx holds that objectification (or the transferring and embedding one's own self-understanding into the material reality through one's work or production so that the external world becomes a reflection of who we are) and therefore an underlying creative productivity to lie at the absolute heart of the human as a species, while what we become as a result of this creative drive is, thereby, socially and historically constituted. So at any point in time the way in which we go about the business of being human is fluid, temporal, and historical, while the fact that it is fluid, temporal and historical is a constant.

My main purpose in this chapter is to show that in Marx's account, this defining characteristic, this persistent and restless trans-historical drive to transform the given, leads us to an exploitative relationship with the natural world that is ultimately to the detriment of our own well-being. Marx's theory of human nature is such, I will argue, that even when private property is overcome and our social circumstances are transformed for the better, the total instrumentalization of nature is assumed, not because of the political forces with which we must cope but because of what we are and the way in which we express and realize ourselves, while nature, pathologically turned against itself, leads itself headlong towards its own destruction.

\footnotetext{
${ }^{12}$ Marcuse, Foundation, 86.
} 


\subsection{The Species-Being}

Since everything that follows in this paper is a response to Marx's theory of human nature a summary of his account is needed from the outset. So I will begin with Marx's discussion of the human as a species-being to show that human creativity gives rise to subjectobject relations of domination. This account of the species-being will be put to work throughout this chapter to show that our own creativity, as it is understood by Marx, compromises our own freedom and well being.

Marx's analysis of human nature begins with the observation that, while there is an underlying principle governing all life forms that renders work of some sort necessary to the fulfillment of needs and the expenditure of some kind of effort necessary to consumption, the workers in industrialized capitalist society are in the remarkable situation whereby the harder they work and the more productive their efforts, the less they are able to fulfill their needs, even as society itself becomes aver more affluent:

The worker becomes all the poorer the more wealth he produces, the more his production increases in power and range. The worker becomes an ever cheaper commodity the more commodities he creates. With the increasing value of the world of things proceeds in direct proportion the devaluation of the world of men. ${ }^{13}$

For Marx, the absurdity of this "actual economic fact" 14 points us straight to the uncomfortable but glaring truth that a society in which such a thing is not only possible but is also held to be axiomatic is a society in which something somewhere has gone terribly wrong. Such a society, in which our own productive life militates against our greater well-being, de-bases our own selfunderstanding and thwarts our ability to fulfill our greater potential, is symptomatic, for Marx, of a pathological relationship between the human being and its own life-forces - a crisis at the very

\footnotetext{
${ }^{13}$ Marx, 1844,71

${ }^{14}$ Ibid.
} 
heart of human existence that can only be grasped in its entirety when we recognize that the world in which we find ourselves is in fact a world of our own making. And for this we must see human nature for what it is in contrast to the way it is manifest in a looking-glass world whose flawed assumptions and irrational workings entail our continued degradation.

Like other creatures, for Marx, the human being's defining characteristics are inseparable from the ways in which we produce: "The productive life is the life of the species. It is life-engendering life. The whole character of a species - its species-character - is contained in the character of its life activity and free, conscious activity is man's species-character." ${ }^{15}$ Other creatures are productive only to the extent that is required by their needs, and so their actions are not free but coerced and constrained by the specific demands of their existence while they themselves remain undifferentiated from their needs and from the activities that the fulfillment of these needs entails. Humans, however, differ from other species in their drive to produce beyond need: "an animal only produces what it immediately needs for itself or its young. It produces one-sidedly, while man produces universally. It produces only under the dominion of immediate physical need, while man produces even when he is free from physical need and only truly produces in freedom therefrom." ${ }^{, 16}$ Humans, on the other hand, are characterized by free and spontaneous productive activity that is liberated by the satisfaction of our needs.

Critically, for Marx's account, productive activity beyond the mandates of need enables us to differentiate ourselves from our needs, which are a subset of human nature rather than its totality; the difference between the two both liberates and delimits our capacity to act freely. Productive activity beyond need therefore opens us to our self-awareness; but in so doing it also embeds in the very structures our self-recognition a differentiation between what is henceforth
${ }^{15}$ Ibid., 76.
${ }^{16}$ Ibid., 77. 
experienced as the inner world of the self and the external world that is made up of everything else. And so where other creatures that, lacking self-awareness, "merge" ${ }^{17}$ with their own life processes and remain indistinguishable from them, we undertake production as an intentional pursuit; our productive activities are objects of our conscious will in response to our conscious awareness of what we want and need.

We can begin to see that subjectivity, within Marx's account, is predicated upon the space between our self and our object - this distance that opens up between the experiencing self and all that is now understood as being external to it as a result of our productive exertions. But where this space is the seat of our individual subjectivity it is also - as it opens before us - the very thing that enables us to be aware of other people both as individual subjects and as other human beings. This space that prizes us apart from other creatures and from nature, is the incubator of our own self-understanding and our understanding of what it is to be human. Through our free and conscious activity we are able to apprehend ourselves and to differentiate ourselves from those things that are external to us, and, critically for Marx's account, to recognize our common humanity. Production beyond need, then, not only defines us as a species but generates our conscious awareness of ourselves as such: we are "species-beings."

Man is a species-being, not only because in practice and in theory he adopts the species (his own as well as those of other things) as his object, but - and this is only another way of expressing it - also because he treats himself as the actual living species; because he treats himself as a universal and therefore a free being. ${ }^{18}$

In other words, as species-beings we each enfold humanity as a whole into the very structures of our own identity. As a species-being my self-recognition, my experience of being $m e$, is therefore not only that of myself as an individual but of myself as a human being, while my subjectivity is a human subjectivity:

\footnotetext{
${ }^{17}$ Ibid., 76.

${ }^{18}$ Ibid., 75.
} 
Man, much as he may therefore be a particular individual (and it is precisely his particularity which makes him an individual, and a real individual, social being), is just as much the totality - the ideal totality the subjective existence of thought and experienced society present for itself; just as he exists also in the real world as the awareness and the real enjoyment of social existence, and as a totality of human life-activity. ${ }^{19}$

Therefore my own self-actualization, or of course that of any one person, is not merely the fulfillment of my potential as an individual but as a member of the human race, and the way in which any of us comes to understand what it is to be an individual is inextricable from the condition of humanity as we find it. "Above all we must avoid postulating "Society" again as an abstraction vis-à-vis the individual. The individual is the social being....In his consciousness of species man confirms his real social life. ${ }^{, 20}$ Thus, for Marx, the individual and the social cannot be understood in isolation from one-another but must be viewed as an integrated whole, from which it follows that no one person can reach their full true potential at the expense of the whole, (or of the social), but only through their contribution to it; nor can the social be fulfilled at the expense of the individual, whose contribution to the whole must, therefore be their own active self-realization.

The notion of the species-being itself originally comes not from Marx but from Feuerbach:

What is this essential difference between man and the brute?...Consciousness - but consciousness in the strict sense; for the consciousness implied in the feeling of self as an individual, in discrimination by the senses, in the perception and even judgment of outward things according to definite sensible signs, cannot be denied to the brutes. Consciousness in the strictest sense is present only in a being to whom his species, his essential nature, is an object of thought. The brute is indeed conscious of himself as an individual - and he has accordingly the feeling of self as the common centre of successive sensations - but not as a species.....In practical life we have to do with individuals; in science, with species....But only a being to whom his own species, his own nature, is an object of thought, can make the essential nature of other things or beings an object of thought....The brute has only a simple, man a twofold life; in the brute, the inner life is one with the outer. Man has both an inner and an outer life. The

\footnotetext{
${ }^{19}$ Ibid., 105.

${ }^{20}$ Ibid.
} 
inner life of man is the life which has relation to his species-to his general, as distinguished from his individual nature... The brute can exercise no function which has relation to its species without another individual external to itself; but man can perform the functions of thought and speech, which strictly imply such a relation, apart from another individual.... Man is in fact at once I and Thou; he can put himself in the place of another, for this reason, that to him his species, his essential nature, and not merely his individuality, is an object of thought... In the object which he contemplates, therefore, man becomes acquainted with himself... The power of the object over him is therefore the power of his own nature. ${ }^{21}$

The influence of Feuerbach on Marx's theory of human nature is unmistakable. But the feedback loop of human self-understanding sketched out by Feuerbach has a relatively small gene pool to draw upon, a simple cross-pollination of the individual and the group: Marx, positing the universality of the human species being, has a rather more extended sphere of influences in mind that includes not only all other living creatures but nature as a whole:

The life of the species, both in man and in animals, consists physically in the fact that man (like the animal) lives on inorganic nature; and the more universal man (or the animal) is, the more universal is the sphere of inorganic nature on which he lives. Just as plants, animals, stones, air, light, etc., constitute theoretically a part of human consciousness, partly as objects of natural science, partly as objects of art - his spiritual inorganic nature, spiritual nourishment which he must first prepare to make palatable and digestible - so also in the realm of practice they constitute a part of human life and human activity. Physically man lives only on those products of nature, whether they appear in the form of food, heating, clothes, and dwelling, etc. The universality of man appears in practice precisely in the universality which makes all nature his inorganic body - both inasmuch as nature is (1) his direct means of life, and (2) the material, the object, and the instrument of his life activity. Nature is man's inorganic body - nature, that is, in so far as it is not itself human body. Man lives on nature - means that nature is his body, with which he must remain in continuous interchange if he is not to die. That man's physical and spiritual life is linked to nature means simply that nature is linked to itself, for man is a part of nature. ${ }^{22}$

We are universal beings because we make everything our object. Marcuse, in his early analysis of the manuscripts, elaborates thus:

If man can make the species of every being into his object, the general essence of every being can become objective for him: he can possess every being as that which it is in its essence. It is for this reason (....) that he can relate freely to every being: he is not limited

${ }^{21}$ Feuerbach, "The Essence of Christianity," quoted in Marx, 1844, editor's footnote p.78.

${ }^{22}$ Marx, 1844, 77-78. 
to the particular actual state of the being and his immediate relationship to it, but he can take the state of the being as it is in its essence beyond its immediate, particular, actual state; he can recognize and grasp the possibilities contained in every being... man as a species being is a "universal" being: every being can for him become objective in its "species character"; his existence is a universal relationship to objectivity. ${ }^{23}$

The human capacity to grasp these 'possibilities' does not, for Marx, express itself as theoretical pastime or an armchair pursuit but as the core of our very existence, manifest in praxis.

Unrestricted by our instincts in the ways in which we produce, we can draw inspiration for our own efforts from everything we see around us to "apply everywhere the inherent standard to the object, ${ }^{, 24}$ and thereby "form objects in accordance with the laws of beauty," ${ }^{25}$ as opposed to the laws of our own physiological constitution.

Meanwhile, as the productive, experiencing self is a universal subject, a human subject, so too is our production universal. We produce as humans for humanity: "my own existence is social activity, and therefore that which I make of myself, I make of myself for society and with the consciousness of myself as a social being. ${ }^{.26}$ In other words we are inherently creative, and, as a universal species-being, freely and consciously surpass our own physical needs in such a way that we are each aware of the effects of our individual efforts on the social whole of which we are all a part. Thus, for Marx, humanity itself is each individual's project and creation, and in creating humanity the individual is, therefore creating his or her self.

As we take up the stuff of the world and work upon it, transform it into the objects of our production, we are creating the shared externality that is the world we inhabit and the reflection of our productive selves and through which our self-understanding is mediated. As Marcuse points out, "Marx expressly emphasizes the fact that 'production' is not economic production but

\footnotetext{
${ }^{23}$ Marcuse, Foundation, 84.

${ }^{24}$ Marx, 1844, 77.

${ }^{25}$ Ibid.

${ }^{26}$ Ibid., 105.
} 
the self-producing process of the whole of human life. ${ }^{, 27}$ While this includes economic production, in the sense of production as a social system for the fulfillment of need, truly 'human' production cannot be contained within these parameters: within a truly human society there is an entire dimension of human experience that lies in a realm - itself the result of our creative productivity - that is qualitatively different to that of need and economic activity. The self-understanding of any one individual is therefore inextricable from production - not his own individual production, but social production as a whole within each and every dimension of the human experience.

It is just in the working-up of the objective world, therefore, that man really proves himself to be a species being. This production is his active species-life. Through and because of this production, nature appears as his work and his reality. The object of labour is, therefore, the objectification of man's species life: for he duplicates himself not only, as in consciousness, intellectually, but also actively, in reality, and therefore he contemplates himself in a world that he has created. ${ }^{28}$

So we see that man's self-understanding is not only mediated through the social - it forms and reforms itself in response to the external in its entirety. Marcuse's analysis shows us how Marx integrates his theory of human nature into a broader conceptualization of nature as a whole:

In this freedom man reproduces "the whole of nature," and through transformation and appropriation furthers it, along with his own life, even when this production does not satisfy an immediate need. Thus the history of human life is at the same time the history of man's objective world and of the "whole of nature" ("nature" in the wider sense given to this concept by Marx, as also by Hegel). Man is not in nature; nature is not the external world into which he first has to come out of his inwardness. Man is nature. Nature is his "expression," "his work and his reality." Wherever we come across nature in human history it is "human nature" while man for his part is always "human nature" too..... On the basis of the unity thus achieved between man and nature Marx moves towards the crucial definition of objectification, through which the specifically human relationship to objectivity, the human way of producing, is more concretely determined as universality and freedom. Objectification - the definition of man as an "objective being" is not simply a further point appended to the definition of the unity of man and nature, but is the closer and deeper foundation of this unity.", 29

\footnotetext{
${ }^{27}$ Marcuse, Foundation, 97.

${ }^{28}$ Marx, 1844, 77.

${ }^{29}$ Marcuse, Foundation, 85-6.
} 
Here our objectivity appears to be twofold, the external being both the object of our contemplation and the object of our creation. But, since we are sensory creatures there is a further way in which we are 'objective,' for through our senses our objects reveal themselves to us, act upon us, making us in turn their object. In Marx's account objectification is a reciprocal arrangement:

To be objective, natural and sensuous, and at the same time to have object, nature and sense outside oneself, or oneself to be object, nature and sense for a third party, is one and the same thing....A being which does not have its nature outside itself is not a natural being, and plays no part in the system of nature. A being which has no object outside itself is not an objective being. A being which is not itself an object for some third being has no being for its object; i.e. it is not objectively related. Its being is not objective. $^{30}$

So mankind creates the object through which human self-understanding and self-recognition are mediated. In an important way, then, the human being is constituted by the objects of its own creation: we are, as Marx tells us, "established by objects." ${ }^{31}$ The process of self-realization therefore entails the process of 'humanizing nature' - of the creative working and reworking of the external reality so that we can see it as a complete reflection of ourselves as creative beings.

For Marx, the greater our freedom from need, the greater our freedom to modify and transform the world into an environment that supports and enhances our lives in whatever form they might take above and beyond our merely biological existence. Yet at the same time, as we have already seen, creative production gives rise to the experience of a separation and a distance between our selves and the world. This separation is the very source of our subjectivity and the structural underpinning of our interactions with our selves, with one another and with our reality. Without it life's raw potential is suspended endlessly within the cycles of existence, wherein the experiencing self remains an undifferentiated element. Yet precisely in the differentiation

\footnotetext{
${ }^{30}$ Marx, 1844, 154-5.

${ }^{31}$ Ibid., 154.
} 
between the self as subject and the world as its object, or, in other words, in man's essence as an objective being, lies a fundamental externality of the human subject to its object. To the extent that our self-understanding arises through our drive to transform the world according to our own purpose and, to the extent that we are at our most energetic in this when we are free, we are seeing the glimmerings, in the early Marx of subject-object relations that lead to the domination of the object by the subject regardless of our social circumstances.

\subsection{The Species-Being and Exchange Economy}

Where objectification is a trans-historical human characteristic, for Marx, with the capacity to propel us towards self-actualization, the differentiation between the self as subject and the world as its object and the experiential externality of the self to the world that this engenders is also the essential pre-condition for alienation - alienation from the object world and nature, certainly, but also, since the individual himself and his species as a whole are the objects of individual contemplation, alienation from the self and the social, all of which can be experienced as hostile external forces over which the individual has no control. In this section I will be turning to Marx's Comments on James Mill to show how this plays itself out within exchange economy.

Marx proposes that a society based upon private property holds it to be a self-evident and basic belief that man is an inherently selfish being who "produces only in order to have."32 The quality and quantity of his production is directed by a "selfish aim,"33 that springs entirely from his own immediate needs, such that "demand and supply exactly coincide." ${ }^{34}$ Exchange, and the

${ }^{32}$ Marx, "Comments on James Mill," in Karl Marx: A Reader, ed. Jon Elster (Cambridge: Cambridge University Press, 1986), 31.

${ }^{33}$ Ibid.

${ }^{34}$ Ibid. 
surplus production it requires, does not alter the fundamentally selfish nature of his production it is just another, less direct, way of ensuring that his needs are met. ${ }^{35}$

But within an exchange system the objects produced have no meaning in and of themselves for their producer, but are valuable to him only to the extent that they meet someone else's needs. In producing and owning something that someone else needs the producer places the other in a position of dependence relative to his product. He fails to gain any meaningful advantage over the other, however, for this is a reciprocal arrangement, “...the basis of which is mutual plundering." 36

"When I produce more of an object than I myself can directly use, my surplus production is cunningly calculated for your need. It is only in appearance that I produce a surplus of this object. In reality I produce a different object, the object of your production, which I intend to exchange against this surplus, an exchange which in my mind I have already completed." 37

In other words, both parties are bound by their own needs to the objects of the other's production, ${ }^{38}$ the relationship between the two producers being "mediated by the object which each side produces and possesses. ${ }^{39}$ Other people, through and because of their needs, are exploitable - and since our own needs must be met indirectly through exchange, our own survival entails their exploitation. For each party involved, therefore, the other person is of purely instrumental value, each useful to the other only in so far as they produce something the other needs, these needs of the other being, in turn, purely instrumental to personal gain. The system of exchange is driven by the hostile interdependence of competing self-interests and subtended by mutual distrust. As Marx later expands, in Grundrisse:

\footnotetext{
${ }^{35}$ Ibid., 31.

${ }^{36}$ Ibid., 32.

${ }^{37}$ Ibid.

${ }^{38}$ Ibid.

${ }^{39}$ Ibid., 33.
} 
Each individual's production is dependent on the production of all others; and the transformation of his product into the necessities of his own life is [similarly] dependent on the consumption of others.... This reciprocal dependence is expressed in the constant necessity for exchange, and in exchange value as the all-sided mediation. The economists express this as follows: each pursues his private interest; and thereby serves the private interest of all, the general interest, without willing or knowing it.....One could just as well deduce from this abstract phrase that each individual reciprocally blocks the assertion of the others' interests, so that, instead of a general affirmation, this war of all against all produces a general negation. ${ }^{40}$

Marx portrays our creative energies in a market society being put to use to outwit, outbluff or out-deceive the other, whose very existence is therefore a hostile force to be overcome. So under capitalism the initial premise of man as a self-interested being who produces only for personal gain becomes self-validating: given the very conditions in which it arises, self-interest and the need to possess is a spontaneous and human response. So with this as the basis of our self-understanding, we continue to create our selves and our circumstances. The mediation of human need entails a carefully calibrated response to our impressions of the other as they are within this system. And so we become something we are not in order to produce stuff for which we have no immediate need and that we may not even like very much so that we can sell it to someone who we cannot ever know since they have also turned themselves into a producer of stuff for which they themselves have no use so as to sell us something in order then to have the money in our pockets to buy what we do actually need to be able to sustain ourselves and our production within a breathless vortex of second-guessing each other as we now appear to be..... This, then, is the objectification under conditions of alienation - the other person is no longer even an other but an object, to be turned by our manipulations into something fit for our own purpose. Yet the process entails the objectification of the self, so that instead of liberating the

\footnotetext{
${ }^{40}$ Marx, Grundrisse: Foundations of the Critique of Political Economy (Rough Draft), trans. Martin Niclaus, (London: Penguin, 1973), 156.
} 
human subject to be freely and creatively its own self, subject-object relations of domination come to permeate our entire self-understanding:

production does not simply produce man as a commodity, the commodity-man, man in the role of commodity; it produces him in keeping with this role as a spiritually and physically dehumanized being. - Immorality, deformity and hebetation of the workers and the capitalists. - Its product is the self-conscious and self-acting commodity... The commodity-man ... ${ }^{41}$

The Hobbesian world, which for Marx is capitalist society, perpetuates not only a war of all against all but of each against himself.

Everything we have seen so far in this story is a direct result of human action in a social system wherein "presupposing private property, my work is an alienation of life, for I work in order to live, in order to obtain for myself the means of life." ${ }^{, 2}$ So systemically ingrained is this notion of what it is to be human in today's world that Marx's conclusion seems to be rather more like a statement of the glaringly obvious than a revolutionary challenge to the known social order. But if we turn to Marx's vision of 'human' production as it arises from our species-being the perversion of human nature that Marx is trying to articulate becomes more clearly visible:

Let us suppose that we had carried out production as human beings. Each of us would have in two ways affirmed himself and the other person. (1) In my production I would have objectified my individuality, its specific character, and therefore enjoyed not only an individual manifestation of my life during the activity, but also when looking at the object I would have the individual pleasure of knowing my personality to be objective, visible to the senses and hence a power beyond all doubt. (2) In your enjoyment or use of my product I would have the direct enjoyment both of being conscious of having satisfied a human need by my work, that is, of having objectified man's essential nature, and of having thus created an object corresponding to the need of another man's essential nature. (3) I would have been for you the mediator between you and the species, and therefore would become recognized and felt by you as a completion of your own essential nature and as a necessary part of yourself, and consequently would know myself to be confirmed in your thought and your love. (4) In the individual expression of my life I would have created your expression of your life, and therefore in my individual activity I

\footnotetext{
${ }^{41}$ Marx, $1844,87$.

${ }^{42}$ Marx, James Mill, 35.
} 
would have directly confirmed and realised my true nature, my human nature, my communal nature. ${ }^{43}$

Within a truly human society we would recognize one another as fellow subjects rather than as externalities and objects to be exploited; within the social realm of our existence we would reject the possibility that subjectivity furnishes for subject-object relations of domination. Critically, for Marx, as we see in the quotation above, it is upon this that our own freedom and selfactualization depend: the 'completion' or fulfillment of the self is either universal or not at all.

The individual is the social being. His life, even if it may not appear in the direct form of a communal life carried out together with others - is therefore an expression and confirmation of social life. Man's individual and species life are not different, however much - and this is inevitable - the mode of existence of the individual is a more particular, or more general mode of the life of the species, or the life of the species is a more particular or more general individual life. ${ }^{44}$

In other words, for Marx, true individuality is a social achievement. But equally, so too is alienation: that we experience ourselves as or atomized individuals, pitted in isolation against one another and against the forces that arise from our aggregated actions, is itself a manifestation of a society in denial of the social. Yet both individuality and alienation arise within the space that opens between the subject and the world beyond through the processes of objectification.

There may in fact be a useful distinction to be made between individuality and individualism: individuality, as it appears in Marx's account, is the subjective experience and expression of the social through an individual's spontaneous, creative, productive contribution to a world that, in turns supports, reflects and stimulates such activity; while individualism, which characterizes our own social arrangements at this time, is concerned with the irreducible unit of fiscal accountability, thereby reducing the individual to a purely administrative category. But when each individual is pitted against the combined economic forces of the market-driven

\footnotetext{
${ }^{43}$ Marx, James Mill, 34.

${ }^{44}$ Marx, 1844, 105.
} 
actions of seven billion others there is no true emancipation of individual potential - there is conformity and compliance in the face of the insurmountable while, as Horkheimer once wrote, “the individual's self-preservation presupposes his adjustment to the requirements for the preservation of the system. ${ }^{25}$ Thus individualism, as an ideology, gives rise not to the successfully individuated individual but to the atomized masses: the individual within an individualistic society, is, then, a thorough reification - a psychological manifestation of social relations of self-alienation projected onto the commodity in question, which, in this instance, is a person.

\subsection{Nature, the Senses and the Social}

So far, alienation has been discussed in terms of the social. For Marx, and later on for Marcuse, the emancipation of the senses is absolutely central to human freedom, which is predicated upon the complete integration of all human faculties. In the 1844 manuscripts Marx argues that since our self-understanding is mediated through the external in its entirety, to the extent that our understanding of nature is depleted so too is our understanding of our selves. Yet our understanding of nature begins with our senses, which, he finds, are distorted and repressed in an exchange economy. I want to turn to Marx's discussion of the political implications of our sensory involvement with nature, for while it helps to illuminate his understanding of human nature it also hovers as an unresolved tension in his account of the way in which nature is to be transformed both in and as a precondition for freedom, as I will argue in the final sections of this chapter.

There is for Marx a prior, sensory dimension both to the healthy or integrated human experience and to the experience of alienation.

${ }^{45}$ Max Horkheimer, Eclipse of Reason, (Eastford Connecticut: Martino Publishing, 2013), 96. 
Just as private property is only the sensuous expression of the fact that man becomes objective for himself and at the same time becomes to himself a strange and inhuman object; just as it expresses the fact that the assertion of his life is the alienation of his life, that his realization is his loss of reality, is an alien reality: conversely, the positive transcendence of private property i.e. the sensuous appropriation for and by man of the human essence and of human life, of objective man, of human achievements - is not to be conceived merely in the sense of direct one-sided gratification - merely in the sense of possessing, of having. Man appropriates his total essence in a total manner, that is to say, as a whole man." ${ }^{46}$

We have seen in Marx's account that at all times, whether alienated or not, the human being creates itself and the object world through which human self-understanding and self-recognition are mediated. Through our senses our objects reveal themselves to us, act upon us, making us, in turn, their object. We have already seen that we are objective beings in as much as we are not only cognizant of our object but are also its author: this however is a reciprocal arrangement given that we are sensuous creatures. Recalling a passage of Marx that we saw a little earlier, we find a further way in which we are objective:

To be objective, natural and sensuous, and at the same time to have object, nature and sense outside oneself, or oneself to be object, nature and sense for a third party, is one and the same thing....A being which does not have its nature outside itself is not a natural being, and plays no part in the system of nature. A being which has no object outside itself is not an objective being. A being which is not itself an object for some third being has no being for its object; i.e. it is not objectively related. Its being is not objective. $^{47}$

The reciprocity of this relationship between the human subject and its object is embedded in the dynamics of need:

Hunger is a natural need; it therefore needs a nature outside itself, an object outside itself, in order to satisfy itself, to be stilled. Hunger is an acknowledged need of my body for an object existing outside it, indispensible to its integration and to the expression of its essential being. ${ }^{48}$

\footnotetext{
${ }^{46}$ Marx, 1844, 106.

${ }^{47}$ Ibid., 154-5.

${ }^{48}$ Ibid.,, 154.
} 
But, as we have already seen, human subjectivity arises through the experience of the self as it works not only to consume but also to produce its object - an activity that moves the fulfillment of need itself into a realm of experience beyond the mere fulfillment of need and where it has the potential to become a creative 'objectifying' act.

But man is not merely a natural being: he is a human natural being. That is to say, he is a being for himself. Therefore he is a species being, and has to confirm and manifest himself as such both in his being and in his knowing. Therefore human objects are not natural objects as they immediately present themselves, and neither is human sense as it immediately is - as it is objectively - human sensibility, human objectivity. Neither nature objectively nor nature subjectively is directly given in a form adequate to the human being. ${ }^{49}$

The further suggestion in this passage is that within a truly human society the way in which we go about meeting our needs would itself be an act of creativity and a fluid expression of our selves and of our historical moment and can thereby be a moment within the unfolding of our self-actualization. "Hunger is hunger. But the hunger which is satisfied with cooked meat eaten with knife and fork is another hunger than that which swallows raw meat with the aid of hands, nails and teeth. ${ }^{, 50}$ In other words, our sensory apparatus itself is, to some degree, historically sensitive to the way in which we fulfill our needs.

But, under conditions of estrangement the processes of need fulfillment propel a vicious circle where nature is molded into a form adequate not for the human being but for the market. In a market economy true sensory relations with nature, (both human nature and external or 'inorganic' nature,) are displaced by the drive to possess, for further possession is experienced as a fundamental need even despite its being a manifestation of alienation from genuine need, supplanting the types of creative interactions that are spontaneously kindled with the external

\footnotetext{
${ }^{49}$ Ibid., 155-6.

${ }^{50}$ Marx, A Contribution to the Critique of Political Economy, quoted in Schmidt, "Concept of Nature", 84.
} 
through production under 'human' or non-alienated conditions. Private property exerts a monopolizing hold over our creative imaginations, distorting and absorbing our capacity for creative production beyond need:

...private property is only the sensuous expression of the fact that man becomes objective for himself and at the same time becomes to himself a strange and inhuman object...it expresses the fact that the assertion of his life is the alienation of his life, that his realization is his loss of reality, is an alien reality... ${ }^{51}$

Possession is always of an object and Marx is suggesting that we cannot apprehend the external in terms of things to be owned or possessed without an ossification of both the self and its object. Through the need to possess we become dispossessed of what would otherwise be a rich, complex and creative interaction with the things around us. Possession itself, for Marx, is a onedimensional relationship with the object world, driven by exchange economy and entailing the suppression of what would otherwise be the full, sensory experience of our world. When our lives are sustained through a system of private ownership and exchange the richness of possibility that is latent within our every intersection with the things of the world is supplanted by the monochromatic need to have. Ownership under conditions of exchange economy, for Marx, is therefore a form of sensory deprivation: as we internalize the economic model upon which the fulfillment of need has come to depend, our compliance with its terms and conditions renders us insensible to crucial dimensions of our own experience, severing ourselves not only from our species being (as we saw earlier) but from the sensory interplay with our world that informs and en-richens our understanding of nature and the self within it. The material world we experience under capitalism is different, therefore, to the world we experience when private property has been transcended.

\footnotetext{
${ }^{51}$ Marx, 1844, 106.
} 
The notion that our economic system fundamentally alters the way in which we perceive the material reality and experience our own physical and sensory beings is not an entirely intuitive idea to grasp, but in the introduction to his astonishing discussion of trees as social beings Peter Wohlleben gives an example of the way this plays itself out in practice that I think is helpful.

When I began my professional career as a forester, I knew about as much about the hidden life of trees as a butcher knows about the emotional life of animals. The modern forestry industry produces lumber. That is to say, it fells trees and then plants new seedlings. If you read the professional literature, you quickly get the impression that the well being of the forest is only of interest insofar as it is necessary for optimizing the lumber industry. That is enough for what foresters do today, and it eventually distorts the way they look at trees. Because it was my job to look at hundreds of trees every day spruce, beeches, oaks and pines - to asses their suitability for the lumber mill and their market value, my appreciation of trees was also restricted to this narrow point of view. ${ }^{52}$

Over time, however, Wohlleben began to organize survival training in the forest and to take visitors on tours.

Visitors were enchanted by crooked, gnarly trees that I would previously dismissed because of their low commercial value. Walking with my visitors, I learned to pay attention to more than just the quality of the tree's trunks. I began to notice bizarre root shapes, peculiar growth patterns, and mossy cushions on the bark. My love of nature... was reignited. Suddenly I became aware of countless wonders I could barely explain even to myself...Life as a forester became exciting once again. ${ }^{53}$

Several aspects of Wohlleben's experience are significant, in terms of Marx's account. We see that as commodities the trees were scrutinized in terms of criteria that were determined elsewhere by market conditions and industry requirements and that have nothing whatsoever to do with the trees themselves as trees. We see that Wohlleben's experience of the trees was also determined not by his own being but by the market. Initially, his day-to-day life among the trees was itself an object of the market, as was he himself. He was, in other words, living his life as

${ }^{52}$ Peter Wohlleben, The Hidden Life of Trees: What They Feel, How They Communicate: Discoveries from a Secret World, trans. Jane Billinghurst (Vancouver: Greystone Books, 2016), xiii.

${ }^{53}$ Ibid., xiv. 
'commodity-man.' When Wohlleben begins to see the forest through the non-proprietorial eyes of his visitors he is, for the first time, seeing the forest as a thing in its own right rather than as an instrument of exchange. Permeated by the sights and the sounds and the textures and the smells of the forest he is, for the first time in his life as a forester, connected with his own sensory being, and as a result of this there is a qualitative change in the way in which the forest appears before Wohlleben: his own sensory epiphany is synchronous with the transformation of his overarching world-view and the liberation of entire new dimensions of the forest, while his rich sensory engagement with the trees in his forest is the spontaneous rejection of his earlier and instrumentalizing priorities. Bur most importantly, the initial propellant for all of these changes is the social re-orientation of Wohlleben's day-to-day working life. Wohlleben's sensory being was liberated through the social. His capacity for a deeper, richer relationship with a more nuanced and complex world began to express itself through his connection to others and his recognition of himself as one among them.

Returning then to Marx, his conviction that the way in which we relate to the social is absolutely critical to the way in which we are able to access the world around us, begins to make more intuitive sense:

Each of his human relations to the world - seeing, hearing, smelling, tasting, feeling, thinking, being aware, sensing, wanting, acting, loving - in short, all the organs of his being, like those organs which are directly social in their form, are in their objective orientation or in their orientation to the object, the appropriation of that object, the appropriation of the human world; their orientation to the object is the manifestation of the human world....Private property has made us so stupid and one-sided that an object is only ours when we have it - when it exists for us as capital, or when it is directly possessed, eaten, drunk, worn, inhabited, etc., - in short when it is used by us. ${ }^{54}$

And of course this, in turn, feeds back into the way in which we connect with our own being and are able to access our own selves:

${ }^{54}$ Marx, 1844, 106. 
“... private property itself again conceives all these direct realizations of possession as means of life, and the life which they serve as means is the life of property-labour and conversion into capital." 55

So although from within the constructs of capitalism private property seems to be necessary to our ability to sustain our existence, it in fact turns our own lives into objects directed towards the servicing and maintenance of the economy. As commodity-beings we are not only emotionally, intellectually and psychologically alienated from ourselves, our world and our species being, but also sensorially.

There is a demonstrably Aristotelian dimension to Marx's argument:

Every perceptual capacity is active in relation to its perceptible object, and completely active when it is in good condition in relation to the finest of its perceptible objects. For this above all seems to be the character of complete activity, whether it is ascribed to the capacity or to the subject that has it. Hence for each capacity the best activity is the activity of the subject in the best condition in relation to the best object of the capacity.

This activity will also be the most complete and the most pleasant. For every perceptual capacity and every sort of thought and study has its pleasure; the most pleasant activity is the most complete; and the most complete is the activity of the subject in good condition in relation to the most excellent object of the capacity. Pleasure completes the activity. ${ }^{56}$

Here in Aristotle we see an early articulation of a sensory and perceptual feedback loop between subject and object, self and world. As Marx points out, in words that echo Aristotle, "It is obvious that the human eye gratifies itself in a way different from the crude, non-human eye; the human ear different from the crude ear, etc.," ${ }^{, 57}$ But what Marx adds to this picture is the insistence that the subject can only be in their best condition in relation to their object when the object itself is encountered through a non-proprietorial lens. This, for Marx, is entirely contingent upon the social arrangements in which the individual finds his or her self. Human

${ }^{55}$ Marx, 1844, 106.

${ }^{56}$ Aristotle, Nichomachean Ethics, trans. Terence Irwin, (Indianapolis: Hackett, 1999), Book X Chapter 4 S.5 15-24.

${ }^{57}$ Marx, 1844, 107. 
flourishing, and the ability to take pleasure in our world and to experience ourselves to the full, is therefore - and in contrast to Aristotle - either universal or not at all.

To be fully human, then, is to liberate the senses and to experience a richness in the world that is concealed from us by private ownership, but this is only possible with a radical transformation of our social and economic organization.

The transcendence of private property is therefore the complete emancipation of all human senses and attributes; but it is this emancipation precisely because these senses and attributes have become, subjectively and objectively human. The eye has become a human eye, just as its object has become a social, human object- an object emanating from man for man. The senses have therefore become directly in their practice theoreticians. They relate themselves to the thing for the sake of the thing, but the thing itself is an objective human relation to itself and to man, and vice versa. Need or enjoyment have consequently lost their egotistical nature and nature has lost its mere utility by use becoming human use. ${ }^{58}$

The idea that the senses function as 'theoreticians' is startling. Here Marx is not only stressing that we view the world with an eye to possession or personal gain we in fact sever ourselves from critical aspects of our own humanity; he is further implying that the possessive orientation is not only mandated by the need to survive under conditions of capitalism - it is internalized and experienced as the natural and logical response to the things around us as they reveal themselves to us sensorially within the framework of exchange economy. The commodity form, then, is the objectification of political economy appearing as a truth of both human and external nature: through the commodity form capitalism is encountered sensorially as a mechanism of our physical reality. As Duy Lap Nguyen has commented:

In Marx's critical analysis of capitalism, commodity fetishism is defined not as an empty illusion or ideology, but rather as an objective form of appearance, one that does not simply distort or disguise an underlying economic reality, but which, on the contrary, constitutes the illusory and mystical foundation of the economic as such. ${ }^{59}$

\footnotetext{
${ }^{58}$ Marx, 1844, 107.

${ }^{59}$ Duy Lap Nguyen, "The Angel of History and the Commodity Fetish: Walter Benjamin and the Marxian Critique of Political Economy," Constellations 22, no. 3 (2015): 341.
} 
Through the commodity form our economic reality, far from being obscured, is in fact laid bare before us. What emerges from Wohlleben's account is that the commodity form is indeed a concealment, but one that conceals not our economic reality but, rather, the sensory foundations of those aspects of reality that defy instrumentalization. Meanwhile, hiding in plain view is the underlying truth of exchange economy, namely that capitalism not only presupposes but depends upon an unobstructed view of the external as pure resource. Until Wohlleben's visitors arrived in his forest, the trees of his dominion revealed themselves to him as dimensional lumber with various appendages such as roots and leaves attached. This was the objective reality of the forest, itself a product of labour for the express purpose of economic exchange. As Wohlleben gradually discovered himself to be in the midst of an entirely different forest, his ability to hack it down and send it off to the wood-chipper was disarmed. His liberated sensory engagement with the given reality changed the nature of that reality and, therefore, his actions within it. In other words, sensory emancipation is at the same time political emancipation. The sensory is political. The commodity form serves its own self-interests by reflecting our economic self-interest back at us, obscuring those dimensions of the external that would, in being recognized, inhibit our drive to possess and to commodify.

The fullness of the world can only be enfolded within the human experience when the human senses and sensibilities are developed to their fullest potential since, as Marx continues:

To the eye an object comes to be other than it is to the ear, and the object of the eye is another object than the object of the ear. The peculiarity of each essential power is precisely its peculiar essence, and therefore also the peculiar mode of its objectification, of its objectively actual living being. Thus man is affirmed in the objective world not only in the act of thinking but with all his senses. ${ }^{60}$

${ }^{60}$ Marx, 1844, 108. 
And here Marx understands the senses to encompass the full sweep of the human perceptual apparatus - an apparatus which is, itself, an historical accomplishment rather than an a-historical given:

"Only through the objectively unfolding richness of man's essential being is the richness of subjective human sensibility (a musical ear, an eye for beauty of form - in short, senses capable of human gratifications, senses confirming themselves as essential powers of man) either cultivated or brought into being. For not only the five senses but also the socalled mental senses - the practical senses (will, love, etc.) - in a word human sense - the humanness of the senses - comes to be by virtue of its object, by virtue of humanized nature. The forming of the five senses is a labor of humanized nature. The forming of the five senses is a labor of the entire history of the world down to the present." ${ }^{\prime \prime 1}$

To the extent that our lives are governed by the basic requirements of subsistence - by need, in other words - our sensory world is impeded, responsive to utility alone, while the objectification that defines us as a species remains unfulfilled:

The sense caught up in crude practical need has only a restricted sense. For the starving man, it is not the human form of food that exists, but only its abstract being as food; it could just as well be there in its crudest form, and it would be impossible to say wherein this feeding-activity differs from the animals....Thus the objectification of the human essence both in its theoretical and practical aspects is required to make man's sense human, as well as to create the human sense corresponding to the entire wealth of human and natural substance. ${ }^{62}$

So when the conditions of exchange economy mean that wages for vast sections of the work-force are set at a rate below that of reliable subsistence, the world itself is encountered as its own poor-relative, humanity busily forming and reforming itself in response to a material reality whose possibilities are qualitatively distorted. Yet in any exchange economy, regardless of the specific approach to distribution, the experience of the self and its world is filtered through the narrow and instrumentalizing portal of profit and exchange. For Marx, it is only when our senses are released from their repressive extrusions through the lens possession and self-interest that we are somehow able to recognize ourselves in a world that nourishes the full spectrum of
${ }^{61}$ Ibid., 108-9.
${ }^{62}$ Ibid., 109. 
our experiential capacities. The 'humanized' nature of the new free society "produces the rich man profoundly endowed with all the senses - as its enduring reality." ${ }^{\prime 63}$

But there is something else going on here that is laid bare by the quotation above. Capitalism is a distortion of our sensory experience, but so too is the natural world in its unprocessed and unmediated form: the 'objectification' of the human essence upon which our sensory liberation rests is, as we have already seen, the transformation of the natural world into a form fit for human purpose. So or Marx, our senses are not fully human when the world beyond the human self is not yet 'objectified' or 'humanized.' The suggestion seems to be that we must continue to process the stuff of nature until such time as we find ourselves fully reflected therein. But this seems to presuppose the very subject-object relations of domination that are so deeply problematic under exchange economy.

Now Marx has shown that there is a way in which objectification within a free society surpasses its alienated form and enables us to see each other as fellow subjects. But since our own self-understanding is mediated through nature as well as through the social it seems that the structural subject-object domination that the humanization of nature entails would be equally problematic, certainly for nature as the dominated, but also for us as the dominators. It is equally hard to imagine how this would liberate our full sensory being rather than extrude it further through a lens as instrumentalizing as that of capitalism. In Marx's account the project of true sensory liberation seems to be at loggerheads with the project of the full objectification of the human essence, in a way that does not immediately seem to bode well for a free and healthy relationship with the external or with our own self-understanding.

${ }^{63}$ Marx, 1844, 109. 


\subsection{Humans and Everything Else.}

I want to take a moment here in these next few paragraphs to explore a little further what I find to be a problematic tension in Marx's account of freedom, self actualization and the objectification of the human being in nature. To that end I need to undertake a very brief recapitulation of some of the main points so far.

We have seen that Marx finds that the central, distinguishing characteristic of the human being is the proclivity for creative, universal, productive activity beyond need. We have seen that this gives rise to a separation between essence of the human being and its existence, and unlocks the capacity for individuation, by moving the individual beyond the visceral claims of biological need and thereby mobilizing the essential precondition for self-awareness, which is the separation of the experiencing subject from their object. In Marx's account human selfawareness is, therefore, self-awareness as a thing somehow and somewhat apart from or external to its world, even as, in striving to surpass the confines of mere physical existence and biological need, it creatively produces and reproduces its world. Marx's account emphasizes that the human experience - to the extent that it is experienced as human - is underpinned by separation - the separation of essence and existence, subject and object, human self and the world, of the fulfillment of need and the fulfillment of the individual.

Yet, Marx also depicts human beings as very much part of the entirety from which we differentiate our selves. We have seen that as social creatures our individual well-being is inextricable from the well-being of society, and we have seen how a society built upon an alienated understanding of human nature reproduces alienation and further entrenches the corruption of our creative capacities while impoverishing both our material reality and our sensory - and therefore material - understanding of our world. We have seen that as 'objective' 
species-beings we take the external in its entirety as our object, in a relationship that is sensorial in its origins and is mutually transformative; for just as the external is perpetually mediated through human production, so, thereby, is human self-understanding mediated through the external. Thus it emerges from Marx's account that to be fully operational as a human being is to be actively involved in a mutually transformative relationship with the world in which one finds oneself, the social being only one element of the greater whole. The self and the external are held in a perpetual feedback loop, which, for Marx, is propelled by the innate human drive to produce beyond need. So although we have seen that the social is fully implicated in the selfunderstanding and the well-being of the individual, so too is the external in its totality. So, in point of fact, Marx's account of human nature shows us not only to be species beings, but to be world beings, whose self-understanding is not merely derived from humanity and human affairs but from everything that surrounds us. The inextricability of the human subject from all that is perceived as external to it suggests that human well-being is inextricable from the state of the external in its entirety; while the interpenetration of nature and the sensory on the one hand, and of the social and the political with the sensory on the other in Marx's account, strongly suggests that the differentiation between humans and nature works against the well-being of the greater whole; that, instead, we need to extend the privileges of the social dimension to nature - that we need to find a way to expand our understanding of the species-being to encompass the world in its entirety and to enter into a new relationship based upon mutuality and reciprocity rather than domination and exploitation. Nature must come to be seen to be part of the social - and it must be treated as such.

The sense of separation from all that is perceived as external to the human subject is an essential precondition for freedom, in Marx's account, but it is also furnishes the possibility for 
domination and exploitation of the object by the subject, and for alienation and reification. Selfactualization and self-estrangement might behave in very different ways, but they inhabit the same terrain, which lies in the space between our selves and our object; and thus the way in which we navigate the distance between our selves and the external is of critical importance. Our relationship with nature, or with that entity of which we ourselves are just one part, clearly seems to matter; and Marx's account strongly suggests that it matters in ways that cannot be addressed by the attempt to isolate or insulate human affairs, either in theory or in practice, from those of the planet on which we happen to find ourselves.

This much seems intuitively straightforward - in fact from today's vantage point the interdependence of humankind and nature seems to be pretty much a matter of common sense, regardless of the extent to which we find ourselves willing or able to recognize this interdependence through our actions. Clearly, under the present conditions of our own historical moment there is a catastrophic tension between humanity and all that is perceived as external to it, and there are ways in which this tension plays itself out externally. Latour, for example, sees a very real possibility of total war erupting in the very near future between 'humans' and 'the earthbound,' or, in other words, between those whose environmental sensibilities foster the recognition that, as people, they are somehow not entirely a thing apart from nature - "not exactly humans, but rather Earth bound, ${ }^{, 64}$ - and those who have not yet surpassed the selfcongratulatory enlightenment 'humanism' that defines humanity in terms of the obstacles it has overcome rather than those it has created, or in Latour's words, those "children of the Enlightenment (who) are used to defining with great relish the threatening past from which they

${ }^{64}$ Bruno Latour, "Facing Gaia: A New Enquiry Into Natural Religion," The Gifford Lectures, June 27, 2015, War of the Worlds: Humans and Earthbound, accessed December 15, 2014, https://www.giffordlectures.org/lectures/facing-gaia-new-enquiry-natural-religion. 
were courageous enough to escape (but who) are largely silent on the shape of things to come.",65 But Marx's theory of human nature suggests an ongoing battle rather closer to home, playing itself out in each and every one of us as a contradiction, a catastrophic tension, between the human as species-being and the human as world-being. As we strive to fulfill our species-being by being ever more productive and finding new ways to shape and reshape the external, and as this process brings external nature to the brink of catastrophe we must wonder, then, if nature as the entirety of which we are part - is innately pathological, moving itself inexorably to its own destruction, or whether the pathology of our present moment is itself historical.

Marx's account becomes swiftly complex, for although our own expansionist exchange economy is clearly driving the cataclysmic exploitation of nature it is equally clear that, for Marx, we humans are at our most productive, our most objectifying, when our species being is liberated, or, in other words, when capitalism, exchange economy and private property have been superseded. Marx envisions communism as the "resolution of the conflict between man and nature" but we must look more closely, now, at the terms and conditions of Marx's proposed resolution, since any resolution that fails to benefit the whole cannot, by virtue of the mediated nature of the human experience, be of ultimate benefit to the individual or to humanity. To this end this we need to turn to Marx's account of the dialectical relationship between human beings and nature.

\subsection{Utopia, Need and the Dialectic}

Marx's dialectical materialism holds that nature, as we encounter it in our own historical moment, is the result of human enterprise. This is not to suggest that nature itself is a product of human activity but, rather, that despite being prior to and external to human consciousness nature

\footnotetext{
${ }^{65}$ Latour, Humans and Earthbound, 106.
} 
is inaccessible to us except as an abstraction in anything other than its historical and socially mediated form: "For that matter, nature, the nature that preceded human history...is nature which today no longer exists anywhere (except perhaps on a few Australian coral-islands of recent origin)..." ${ }^{, 66}$ Marx’s views on the antecedence of nature are in fact unequivocal: "Man has not created matter itself. And he cannot even create any productive capacity if the matter does not exist beforehand..." ${ }^{, 67}$ Our awareness of ourselves both as individuals and as species beings is itself formed in response to nature as the medium within and through which we must survive. So for Marx, as we can infer from his views on the political dimension of our sensory interactions with nature, "the whole of nature is socially mediated and, inversely, society is mediated through nature as a component of total reality..."68

Meanwhile, matter, for Marx, has, at all times, the particular form of things: it is the stuff of nature, in other words, and reveals itself historically in a way that is determined by the human, and therefore social, appropriation of nature in accordance with human aims. "Men, whatever historical conditions they live in, see themselves confronted with a world of things which cannot be transcended and which they must appropriate in order to survive. ${ }^{, 69}$ In other words need, and therefore labour, is an a-historical given.

So far, therefore, as labour is a creator of use-values, i.e. is useful labour, it is a necessary condition, independent of all forms of society, for the existence of human beings; it is an eternal nature-imposed necessity, through which is mediated the metabolic interaction between man and nature, i.e. human life itself. ${ }^{70}$

${ }^{66}$ Karl Marx and Friedrich Engels, The German Ideology, (New York: Prometheus Books, 1998), 46.

${ }^{67}$ Marx and Engels, The Holy Family, or Critique of Critical Critique, (London: 1957), 65, quoted in Schmidt, Concept of Nature, 64.

${ }^{68}$ Ibid., 79.

${ }^{69}$ Ibid., 64.

${ }^{70}$ Marx, Capital, vol.1, quoted in Schmidt, Concept of Nature, 71. 
In defining labour, Marx tells us that: "labour is, first of all, a process between man and nature, a process by which man, through his own actions, mediates, regulates and controls the metabolism between himself and nature." ${ }^{, 71}$ While the processes and techniques of labour are historically determined there is an enduring a-historical characteristic of human labour that differentiates it from the life-sustaining activities of other creatures: human labour knows its own outcome in advance.

A spider conducts operations which resemble those of the weaver, and a bee would put many a human architect to shame by the construction of its honeycomb cells. But what distinguishes the worst architect from the best of bees is that the architect builds the cell in his mind before he constructs it in wax. At the end of every labour process, a result emerges which had already been conceived by the worker at the beginning, hence existed ideally. Man not only effects a change of form in the materials of nature; he also realizes his own purpose in those materials. And this is a purpose he is conscious of, it determines the mode of his activity with the rigidity of a law, and he must subordinate his will to it. This subordination is no momentary act. Apart from the exertion of the working organs, a purposeful will is required for the entire duration of the work. ${ }^{72}$

Through the rationalization of production - through what Engels describes as "conscious organization on a planned basis" ${ }^{73}$ - it might very well be that human society can transform production and its ongoing mediations of nature in such a way that, far from the individual being confronted by them as alienating forces to which he must submit, "the laws of his own social activity, which have hitherto confronted him as external, dominating laws of nature, will then be applied by man with complete understanding, and hence will be dominated by man...."74 After all, in Marxian theory this is one of the essential pre-conditions for universal self-actualization; it is, as Engels claims, “ humanity’s leap from the realm of necessity into the realm of freedom."75 Yet neither the rationalization of production nor the ability to control its outcome does anything

${ }^{71}$ Karl Marx, Capital,vol.1, trans. Ben Fowkes, (London: Penguin Books, 1976), 283.

${ }^{72}$ Ibid., 284.

${ }^{73}$ Friedrich Engels, Herr Eugen Dühring's Revolution in Science (Anti-Dühring), (London:

1936), 311-12, quoted in Schmidt, Concept of Nature, 134.

${ }^{74}$ Ibid.

${ }^{75}$ Ibid. 
to obviate the ongoing demands of need itself as an element of human existence: freedom, becoming a genuine possibility only through the fulfillment of need, is thereby inextricably bound to need. Where Engels declares that human freedom will be fully liberated through true socialism, Marx, as Schmidt comments “...was both more skeptical and more dialectical in seeing that the realm of freedom does not simply replace that of necessity, but retains it as an inextinguishable internal moment." The new rational society will emancipate the species-being and furnish, universally, such freedom as is possible, but it cannot overcome need itself which will ever punctuate the human experience and determine the outer limits of our freedom. Thus a more perfect world is attainable, but retains the fulfillment of human need as a determining factor. Utopia, for Marx, is attainable only as an approximation - not the overcoming or the surpassing of need, but a rational system for its universal fulfillment. It is no mere happenstance that Marx - in what Feenburg calls his "marvelous epigram"76 - commits need and its fulfillment to the very heart of the principle by which the new society will organize itself: "from each according to his abilities, to each according to his needs!"77 Thus, despite retaining his early conviction that the progression towards communism is held within our present moment as a genuine possibility, Marx finds that his exuberant 1844 proclamation of the eventual and total "resolution of the conflict between man and nature" $" 78$ can never fully be attained.

In all possible societies, then, the ongoing fulfillment of biological need and thus the human appropriation of nature is a constant - a given. The form that it takes - or in other words the modes and conditions of labour or of production - is in part constituted by the underlying laws that govern nature and in part by mankind's socio-historical reality: production, however it

\footnotetext{
${ }^{76}$ Feenberg, "Introduction" to the essential Marcuse, xxv.

${ }^{77}$ Marx, "Critique of the Gotha Programme," in Marx: Later Political Writing, ed. Terrell Carver, (Cambridge: Cambridge University Press, 2012), 215.

${ }^{78}$ Marx, 1844, 102.
} 
is undertaken, is "the appropriation of nature by the individual within and through the mediation of a definite form of society." ${ }^{, 79}$ And so the way in which we fulfill our needs is specific to our own historical moment, from which arise a whole host of systemic needs above and beyond those of basic biological subsistence, while labour, as an element of human existence, will never fully recede since needs themselves can never, fully, be extinguished. ${ }^{80}$

We submit ourselves to the process of mastering the laws of nature and of understanding its governing principles precisely to harness them in such a way as to render external nature fit for our own purpose; meanwhile our purpose is itself conditioned by our social arrangements. Thus it is that in production, Marx tells us, man

confronts the materials of nature as a force of nature. He sets in motion the natural forces which belong to his own body, his arms, legs, head or hands, in order to appropriate the materials of nature in a form adapted to his own needs. Through this movement he acts upon external nature and changes it, and in this way he simultaneously changes his own nature. $^{81}$

Nature is appropriated in such a way as to render the material conditions of life fully 'human,' but our understanding of what it is to be fully human is historically determined. For Marx, then, and as we saw earlier, our understanding of 'the human' is itself mediated through the social in particular and through the external as a whole in general: "All social relations are mediated through natural things and vice-versa. They are always relations of men 'to each other and to nature." $" 82$

In language which is only partly metaphorical Marx describes the transformation of nature (both human and external nature) through human production as a 'metabolic' process: as humans take up the stuff of nature and work upon it both nature as a basic resource and the

${ }^{79}$ Marx, A Contribution to the Critique of Political Economy, (Chicago: 1913), 273, quoted in Schmidt, Concept of Nature, 68.

${ }^{80}$ Schmidt, Concept of Nature, 136.

${ }^{81}$ Marx, Capitol, vol. I, 283.

${ }^{82}$ Schmidt, Concept of Nature, 69. 
human labour that is expended interact with one another in the formation of the new object. Nature provides material resources, some of which are of direct or immediate 'use-value' such as air and water and which can therefore be consumed without labour per se; ${ }^{83}$ others, however, must be removed or severed from their environment in order to be turned - by human labour that is itself a "material of nature transferred to a human organism" ${ }^{\prime 84}$ - into raw-material. ${ }^{85}$ Certain types of raw material, such as certain kinds of food for example, can be consumed immediately, i.e. directly and without the further mediations of production, while others are further processed, sometimes through many different stages of development, until the material in question "has obtained at the end the form in which it can directly become an object of consumption, when, therefore, the consumption of the material and the suspension of its form satisfies a human need, and its transformation is the same as its use." ${ }^{\prime 86}$ Those elements of this 'second nature' - of the external, material reality that is the result of human enterprise - that are neither consumed nor further processed gradually break down, de-compose or degenerate, to be restored, slowly, to the metabolic processes of the 'first nature' that was their pre-production point of departure. Just as the raw stuff of nature cycles through growth and decay, so too do the objects of human production cycle from first to second nature and back again. Through these metabolic processes of production and consumption, nature, for Marx, becomes man's "inorganic body" $" 77$ - external nature is the material extension of the human being, while labour is the force of nature through which nature comes to release its further and more fully 'human' possibilities.

\footnotetext{
${ }^{83}$ Ibid., 73.

${ }^{84}$ Marx, Capital Volume I, (Moscow, 1965), quoted in Schmidt, Concept of Nature, 78.

${ }^{85}$ Schmidt, Concept of Nature, 73.

${ }^{86}$ Marx, Grundrisse, 361.

${ }^{87}$ Marx, 1844, 76.
} 
We have already seen in his account of the species-being that, for Marx, subjectivity entails the differentiation of the subject from its object, and that the subject-object distinction, as it is experienced, arises through the individual subject's productive activities in the realm beyond need. External nature - all that lies beyond the human perception of the self and which Marx calls "man's inorganic nature" 88 - would, otherwise, remain indistinguishable from the self which, fully contained within its own life-sustaining processes, would therefore lack selfawareness as a subject. Yet human beings are, unquestionably for Marx, an inextricable part of nature, as are the life processes through which we appropriate the stuff of nature and transform it to make it suitable for our own aims and ambitions. Labour itself $i s$ the force of nature from which man's self-awareness has arisen, ${ }^{89}$ but only because production itself, albeit free universal production, also characterizes the realm beyond need, thereby enabling nature itself to release its further and more fully 'human’ possibilities.

So the metabolic exchange between mankind and external nature does not simply change the raw stuff of external nature into a product for further human use and consumption; it releases possibilities that would otherwise be forever dormant: as Schmidt writes, citing Marx, "By releasing the 'slumbering powers' of the material of nature, men 'redeem' it: changing the dead 'in-itself' into a living 'for-itself', they so to speak lengthen the series of objects brought forth in the course of the history of nature, and continue it at a qualitatively higher level. Nature propels forward its process of creation by the agency of human labour." ${ }^{90}$ So where nature is the physical extension of the human being, the human becomes the conscious extension of nature.

${ }^{88}$ Ibid., 75.

${ }^{89}$ This point will be explored further in the section that follows, since it suggests that the inextinguishability of need is not the only reason that labour and production of one kind or another will permeate all human society at all times - the demands of subsistence alone do not fully account for the persistence of human labour, given Marx's understanding of what the human being is - needs themselves, therefore, do not, on their own, fully account for the fact that freedom in the new society is only partial.

${ }^{90}$ Schmidt, Concept of Nature, 77. 
Self-awareness, consciousness of the object and of subjectivity, arise within the human experience through human efforts for the sake of human purpose, as mankind therefore functions as the operational self-awareness of the natural world of which he is a part. Human labor 'metabolically' catalyzes the transformation of nature from the passive to the active; history, for Marx, is not a mechanically determined process that happens to or is visited upon an impersonal and insentient nature but is a conscious, dynamic process in which nature itself, through the productive activities of the human being as its conscious and self-aware subject, has its own vested interest; while the latent potentiality of the external furnishes the creative imagination of the human subject and its translation into material reality.

Therefore nature, as an entity comprised of humans and everything else, experiences itself through its ongoing transformation: "Sundered into two parts, man and material to be worked upon, nature is always present to itself in this division." ${ }^{, 91}$ Nature, which for Marx is reality in its entirety, is therefore both subject and object. And so we see that in Marx's account, nature is in a constant state of self-mediated flux, and experiences itself therefore not as a stasis of being but as a perpetually self-mediated becoming: "The world is matter in motion in definite forms. ${ }^{.92}$

Schmidt summarizes Marx's dialectic of nature in the following passage:

Nature becomes dialectical by producing men as transforming, consciously acting Subjects confronting nature itself as forces of nature. Man forms the connecting link between the instrument of labour and the object of labour. Nature is the Subject-Object of labour. Its dialectic consists in this: that men change their own nature as they progressively deprive external nature of its strangeness and externality, as they mediate nature through themselves, and as they make nature itself work for their own purposes. ${ }^{93}$

\footnotetext{
${ }^{91}$ Schmidt, Ibid., 79.

${ }^{92}$ Ibid., 77.

${ }^{93}$ Ibid., 61.
} 
Subjectivity, in other words, is dynamic - for Marx the subject is ever in transformative motion as it works upon nature as its perceived object which is to be made ever more 'human,' in a process which has as its end the "naturalism of man and the humanism of nature, both brought to fulfillment." 94

\subsection{Subjects, Objects and Indifference}

That nature can undergo any such transformation is, in part, the result of its own physical laws. For Marx the laws of nature are prior to human consciousness and while consciousness facilitates their application for human ends it cannot, in itself, alter them, so "when man engages in production, he can only proceed as nature does herself, i.e. he can only change the form of the materials." $" 95$ That the form of the materials can be altered, however, is due to the curious relationship between material and form that Marx finds to be one of "mutual indifference." 96 As he explains: "the form is itself external to the substance (as the form of the table is external to the wood, or the form of the roller is external to the iron), in other words it merely exists in the

external form of the material." ${ }^{, 97}$ As such, there is no law governing the relationship between raw materials and the things that they become that requires them to assume one form and one form only: the same piece of wood could just as easily be turned into a small picture frame, a large pile of toothpicks or a cricket-bat. For Marx, the simple fact that when neglected for an extended period the manufactured product gradually decays and starts on a compositional journey back to 'first nature' bears out the lack of any integral relationship persisting between matter and form. ${ }^{98}$

\footnotetext{
${ }^{94}$ Marx, 1844, 104.

${ }^{95}$ Marx, Capitol Vol. I, 133.

${ }^{96}$ Schmidt, Concept of Nature, 74. See also Marx, Grundrisse, 360

${ }^{97}$ Marx, Grundrisse, 360.

${ }^{98}$ Schmidt, Concept of Nature, 74.
} 
The 'metabolic' processing of the raw materials furnished by nature has the effect of uniting human labor and nature in the new form given to the materials by the working processes; but the distinction between the subject and object - between the human as subject and the materials being worked upon as object - remains. Subject and object, the two parts of nature as a whole, retain their state of non-identity. In point of fact for Marx, as Schmidt comments, "the moment of non-identity is retained under all social conditions, precisely on the basis of labour, which nevertheless, on the other hand, unites the Subject and Object." ${ }^{, 99}$ Human production (as we have already seen) is the source of the subject-object distinction, in Marx's account; but through labor part of the human self is objectified - it is metabolized with the materials in question and embodied in the resulting object of production. Nonetheless the self continues to experience the thing - the object in which its labour is manifest - as an externality. So, as an example, I might take the branch of a sapling and peel away the leaves, strip off the bark and whittle it away until I have sharpened its point and turned it into a skewer. My time, my energy, my idea, my will power - in short, my labour and every part of me that it involves - is now manifest in the new form of the sapling branch, present in the object as "the vanished external form of its [i.e. labour's] natural substance, ${ }^{, 100}$ while to point out that the skewer and I are two different things is to state the glaringly obvious. As subject, I remain a thing apart from my object: in labour subject and object remain differentiated from one another and retain their nonidentity, despite their conjunction in the external form of the object.

For Marx, (again, as we have already seen earlier) the human being, by virtue of its enduring creative productivity, experiences nature as an externality, or in other words as its object. Meanwhile labor is, essentially, the expenditure of the human self - of human thought,

\footnotetext{
${ }^{99}$ Ibid., 74.

${ }^{100}$ Marx, Grundrisse, 360.
} 
energy, creativity and so on - in the thing that is being produced, and is therefore an aspect of the human being that is present within the object. And so nature, as the external in its totality and in the form in which we encounter it in our own historical moment, is, within Marx's account the externalized form of human enterprise, suspended in the form of its object.

There is a social and economic significance to this that becomes quickly apparent when we compare Marx's views with those of Locke, for whom the object of labor becomes an addendum to the subject:

Though the earth, and all inferior creatures, be common to all men, yet every man has a property in his own person: this no body has any right to but himself. The labour of his body, and the work of his hands, we may say, are properly his. Whatsoever then he removes out of the state that nature hath provided, and left it in, he hath mixed his labour with, and joined to it something that is his own, and thereby makes it his property. It being by him removed from the common state nature hath placed it in, it hath by this labour something annexed to it, that excludes the common right of other men: for this labour being the unquestionable property of the labourer, no man but he can have a right to what that is once joined to, at least where there is enough, and as good, left in common for others. ${ }^{101}$

Locke determines that there is a one-way flow from the world, via human enterprise and on to private property. In the absence of any plausible mechanism by which the object somehow becomes the property of the person, when it might equally be the case, one would presume, that the labor of the person becomes the property of the object, it appears that the stuff of nature undergoes not only a legal but also, apparently, a mystical transformation to become the material and economic augmentation of the person.

In a move that cocks something of a full frontal snook at the presumptions of classical liberalism, Marx reverses the direction of the flow: adding our labor and our ingenuity to the stuff of nature we relinquish it and send out in to the world, for the benefit of all who behold it, something that previously was ours alone. We have already seen that Marx's free individual

${ }^{101}$ John Locke, Second Treatise of Government, (Indianapolis: Hackett, 1980), V.27. 
produces 'universally' ${ }^{102}$ - we now see the mechanism that makes this possible. In transcending private property and in fulfilling the species-being the freely producing individual is externalizing his own creative energy as a bequest to the external, molded into the new form of the materials of his production. Recalling that, for Marx, free, universal production is the primary act of self-realization and the expression of the creative self and species-being that affirms man as an 'objective' being - (in contrast to that of alienated labour which confronts its progenitor as an external and hostile force) - we can start to see that self-realization entails a loss of that which is 'properly his', an expenditure of the self, that is, itself the vital act of selfaffirmation.

Nonetheless, the self-actualization of the human being as a world-being, rather than merely as a species-being, is heavily dependent upon the human relationship with the external world in its entirety, as well as in its social and economic aspects, so the significance of the metabolic mediations of nature for the well-being of the external needs to be explored, and here Marx's own account of cloth production is revealing:

Labour is the living form-giving fire; it is the transitoriness of things, their temporality, as their formation by living time. In the simple production process.... the transitoriness of the forms of things is used to posit their usefulness. When cotton becomes yarn, yarn becomes fabric, fabric becomes printed etc. or dyed etc. fabric, and this becomes, say, a garment, then (1) the substance of cotton has preserved itself in all these forms....(2) in each of these subsequent processes, the material has obtained a more useful form, a form making it more appropriate to consumption... ${ }^{103}$

The more fit something is for human purpose the less akin it is to its previous living form. A living plant is transformed in ways that render it, as a piece of clothing, fully unrecognizable as the living form whence it came.

\footnotetext{
${ }^{102}$ Marx, 1844, 77.

${ }^{103}$ Marx, Grundrisse, 361.
} 
Schmidt has pointed out that within Marx's dialectic of nature "the non-identity of Subject and Object has the consequence that the human form is indifferent towards the stuff of nature, that it remains external to it."104 This is of tremendous importance to Marx's account of the interactions between humans and nature; for where the human experience is the experience of being somehow non-identical with and indifferent to nature, i.e. to his own 'inorganic body,' there is a transfusion of non-identity from the subject into the object through the form-changing, metabolic mechanisms of free, universal production that are the expression of the human speciesbeing, as the raw materials of nature are worked and reworked to become ever further from their living form. Labor metabolized into form becomes external both to the subject and to the object. Human labor is externalized in the form of the object that becomes, in turn, ever more external to the life-forces that brought it into being in the first place. But this also means that there is an important way in which non-identity - or a state of being present in a form that is extrinsic to the thing itself - is therefore an aspect of everything that mankind produces.

Now Marx seems to recognize that for actual living things matter and form are very far from indifferent to one another. In this regard raw materials differ significantly from the natural form of their biological origins: "no immanent law of reproduction maintains this form in the way in which the tree maintains its form as a tree (wood maintains itself in the specific form of the tree, because this form is a form of the wood; while the form of the table is accidental for wood, and not the intrinsic form of its substance.)" ${ }^{\prime 105}$ There is an acknowledgement, then, in Marx that some other kind of relationship, a kind of existential friction, binds the living form to its materials. This friction, this living bond that differentiates the 'intrinsic form' of nature from the raw materials of production must first be overcome or undermined if nature is to be rendered

${ }^{104}$ Schmidt, Concept of Nature, 74.

${ }^{105}$ Marx, Grundrisse, 360. 
fit for human purpose. In other words, the indifference of matter to form is very far from innate it is something that is done to the stuff of nature by human enterprise. Yet, Marx seems to overlook the immense significance of this for his own account of the dialectic of nature:

All those things which labour merely separates from immediate connection with their environment are objects of labour spontaneously provided by nature, such as fish caught and separated from their natural element, namely water, timber felled in virgin forests, and ores extracted from their veins. ${ }^{106}$

The 'mere separation' of living things from their immediate environment has a mordantly euphemistic ring that is strangely at odds with Marx's habitual turn of phrase and suggests an underlying, yet perhaps consistent, indifference on Marx's part to the living form of nature. The 'mere separation' of a fish from water is hardly a 'mere' moment in the life of the fish. Certainly, by the time the stuff of nature has been reduced from the living form to the raw material, we might perhaps view it as a 'dead in-itself.' This is precisely because human enterprise has severed it from its own life forces. Far from human labour taking the dead in-itself and transforming it into a living for-itself, as Schmidt has argued, ${ }^{107}$ in Marx's account of the metabolic interaction between man and nature the process of releasing the "humanism of nature" ${ }^{108}$ begins - albeit somewhat parenthetically, as if the raw brutality that is the unavoidable starting point of all human production, in Marx's account, is, itself, of little relevance to his account of the human experience - by taking something fully alive and killing it. The living foritself of nature is killed off, wrenched apart from its own life forces so that it can be endlessly modified through a series of different forms or 'in-themselves,' each taking it further and further from its original form. Colour, texture, shape, taste, function - all are to be processed and modified until the object is in suitable shape for human consumption, to be a 'for-us,' while the

${ }^{106}$ Marx, Capital vol.I. 28.

${ }^{107}$ Schmidt, Concept of Nature, 77.

${ }^{108}$ Marx, 1844, 104. 
"consummated oneness in substance of man and nature" 109 that is human self-realization is to achieve its 'oneness' by the eventual consumption of the object by the subject.

Now we might choose to view this as some kind of transcendence - as man somehow surpassing the given and transcending the confines of his material reality - but this seems to be little more than a linguistic whitewashing of the brutality of the transformations visited upon nature by human production. When we begin with a living form, such as a tree, that sustains and is sustained by the other living forms around it and we cut it down - once again, merely separating it from its immediate environment - it will, eventually decompose and will continue to contribute to the life forms around it. But supposing we saw it into planks and pressure treat it with chrome or copper or arsenic, or grind it up and stick it back together with glue so that, as chip-board, we can carve it up into any shape we choose? The further the tree is processed the less its original living properties, such as its grain, its curvature, its humidity and so on, exert themselves on our working processes and the more malleable it is as a material for human purpose. But, also thereby, the more mephitic its metabolic decay - its reversion back to first nature is a toxic process that, very far from contributing to the life forms around it, poisons them. A previously living, life-engendering form is eviscerated of its life-producing properties. Transcendence predicated upon the destruction of that which is transcended does not seem like reasonable cause for celebration, and in fact the very use of the word in the context of human production seems less like a description and more like an out and out obfuscation. In destruction, even when it is indirect, we do not, in fact, go anywhere and we certainly do not rise above anything - we stay precisely where we are in the wasteland of our own creation.

${ }^{109}$ Marx, 1844, 104. 


\subsection{An Intractable Alienation}

Within dialectical materialism reality remains internally bifurcated, with mankind as its subject and nature as its object. The dialectic tension mobilizing the endless modifications of the one by the other can never be overcome fully and their struggles of non-identity, which drive the teleology of the free 'human' society towards the eventual "naturalism of man and the humanism of nature both brought to fulfillment," 110 never fully abate: "even in a fully human world there is no full reconciliation of Subject and Object." ${ }^{111}$ In pointed contrast with the Hegelian notion of consciousness that, seeking 'the good,' strives for the "identity of objective reality with selfconsciousness," 112 Marx's new society, the approximate utopia, is "heavily encumbered with 'the bad' i.e. the non-identity of man and the material to be appropriated." ${ }^{\prime 13}$ Certainly, nature is gradually domesticated or 'humanized' by the metabolic interactions between humans and nature: "In the Marxist dialectic, as in the Hegelian, what is non-identical with the Subject is overcome stage by stage. Greater and greater areas of nature come under human control."114 But the process itself, far from moving towards the reconciliation of Subject and Object, entrenches a relationship based upon the ever greater domination of the object by the subject: "nature becomes...pure Object for man, a pure thing of utility; it ceases to be recognized as a power for itself; and the theoretical knowledge of its autonomous laws itself appears only as a stratagem for subjecting it to human needs, be it as object of consumption or means of production."

Marx's goal posts appear to have shifted. What began as a problem of the non-identity of subject and object and the drive to resolve the conflict between the two, (i.e. between mankind

${ }^{110}$ Marx, 1844, 104.

${ }^{111}$ Schmidt, Concept of Nature, 158.

${ }^{112}$ Hegel, The Phenomenology of Mind, trans. J.B. Baillie, (London: 1951), 522, quoted in Schmidt, Concept of Nature, 137.

${ }^{113}$ Schmidt, Concept of Nature, 137.

${ }^{114}$ Ibid., 136.

${ }^{115}$ Schmidt, Concept of Nature, 157. 
and nature), has metamorphosed into the matter of an ever-incomplete domination of the object by the subject. To the extent that the former problem of the non-identity of subject and object is retained within the latter problem of domination it seems, therefore that the move towards identity or unification is held to be accomplished through domination. The mutuality and reciprocity of the transformation of mankind and nature that propelled the early account of human self-actualization in the 1844 manuscripts has given way to a strictly unilateral process in which the human as world-being is to be sacrificed in perpetuity to the well-being of the human as species-being:

In later life he [Marx] no longer wrote of a 'resurrection' of the whole of nature. The new society is to benefit man alone, and there is no doubt that this is to be at the expense of external nature. Nature is to be mastered with gigantic technological aids, and the smallest possible expenditure of time and labour. It is to serve all men as the material substratum for all conceivable consumption goods. ${ }^{116}$

If the reconciliation of reality with itself is at odds with mankind's objectifying

tendencies, Marx makes it clear that objectification takes precedence: human self-actualization as an aim entails 'free labour,' but, as Marx tells us,

The labour of material production can only take on this character given that, first, its social character is determined and, second, it is of a scientific nature, as well as being general labour, not the exertion of a specifically trained force of nature, but of a Subject which, instead of appearing in the process of production in a merely natural original form, appears as the activity which directs all the forces of nature. ${ }^{117}$

Thus the rationalization of society and of production emancipates the individual subject through the domination of nature as its object, while nature - as we saw in the previous section becomes ever more external to itself.

Yet, for Marx, the domination of nature is destined to remain ever incomplete, for two interconnected reasons: the first is that need, an a-historical given, can never permanently be

${ }^{116}$ Ibid., 155.

${ }^{117}$ Marx, Grundrisse, (Berlin: 1953), 505, partial English translation in Pre-Capitalist Economic Formations, (London: 1964), quoted in Schmidt, Concept of Nature, 144. 
abated; the second is that human exertion effects only the form of nature or the object, thereby remaining external to it and ever vulnerable to the processes of decay. It is against nature's own law for nature to be suspended permanently in any form - so no matter how extensive our transformation of nature the end result is impermanent, mutable and degenerative. Some kind of further human input is needed if the processes of decay are to be arrested or postponed or if any particular form is to be extended as that form beyond its natural life-span. Nature - by its own very nature - thwarts any move we make towards its permanent subjugation and control. But needs themselves persist, so continued effort will ever be required in the struggle to draw nature further under our control. Freedom, to the extent that we have any at all, unfolds in whatever time is left over when needs have been met.

There is something deeply puzzling at work here. We have been looking at a story in which the dialectic of freedom and necessity and the dialectic of subject and object become entangled with one another in ways that militate against the resolution of either. The freedom of the subject is predicated upon the fulfillment of need, which in turn is predicated upon the domination of the object by the subject. The underlying thrust of Marx's argument is that if only needs could be permanently abated we could experience uninterrupted freedom

However, Marx's own account of human nature makes it clear that things are not that simple. Human subjectivity is predicated upon there being an object - it requires there to be an object from which we experience ourselves as being clearly differentiated. To the extent that humans maintain their identity as humans the space between the self and object is instrumentally central to our humanity: for Marx it is the defining human need. And so human nature in Marx's account, to the extent that it experiences itself as such, cannot BUT experience itself as external either to its own physical being, when in need, or to the world in which it finds itself, when need 
is fulfilled. The problem, then, is not that we are prevented by the intractable nature of need from achieving the reconciliation of subject and object and from reaching a point in which human nature and external nature can experience unity: that much is clear from the fact that other animals fulfill their needs by 'merging' with their life activities and remain undifferentiated from their object. The problem, as it emerges from Marx's account, is that such a reconciliation is precluded by the very experience of being human. Marx tells us that "the animal is immediately identical with its life-activity. It does not distinguish itself from it. It is its life-activity." It is precisely from this point of identity that we escape as we move into the realm beyond need. The leap to freedom, therefore cannot be a movement towards a reconciliation with nature; it can only be the attempt to flee from its all-enveloping embrace.

What, then, are we to make of the 'humanization' of nature? Marx describes this as the process of turning nature ever more fully into the object of our own production:

It is just in the working-up of the objective world, therefore, that man first really proves himself to be a species being. This production is his active species life. Through and because of this production, nature appears as his work and his reality. The object of labor is, therefore, the objectification of man's species life: for he duplicates himself not only, as in consciousness, intellectually, but also actively, in reality, and therefore he contemplates himself in a world that he has created. ${ }^{118}$

But since universal production is defining of our species, and since our production cannot but externalize, in Marx's account, the 'humanization' of nature turns out to be the rendering of our material reality, in its entirety, into a form that is ever more external to itself. The metabolic processes by which the process of 'humanization' are to be accomplished are process by which the externality of the human form is passed like some strange contagion via labour and on to the natural world, whose life-forms are severed from their own life forces and rendered, step by step, form upon form, ever more external to themselves. Nature, mediated through ever more complex

${ }^{118}$ Marx, 1844, 77. 
and sophisticated technological processes, becomes a force that is hostile and external to itself in other words through human labour nature becomes not only self-destructive but also selfestranged. The supersession of human self-estrangement is to be accomplished through the selfestrangement of nature.

\section{Conclusion}

From within the framework of dialectical materialism, the endless modification and consumption of nature by humans has a veneer of legitimacy; when subject and object are viewed as internal divisions of the same entity then nature is effectively held to be at the helm of its own modification and transformation for its own purpose.....who, then, are we to interfere with that? Any attempt to change direction starts to look a lot like hubris. Marx positions the human species as the consciousness of material reality - as the means by which nature is self aware and self-directing - in a theoretical gesture that seems to give license to whatever violations of the natural world might serve human purpose in some way, shape or form. Yet, as the ostensible brains of the operation, ought we to be concerned that on our watch the dialectical process as a whole looks a lot like a snake eating its own tail? That nature, as a self aware and cognizant entity, is busily engaged in the pathological process of wrenching itself apart from its own life processes and devouring itself? Driving itself headlong and knowingly to its own destruction? And ought we to care that, within Marx's model, the human species-being quickly looks less like the conscious driving mechanism of historical progress and rather more like an increasingly distended digestive tract, our products the raw, untreated effluence of an ever-more toxic metabolic process? 
Within market society, the modern urban human being is, unabashedly, a creature who instrumentalizes his world, himself and even his own self-understanding. Under conditions of economic liberalism, propelled by the demand for unceasing economic expansion, the natural world, even in much of the ongoing conversation about 'sustainability,' is valued in terms of its ability to support and facilitate human ends; yet when we consider what these ends might be we find ourselves caught up in a market-oriented perpetual-motion in which such things as education, good health, a happy childhood and creative imagination (to name but a few) are pursued not as ends in themselves but as necessary foundations for successful participation in the market, upon which our economic prosperity depends. In a system of total instrumentalization that lacks any credible concept of the intrinsic and which therefore has no internally coherent braking mechanism, it is ever tempting to view the catastrophic violations of nature that fuel our economy as a problem of 'the system'. But in Marx's account the intertwining dialectics of subject and object, freedom and necessity, are themselves propelled by instrumentalization. In the 1844 manuscripts Marx gestures towards a beguiling vision of a different way of being, of an altogether different consciousness with the power to subvert the sensory distortions of instrumental reason and to affect an altogether transformed, transforming and above all integrated relationship with the external; yet embedded in his account of human nature is a fundamental schism that compels the ceaseless objectification of the external so that, from the vantage point of the natural world, the trajectories of self-alienation and self-actualization have little to differentiate them one from the other. No doubt it matters little to the fish, merely separated from its immediate environment, that the appetite it assuages is communist rather than capitalist. 


\section{Chapter 2}

Capitalism has absorbed the greens, as it absorbs so many challenges to its ascendancy. A radical challenge to the human machine has been transformed into yet another opportunity for shopping.

(Paul Kingsnorth and Dougald Hine, Uncivilisation: the Dark Mountain Manifesto)

\section{Introduction}

"What, precisely, are the dimensions of non-alienated experience?"119 The question, which was raised a few years ago in a discussion of non-hierarchical societies and political engagement, seems straightforward enough, but when we try to formulate a cogent reply we quickly find ourselves in thorny terrain. It is, of course, easy enough to deflect the matter entirely - to defer to the members of the free society yet to come as a matter that can only be determined from within the structures of their non-alienated experience; or, alternatively, to maintain that even the very attempt to define freedom for another (since we ourselves are neither free nor nonalienated) is an act of oppression. Yet as Andrew Feenberg has pointed out, in trying to translate the revolutionary impulse into something akin to effective action we are confronted with "a dilemma as old as the Marxian theory of class revolution itself," namely that to fulfill our greater potential and to move forwards from the catastrophe of our current historical moment the revolutionary must proceed in thought and action as if he or she is already secure in the knowledge of something they cannot know - something that, having not yet been brought into being, is as yet unknown and has yet to be experienced. ${ }^{120}$ How, then, are we to get somewhere when we have neither a map of the route nor an image in mind of what our destination actually looks like? How do we find it and how do we recognize it? In other words, liberation needs an account - or, better still, an experience - of true freedom ahead of the fact; self-actualization

${ }^{119}$ David Graeber, Fragments of an Anarchist Anthropology, (Chicago: Prickly Paradigm Press, 2004) 75.

${ }^{120}$ Feenberg, "Introduction," to the Essential Marcuse, xxxv. 
needs an account of non-alienation. Marx proposes that human endeavor involves, above all else, an articulate vision of the thing to be produced; freedom as a project - a human undertaking and a thing yet to be accomplished - seems, then, to be no different. So if we are to mobilize ourselves towards a radical transformation of society we need to have some clear vision of what it is we want to accomplish. And in the absence of any such account or experience how easy, then, for any system possessed of totalizing tendencies to convince us that what we think we want is precisely what we already have - to convince us that if there is progress then it looks just like us; if there is freedom then this is what it feels like; if there is such a thing as justice then monstrous inequality must in fact be its manifestation.

Meanwhile, in Marx's account, somewhere on its long, painful journey to self-realization the human species-being has arrived at a stalemate. The historical sweep of Marx's dialectical materialism does not roll us forwards to the glories of the new and free society but falters and grinds to a halt at a devastating dialectical impasse: to be human is to experience one's very self as being a thing somehow apart from the natural world of which one is, nonetheless, very much a part. To be fully re-absorbed back into nature and to 'merge' or unify with our own lifesustaining activities would be the reversion to "naïve immediacy"121 which, even were it possible, (which of course it is not), would be the denial of the very basis of our humanity. (This is something of which the ancient Greeks were already well and acutely aware, which is why Odysseus had to haul his men away from the bland and vegetative pleasures of life among the Lotus-eaters, where their un-conflicted days would otherwise roll by in the gratification of their basic needs while the essence of their humanity was sucked straight back into their most

${ }^{121}$ Schmidt, Concept of Nature, 153. 
rudimentary biological existence). ${ }^{122}$ However, the perception of distance between our selves and nature generates a tension at the very heart of Marx's account of the human experience. This tension is problematic in the context of Marx's model of freedom as a form of reconciliation between human and external nature, since it places us profoundly at odds with the natural world whose well-being, nonetheless, is simultaneously our own. In Marx's account this tension leads to change, certainly, in the form of the ever more aggressive exertions of modern man upon the natural world and the 'humanization of nature,' but in so doing fails to generate any genuine qualitative improvement in the relationships among people, or between people and the natural world, leaving us marooned in perpetuity on this side of true self-actualization and freedom. The supersession of private property liberates us, in Marx's account, from the most egregious and exploitative practices of capitalism and from its sensory, social and self alienations. However where, for Marx, such liberation has true socialism and the free society as its eventual goal, the fulfillment of its promise is ever incomplete: liberation itself unfolds as the freedom of the species-being to wage war against its world-being - as the freedom to subjugate nature, to strip nature as far as possible of its own life-forces and to deplete it of all but its most "humanizable" properties, all the while undermining the realm of freedom itself as a locus of self-actualization and fulfillment by turning it into an arena of self-destruction. Ultimately, the subject fails to overcome the rigid and exploitative hierarchy that is embedded in its tyrannical relationship with its object, and thus the mediated self-understanding that is reflected back at us from our incessant exploitation of the natural world, our object, can, within Marx's account, only be that of destructive co-dependence. Through the unhappy coupling of adversarial subject/object relations with the industrialization of production we come to experience ourselves as creatures utterly

\footnotetext{
${ }^{122}$ The adventures of Odysseus and the Lotus Eaters is analyzed in greater depth in the final section of chapter 3 .
} 
dependent upon the endless technological modification of the natural world - internal and external, human and non-human - whose constant violation, is understood as a necessary condition of our own continued existence.

Clearly this is not what Marx intends. If Marx's socially integrated, sensorially awakened, self-actualizing human being turns out to be "exhaling and inhaling all the forces of nature,"123 huffing and puffing, just to blow the whole thing down - pumping up his muscles only to destroy life in its every manifestation, then something somewhere has gone terribly wrong; for, as we have already seen, the very promise of socialism, as per Marx's early outline, is the promise of a life-affirming and pleasurable relationship with the natural world. In Marcuse's words:

The Marxian conception understands nature as a universe which becomes the congenial medium for human gratification to the degree to which nature's own gratifying forces and qualities are recovered and released. In sharp contrast to the capitalist exploitation of nature, its "human appropriation" would be non-violent, non-destructive: oriented on the life-enhancing, sensuous, aesthetic qualities inherent in nature. Thus transformed, "humanized," nature would respond to man's striving for fulfillment, nay, the latter would not be possible without the former. ${ }^{124}$

Needs, of course, must be fulfilled; but the beguiling promise of socialism, in Marx's early account, is the promise of an emancipated sensory experience of nature which is to liberate ourselves and nature as two parts of an integrated and pleasurable whole: the promise of a reality in which needs can be fulfilled in a truly 'human' way that is reflective of who we really are in our own historical moment. Within an exchange economy such freedom as we are able to experience amounts to freedom from toil - given that labour is ever necessary to some degree, freedom, therefore, boils down to free time. ${ }^{125}$ This is not the complete resurrection of nature,

${ }^{123}$ Marx, 1844, 153.

${ }^{124}$ Herbert Marcuse, Counter-Revolution and Revolt, (Boston: Beacon Press, 1972), 67.

${ }^{125}$ Schmidt Concept of Nature, 145. 
nor does it come close to being a reconciliation of the subject with its object ${ }^{126}-$ free time is respite from the unfreedom of labour within a world that remains, to no small degree, un-free. Nonetheless, Marx is convinced that free time has the capacity to "transform its possessor into a different subject, and he then enters into the direct production processes as this different subject. $" 127$

The utopian buoyancy of Marx's early writing is grounded in the notion that the qualitative transformation of our relationship with the external world in the realm of freedom will, in some way that is mutually beneficial, infuse our relationship with nature in the realm of necessity. As we have already seen, Marx's dialectical materialism gradually commits itself to the view that subject-object relations of domination are as inevitable as the needs that propel them; yet here, in the subtext of Marx's early train of thought, is the pre-emptive (if almost covert), suggestion that if we are to recalibrate our relationship with nature and if the pathological relationship between subject and object is to be overcome, the pressing concern, at least to begin with, is not how we go about diminishing the burden that needs place upon our lives, but, rather, what we do with the free time that is available to us - how we turn free time into freedom. ${ }^{128}$ From there we need to understand more precisely the nature of the transformation that takes place within us as a result of this freedom and how this can bring itself to bear positively on the realm of necessity as we move back and forth between them.

In particular, we need some insight as to how the experience of freedom can inform our system of production and the fulfillment of need in such a way as to enable the 'human appropriation' of nature to fulfill the terms and conditions of a non-violent, non-destructive and non-exploitative relationship. From the point of view of our relationship with nature as it appears

${ }^{126}$ For further discussion of this point please refer back to section 7 of chapter 1.

${ }^{127}$ Marx, Grundrisse, 712.

${ }^{128}$ Schmidt, Concept of Nature, 144-6. 
within Marx's account, this is of primary concern, since needs of some kind or other will unavoidably be retained as a condition of life itself whether they are genuine needs or merely systemic contrivances. So any theory that offers an account of freedom in the realm beyond need without giving us some kind of insight as to how we might transform our binding relationship with need and the processes of its fulfillment is going to be more or less redundant in many areas of the current conflict between ourselves and nature.

To no small extent we are left guessing as to how Marx might answer these questions, but there are one or two clues, nonetheless. Presupposing liberation from exchange economy and private property, Marx finds that the realm beyond need involves consciously undertaken production, free from and beyond biological need; he also finds that in contrast to the production methods of other creatures and, crucially, regardless of whether it is alienated or non-alienated, human production involves having a clear vision of the thing to be produced and the will to see the process through to its already known conclusion. In addition, Marx tells us that time away from labour and toil is time "gained for other kinds of production, material and intellectual."129 We have some sense, then, from his account, as to what we he thinks we do with our freedom, but no insight as to what he thinks the experience of this, or of its correlate that is the state of non-alienation, is actually like. He also tells us of various changes that will arise as a result of our freedom, as for example in our system of distribution. However, these things in themselves do not tell us anything particularly useful about the experience itself; trying to understand an experience in terms of its by-products in other areas tends to lead to frustration rather than insight. (As any musician knows, being told that relaxing your breathing will help you to make a bigger sound is of absolutely no help with sound production unless you already have some experiential understanding of what relaxed breathing is like and of how to reproduce it.)

${ }^{129}$ Marx, Grundrisse, quoted in Schmidt, Concept of Nature, 149. 
Nonetheless, one way or another, alienated or non-alienated, freely undertaken or coerced and regardless of the historical moment, Marx's account tends to re-enforce his initial assertion that the life experience of the human species-being is grounded in and circumscribed by production. If, then, the experience of freedom is to effect a radical transformation of the realm of need there must be a profound difference between alienated production and non-alienated production as it is experienced in the moment by the person doing the work, and regardless of what it is that is being produced and how it is distributed; it must be this transformed and transformative experience of work itself that will be carried back into the realm of need, and it is, therefore and above all, the nature of this experience, that we need to anticipate if our relationship with nature and our external reality is to be transformed for the better.

Where my own reading of Marx suggests that, instead of producing universal freedom, his dialectic of nature leads to universal destruction, the hope that lingers from his early manuscripts is that there may be a way to divert our trajectory away from disaster and towards liberation if we can only understand more clearly how the experience of freedom might enable us to enter into a different relationship with our object, nature. But here Marx falls silent.

\subsection{The Aesthetic Dimension and the Radical Sensibility}

Where Marx takes pause, however, Marcuse is swift to pick up the gauntlet, revisiting the theme of nature and its interconnection with mankind's sensory being that runs through Marx's 1844 manuscripts with a view to rehabilitating its revolutionary and utopian elements in his own account of the realm beyond need.

The subversive potential of the sensibility, and nature as a field of liberation are central themes in Marx's Economic and Philosophic Manuscripts. They have been reread and reinterpreted again and again, but these themes have been largely neglected. Recently, the manuscripts served to justify the concept of "humanistic socialism" in opposition to the 
bureaucratic-authoritarian Soviet model; they provided a powerful impetus in the struggle against Stalinism and post-Stalinism. I believe that in spite of their "pre-scientific" character, and in spite of the prevalence of Feuerbach's philosophic naturalism, these writings espouse the most radical and integral idea of socialism, and that precisely here, "nature" finds its place in the theory of revolution. ${ }^{130}$

Marcuse is buoyantly optimistic that scientific and technological developments can lend themselves to the radical re-structuring of our society and its apparatus. Yet he is appalled and frustrated by the ways in which they are used instead to perpetrate violence on a scale previously unimaginable and to facilitate the excessive exploitation of the natural world. So Marcuse finds that although the liberation of mankind fully entails scientific progress, it is both unthinkable and undoable without the simultaneous liberation of nature. However, with the aid of the senses as go-betweens there, he suggests that there is a way in which mankind and nature can be liberated and reconciled with one another in an aesthetic dimension of experience that is itself liberated by technology.

Taking issue with the way nature is effectively type-cast to appear in Marx's later work in only two possible roles - adversary or resource - Marcuse proposes that these images of nature fail to reveal anything other than the projected workings of operational or instrumentalized thinking. As Marx's dialectical materialism rolls onwards, Marcuse finds that nature is condemned to appear "as that which capitalism has made of nature: matter, raw material for the expanding and exploiting administration of men and things. "131 To the extent that we are indeed species-beings whose self-understanding is mediated through the external, (Marx's account being foundational to Marcuse's model), nature in the form in which it appears in Marx's account is fully incompatible with freedom. This, for Marcuse, is nothing short of an out and out betrayal the very utopian essence of the 1844 Manuscripts and their intuition that true

\footnotetext{
${ }^{130}$ Marcuse, Counter-Revolution and Revolt, 63-4.

${ }^{131}$ Ibid.,62.
} 
human freedom entails the discovery of nature not only as a productive force to be harnessed to human purpose, but also as something that exists "for its own sake" and, in this mode of existence, for man."132

Where an industrialized understanding of nature comes to permeate Marxist theory in general, ${ }^{133}$ Marcuse is troubled, most especially, by the "hubris of domination" ${ }^{134}$ that hovers in and around Marx's early work as a nascent presence in the Manuscripts, gradually taking root in the idea that nature can be liberated through 'human appropriation':

Certain brute facts, unconquered and perhaps unconquerable facts, call for skepticism. Can the human appropriation of nature ever achieve the elimination of violence, cruelty, and brutality in the daily sacrifice of animal life for the physical reproduction of the human race? To treat nature "for its own sake" sounds good, but it is certainly not for the sake of the animal to be eaten, nor probably for the sake of the plant.... "appropriation," no matter how human, remains appropriation of a (living) object by a subject. It offends that which is essentially other than the appropriating subject, and which exists precisely as object in its own right - that is, as subject! $!^{135}$

It is one thing to stress the need for humans to appropriate nature; but to suggest that it is for nature's benefit to do so is to disregard precisely that quality in nature that makes its appropriation so very problematic in the first place. With a single gesture that appears simultaneously to anticipate and bypass Marx's dialectic of nature, Marcuse proposes that the utopian longing for true freedom becomes a tangible possibility when we recognize nature as "a subject in its own right - a subject with which to live in a common human universe." ${ }^{136}$ There is the suggestion here that nature can be enfolded into the social, or, to frame this slight differently, that our self-understanding as species-being must expand to encompass our world-being. But since even our most basic survival entails the consumption of nature, an adversarial relationship with nature is, in some shape or form and to a lesser or greater extent, unavoidable: "the end of
${ }^{132}$ Ibid., 68.
${ }^{133}$ Ibid., 61-2.
${ }^{134}$ Ibid., 69.
${ }^{135}$ Ibid., 68-9.
${ }^{136}$ Ibid., 60. 
this war, the perfect peace in the animal world - this idea belongs to the Orphic myth, not to any conceivable reality. ${ }^{137}$ Since we can only work from within our given reality it follows that if, indeed, we are to embrace nature as a thing that exists 'for its own sake,' and if we are to explore the potential this affords for the development of a society grounded in freedom and for a nonviolent, non-exploitative relationship between humans and nature, we must turn to that realm of experience, currently available, wherein our need to exploit nature becomes non-necessary, and where we can enlist nature, liberated as fellow subject, as our ally in the struggle for a nonviolent, non-exploitative, non-repressive society. ${ }^{138}$ Thus, for Marcuse, the search for freedom and the quest to enlist nature as our fellow subject along the way must be sought out within the aesthetic dimension of human experience, as that realm within our current experience in which our relationship to nature unfolds in freedom rather than being driven by necessity.

Here in the aesthetic realm, "liberated from the pressure of painful purposes and performances necessitated by want,"139 lies the potential for a profound transformation of our most immediate sensory and intuitive interactions with the world that give shape to our understanding of ourselves and our world: "it is this qualitative, elementary, unconscious, or rather preconscious, constitution of the world of experience, it is this primary experience itself which must change radically if social change is to be radical, qualitative change. ${ }^{140}$ It is precisely at this preconscious level of experience that our social relationships take root and embed themselves within the structures of our own self-understanding: radical social transformation is therefore possible only when the need for the liberation of society as a whole is

${ }^{137}$ Ibid., 68.

138 Ibid., 59.

${ }^{139}$ Herbert Marcuse, Eros and Civilization: A Philosophical Inquiry Into Freud. (Boston: Beacon Press, 1966), 189.

${ }^{140}$ Marcuse, Counter-Revolution and Revolt, 63. 
experienced as an individual need. ${ }^{141}$ The problem with which we are confronted, however, is that this is also the level of our experiential being where we are most powerfully conditioned to internalize the operational perspective of our current social order:

conditioned and "contained" by the rationality of the established system, sense experience tends to "immunize" man against the very unfamiliar experience of the possibilities of human freedom. The development of a radical, nonconformist sensibility assumes vital political importance in view of the unprecedented extent of social control perfected by advanced capitalist societies: a control which reaches down into the instinctual and physiological level of existence. ${ }^{142}$

So, he continues, in capitalist society, the ingression of market values into the structures of our self-understanding and our subjectivity is so exhaustive that the requirements of the system are internalized and experienced as our own vital needs and desires. "A vested interest in the existing system is thus fostered in the instinctual structure of the exploited, and the rupture with the continuum of repression - a necessary precondition of liberation - does not occur." ${ }^{143}$ If any major systemic social transformation is to occur the forces of liberation must also, therefore, penetrate our 'biological' being and "reach down into the instinctual and physiological level of existence," 144 but our current system of socialization and our modern way of being is finely honed to prevent this from happening. ${ }^{145}$ Scientific and technological progress, which has the capacity to liberate us from the pursuit of need, has instead been harnessed to consumer-culture wherein "the need for possessing, consuming, handling, and constantly renewing the gadgets,

${ }^{141}$ Ibid., 62.

${ }^{142}$ Ibid., 62.

${ }^{143}$ Herbert Marcuse, An Essay on Liberation (Boston, MA: Beacon Press, 1969), 16.

${ }^{144}$ Ibid., 16.

${ }^{145}$ Marcuse recognizes that his use of the term 'biological' is a departure from its strict scientific application - his own footnote is helpful to clarify his approach here: "I use the terms "biological" and "biology" not in the sense of the scientific discipline, but in order to designate the process and the dimension in which inclinations, behaviour patterns, and aspirations become vital needs which, if not satisfied, would cause dysfunction of the organism....If biological needs are defined as those which must be satisfied and for which no adequate substitute can be provided, certain cultural needs can "sink down: into the biology of man. We could then speak, for example, of the biological need for freedom, or of some aesthetic needs as having taken root in the organic structure of man..." Marcuse, An Essay on Liberation, footnote p.10. 
devices, instruments, engines, offered to and imposed upon the people, for using these wares even at the danger of one's own destruction, has become a 'biological need.' ${ }^{146}$ Those manufactured needs that perpetuate our system are experienced as being a perfectly natural expression of who and what we are. True social change therefore involves nothing less than the total sensory rupture from the well-trodden, historically inculcated experience of life in the technological market society - a total severance from the familiar and from "the routine ways of seeing, hearing, feeling, understanding things so that the organism may become receptive to the potential forms of a nonaggressive, non-exploitative world." ${ }^{\prime 147}$ Only then, Marcuse argues, can we move towards the construction of a free society, which, if it is to succeed, must be built upon “biological foundations."148

By his own admission, Marcuse's move to build the biological foundations for freedom and the new society from within the confines of the aesthetic dimension of human experience has every appearance, initially, of undermining the greater project of the true liberation of mankind and nature: "like imagination, which is its constitutive mental faculty, the realm of aesthetics is essentially "unrealistic": it has retained its freedom at the price of being ineffective in the reality." 149 We might then wonder why Marcuse finds aesthetic experience to be so pivotal to the project of universal emancipation. For this we need to turn Marcuse's understanding of the aesthetic imagination which, by its very nature, begins with the sensory and the instinctual rather than the conceptual. The term 'aesthetic' has come to mean 'pertaining to the arts,' but this, as he points out, is a relatively recent connotation of the word, which originally meant 'pertaining to

\footnotetext{
${ }^{146}$ Ibid., 11.

${ }^{147}$ Ibid., 6.

${ }^{148}$ Ibid., 7.

${ }^{149}$ Marcuse, Eros, 172.
} 
the senses. ${ }^{150}$ The aesthetic is, in Marcuse's words, "essentially intuition, not notion."151 In our own socio-historical realm of necessity, (and as we saw earlier in the discussion of Marx's account of the senses), the object, having become a material repository of market driven relationships and the machinations of instrumental reasoning, reveals itself in terms of utility. But in the aesthetic imagination, a dimension of the human mind free from the coercions of need and the impositions of socially oriented performance and competition, a different exploration of the object is possible: ${ }^{152}$

In the aesthetic imagination, the object is rather represented as free from all such relations and properties, as freely being itself. The experience in which the object is thus "given" is totally different from the every-day as well as scientific experience; all links between the object and the world of theoretical and practical reason are severed, or rather suspended. This experience, which releases the object into its "free" being, is the work of the free play of imagination. ${ }^{153}$

The stimuli for this 'free play' are furnished by nature, as the external, and carried to the imagination by the senses. ${ }^{154}$ We have already seen how, for Marx, human subjectivity and selfunderstanding arise through production - which itself presupposes an instrumentalized orientation toward the stuff of nature. Marcuse proposes that aesthetic experience also makes a formative contribution to the structures of the human self-understanding but, since the aesthetic imagination is unconcerned with the utility of the object - a utility which therefore plays no role in the aesthetic appropriation of the object by the imagination - the subjective self understanding

${ }^{150}$ Marcuse, An Essay on Liberation, 24.

${ }^{151}$ Marcuse, Eros, 176.

${ }^{152}$ Marcuse's views on aesthetic imagination and experience its role in the liberation of mankind and nature are developed at length in several chapters beginning, notably, in Eros and Civilization and further elaborated in many of his later works. He undertakes a detailed account of Kant's Critique of Judgement and of Schiller's response On the Aesthetic Education of Man as the basis for his own account, and anyone familiar with these works will notice their influence. However, for my present purpose it is Marcuse's findings that are of relevance rather than its historical influences or its position within their tradition, both of which fall beyond the scope of this project.

${ }^{153}$ Marcuse, Eros 178.

${ }^{154}$ Ibid., 178-9. 
that arises in and through the aesthetic experience is derived from an altogether different experience of the object:

In this universe, every word, every colour, every sound is "new," different - breaking the familiar context of perception and understanding, of sense certainty and reason in which men and nature are enclosed. By becoming components of the aesthetic form, words, sounds, shapes and colours are insulated against their familiar ordinary use and function; thus they are freed for a new dimension of existence. ${ }^{155}$

With the senses as its messengers the external world can infuse the intellect while bypassing our habituated orientations and responses, giving our capacity for reason new information about the object world and about itself. This information, transported as sensory data is received as aesthetic qualities, such as proportion, balance, harmony, timbre, contrast and so-on - qualities that have no 'purpose' beyond their own being and that reveal and direct themselves according to their own laws and properties, so while the aesthetic form takes shape within the imagination it is, nonetheless autonomous.

The result is the creation of an object world other than and yet derived from the existing one, but this transformation does not do violence to the objects (man and things) it rather speaks for them, gives word and tone and image to that which is silent, distorted, suppressed in the established reality. ${ }^{156}$

The aesthetic imagination, then, is a locus of revelation - a point of intersection, where nature, the senses and the intellect can meet in freedom from the demands of our own social reality. ${ }^{157}$ The aesthetic exploration of the object is, in itself, a subversion of instrumentalized reasoning and self-understanding, a realm of exploration and discovery that is itself a form of freedom the freedom of the subject to discover and understand its object and, thereby its own self, in terms of that which is invisible to operational and utilitarian thought and sense experience, namely the intrinsic.

${ }^{155}$ Marcuse, Counter-Revolution and Revolt, 98.

${ }^{156}$ Ibid., 96.

${ }^{157}$ Marcuse, Eros, 179. 
Consequently, in the aesthetic realm we have the possibility to release our intuitive and sensory interactions with the world from their systemic distortions and repressions under our particular reality principle: "The aesthetic reconciliation implies strengthening sensuousness as against the tyranny of reason and, ultimately, even calls for the liberation of sensuousness from the repressive domination of reason." 158 This reconciliation, for Marcuse, is "the recovery of the life-enhancing forces in nature, the sensuous aesthetic qualities which are foreign to a life wasted in unending competitive performances," whereupon "the senses become also "sources" of a new (socialist) rationality: freed from that of exploitation. The emancipated senses repel the instrumentalist rationality of capitalism..." ${ }^{159}$ Where Marx's senses are theoreticians operational within our own reality, Marcuse's are put to work in the aesthetic dimension as revolutionaries, nature working in us and for us to liberate itself.

Nonetheless, the life of unending competitive performances is the mainstay of our current reality, so, the revolutionary activity of the senses remains cordoned off from 'reality' per se as the sole purview of the aesthetic imagination. Contained - and therefore constrained - within a highly rarified domain, the raw, visceral, sensory response to the world is granted free speech, but on the strict condition that, (in the increasingly unlikely event that it should arise), it express itself through art.

The non-conceptual truth of the senses is sanctioned, and freedom from the reality principle is granted to the "free play" of creative imagination. Here a reality with quite different standards is recognized. However, since this other, "free" reality is attributed to art, and its experience in the aesthetic attitude, it is non-committing and does not engage the human existence in the ordinary way of life; it is "unreal.",160

To the extent that this is freedom it is freedom from our day to day reality - a day to day reality that not only inculcates itself into every possible aspect of our lives but that, in so doing,

${ }^{158}$ Marcuse, Eros, 179-180.

${ }^{159}$ Marcuse, Counter-Revolution and Revolt, 64.

${ }^{160}$ Marcuse, Eros, 185. 
increasingly shrinks the aesthetic domain and shuts down the sensory causeway that connects it

to our daily existence. The issue then remains, as to how the aesthetic experience can be released from its holding pen in the aesthetic imagination, and can be taken up within the material reality of established society, such that freedom becomes freedom in our reality. ${ }^{161}$

\subsection{Civilization and the Aesthetic}

Marcuse's approach to resolving this problem is initially startling, most especially given the overall trajectory of his life's work, reflected here in a short passage here by Feenberg:

Simply stated, what chiefly distinguishes Marcuse's career as a thinker and activist from those of his closest colleagues in the Frankfurt School is that unlike them he never gave up. For more than thirty years after their trails turned in different directions, Marcuse never ceased reinterpreting and reconfiguring the critical theory of society with a single aim in mind: to track the obscure path to socialist utopia through the latest transformations in capitalist societies in an epoch marked by an astonishing rise in material wealth. ${ }^{162}$

Yet, despite unwavering life-long commitment to the realization of his aims Marcuse is equally and obstinately committed to the imperative of maintaining the aesthetic realm as a thing apartas a separate and autonomous domain. To grasp Marcuse's position here we need to turn to his discussion of high or autonomous art, that he finds to be both the greatest achievement and the greatest indictment of the liberal market society (or of bourgeois society), and of its relationship to the realm of necessity.

The higher culture indicts, rejects, withdraws from the material culture of the bourgeoisie. It is indeed separated; it dissociates itself from the world of commodities, from the brutality of bourgeois industry and commerce, from the distortion of human relationships, from capitalist materialism, from instrumentalist reason. The aesthetic universe contradicts reality - a "methodical," intentional contradiction. ${ }^{163}$

\footnotetext{
${ }^{161}$ Marcuse, Eros, 187-8.

${ }^{162}$ Feenberg, 'Introduction' to the essential Marcuse, xxxix.

${ }^{163}$ Marcuse, An Essay on Liberation, 86.
} 
Where our own reality is characterized by alienation, the aesthetic dimension is, likewise, a form of alienation: "It is a second alienation, by virtue of which the artist dissociates himself methodically from the alienated society and creates the unreal, "illusory" universe in which art alone has, and communicates its truth." ${ }^{" 164}$ It is precisely this willful or intentional alienation from reality that makes possible the vital rupture from the habitual and familiar upon which liberation ultimately rests.

By virtue of this transformation of the specific historical universe in the work of art- a transformation which arises in the presentation of the specific content itself - art opens the established reality to another dimension: that of possible liberation. To be sure, this is illusion, Schein, but an illusion in which another reality shows forth. And it does so only if art wills itself as illusion: as an unreal world other than the established one. ${ }^{165}$

At stake is the "affirmative character" of bourgeois culture, by virtue of which art serves to beautify and justify the established order. The aesthetic form responds to the misery of the isolated bourgeois individual by celebrating universal humanity, to physical deprivation by exalting the beauty of the soul, to external servitude by elevating the value of inner freedom.

But this affirmation has its own dialectic. There is no work of art which does not break its affirmative stance by the "power of the negative" which does not, in its very structure, evoke the words, the images, the music of another reality, of another order repelled by the existing one.... Where this tension between affirmation and negation, between pleasure and sorrow, higher and material culture no longer prevails, where the work no longer sustains the dialectical unity of what is and can (and ought to) be, art has lost its truth, has lost itself. And precisely in the aesthetic form are this tension, and the critical, negating, transcending qualities of bourgeois art - its anti-bourgeois qualities. ${ }^{166}$

Marcuse is proposing that in high art, or in culture we find those values, beliefs and aspirations towards which our society believes itself to be directed and, which, as our purported ends, serve to justify its own instrumentalizing operations. The truth, in art, then, is the tension between affirmation and negation: art by its very existence as a form affirms and validates that which its contents negate and condemn. Or, as Marcuse writes, "the work of art thus re-presents reality

${ }^{164}$ Marcuse, Counter-Revolution and Revolt, 97.

${ }^{165}$ Marcuse, An Essay on Liberation, 87.

${ }^{166}$ Ibid., 92-93. 
while accusing it." ${ }^{167}$ Within our reality the attainment of our own legitimizing ends is always at arms length - always just beyond the next bend in the road - ever the thing yet to be accomplished within a civilization whose means and ends are, in practice, innately discordant with one another. ${ }^{168}$ Civilization and art, in other words, occupy two related but nonetheless separate realms, civilization being the systemic and structural adaptation to the necessary, as it is perceived, and art or culture being its validating aspirations.

Traditionally in the West, our civilization and its art have held one another in a state of dynamic tension, that, Marcuse suggests, is none other than the tension between the $i s$ and the ought, ${ }^{169}$ (which, translated into Marx's terms is the tension between the realm of need and the realm of freedom). To the extent that culture remained the preserve of an elite establishment - a rarified domain accessible to the very few on the basis of wealth and social privilege and a thing apart from "the toil and misery of those who by their labour reproduced the society whose culture it was," ${ }^{170}$ - it was, essentially, ideology. And so although its very existence was predicated upon social division and domination it nonetheless offered a vantage point from which its own supporting structures could be challenged. Traditionally, therefore, art has been a locus of dissent, of subversion and of negation. "By virtue of its remoteness from the world of socially necessary labour, of socially useful needs and behavior, because of its separation from the daily struggle for existence, culture could create and preserve the mental space in which critical transgression, opposition and denial could develop..." ${ }^{171}$ Culture was, as Marcuse puts it, the "Archimedean Point" ${ }^{172}$ from which the given could be subject to reappraisal and from

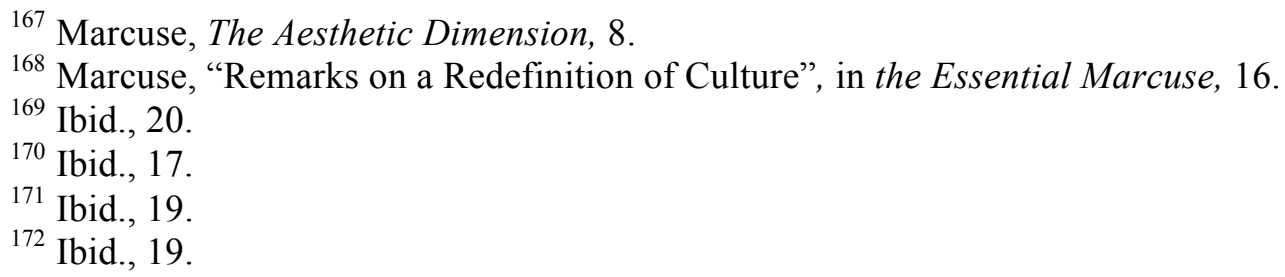


which its further possibilities could be explored. And the chasm between culture and civilization served as a protective buffer enabling the immersive exploration non-scientific thinking, protected from the 'operational' demands of perceived social necessity. So long as culture remains a thing apart from civilization, "literature and the arts could attain and communicate truths which were denied and repressed in the established reality..." ${ }^{, 173}$ It is, in other words, "a barrier to totalitarianism." 174

The fact that we now have the technological capacity to shake ourselves loose from manual work, mindless labour and a self-experience dominated by necessity and operational thought, and the fact that the possibility of free time is now a real possibility, only seems to cast a more bitter aspersion on the incoherence of a social reality in which the struggle for existence only increases its ferocity as society becomes ever more affluent. ${ }^{175}$ And while the tensions between the 'is' and the 'ought', freedom and necessity, civilization and culture might, therefore, be ever more palpable, what is instead happening is the absorption of culture into civilization. Culture, Marcuse, continues, is ever more accessible - "more widely read and seen and heard than ever before" but in its universal distribution, as mass culture in other words, its truth is no longer disseminated as universal critique: culture filtered through the operational mechanisms of civilization, is stripped of its subversive truth, and its power to resist, to repel and to transform is disarmed as the space between culture and civilization shrivels and shrinks until the two overlap fully with one another. The collapse of culture into civilization "cancels the alienation of culture from civilization" ${ }^{\prime 176}$ - an alienation that was foundational to its critical and subversive orientation. "Culture is redefined by the existing state of affairs: the words, tones, colors, shapes

\footnotetext{
${ }^{173}$ Ibid., 19.

${ }^{174}$ Ibid., 18.

${ }^{175}$ Ibid., 22.

${ }^{176}$ Ibid., 20.
} 
of the perennial works remain the same, but that which they expressed is losing its truth, its validity; the works which previously stood shockingly apart from and against the established reality have been neutralized as classics; thus they no longer preserve their alienation from the alienated society."177 Meanwhile, not only have the central figures of our cultural past faded beneath the operational gaze of civilization - "the gods, heroes, kings and knights whose world was that of tragedy, romance, song, and festival, ${ }^{178}$ but their struggles and strife - the impossible dilemmas that nourished our imaginations and compelled our quest for selfunderstanding to reach into dimensions far beyond our own immediate experience - have been rendered obsolete by a technologized and mass-produced culture that promises to solve even those problems and needs that are of its own creation.

Marcuse's overriding concern is neither the popularization nor the degeneration of culture, per se, but the "closing of a vital space for the development of autonomy and opposition, the destruction of a refuge, of a barrier to totalitarianism," and the "surrender (of) nonoperational truths to the rules governing the established society." ${ }^{179}$ So while our civilization has clearly and spectacularly failed to fulfill its own self-legitimizing aims as embedded historically in our culture, the greater concern for Marcuse is that the move to reduce the distance between the aesthetic dimension and our civilizational reality is moving reality as a whole in the wrong direction - it is achieving its ends not by transforming civilization but by disarming the aesthetic.

In short, then, there is a problem, and one that threatens to keep us spinning in what begins to feel like an uncomfortably familiar circle. On the one hand, we see through Marcuse's lens a social reality of systemic violence, brutality and repression faultlessly adapted to its own self-propagation: "In the advanced capitalist countries, the radicalization of the working classes

${ }^{177}$ Ibid., 21.

${ }^{178}$ Ibid.,20.

${ }^{179}$ Ibid., 18. 
is counteracted by a socially engineered arrest of consciousness, and by the development and satisfaction of needs which perpetuate the servitude of the exploited." ${ }^{, 180}$ Science and technology are so seamlessly integrated into the driving mechanism of the system - its simultaneous production of affluence and waste, luxury and weaponry and its endless manufacture of false need - that despite the possibilities they afford us to furnish the true needs of an altogether different society based upon life-enhancing and life-sustaining principles, the revolutionary transformation of civilization is inconceivable without a preceding and total transformation of human sensibility and need. Only then can we redirect the forces of progress towards the principles of freedom and non-violence. On the other hand, the realm in which such a transformation might occur - the aesthetic realm - loses its very transformative capacity unless it is somehow maintained in its critical unreality as a realm apart. On this point Marcuse is adamant. And to the extent that art attempts to translate its critical dimension as overt rebellion within and against the social order - songs of protest, political graffiti and so-on - it too is seamlessly integrated into the establishment.

It is this second alienation which disappears in today's systematic efforts to reduce, if not close, the gap between art and reality. The effort is doomed to failure. Certainly, there is a rebellion in the guerilla theatre, in the poetry of the "free press," in rock music - but it remains artistic without the negating power of art. To the degree to which it makes itself part of real life, it loses the transcendence which opposes art to the established order. ${ }^{181}$

What the concert condemns its promotional T-shirt affirms, and "the rebellious music, literature, art are thus easily absorbed and shaped by the market - rendered harmless." ${ }^{182}$ (How quickly the subversions of Wohlleben's experience in the woods became a world-wide best-seller, and how readily the life-enhancing properties of nature are marketed for eco-tourism.)

\footnotetext{
${ }^{180}$ Ibid., 16.

${ }^{181}$ Marcuse, Counter-revolution and Revolt, 101.

${ }^{182}$ Marcuse, An Essay on Liberation, 47.
} 
The crucial question then is how the aesthetic dimension can, in any way help us to transform our world. Or, as Marcuse frames the issue:

A subversive potential is in the very nature of art but how can it be translated into reality today, that is to say, how can it be expressed so that it can become a guide and element in the praxis of change without ceasing to be art, without losing its internal subversive force? How can it be translated in such a manner that the aesthetic form is replaced by "something real," alive, and yet transcending and denying the established reality? ${ }^{183}$

By way of answer, Marcuse urges that we have to recognize that the only effective intersection of art and rebellion is in the aesthetic realm itself. The attempt to utilize art for the transformation of our reality either from the ground up, with protest art, or from the top down with the popularization and mass-production of culture, cannot but fail to mobilize systemic change. Instead we must find ways to expand the aesthetic domain as the very thing that it is - that we must allow high art to retain its distant and alienated position as the unfiltered expression of the aesthetic imagination. "What appears in art as remote from the praxis of change demands recognition as a necessary element in a future praxis of liberation... Art cannot change the world, but it can contribute to changing the consciousness and drives of the men and women who could change the world." Exposure to art, not to art as protest but as art -itself - as the autonomous aesthetic form - will change, not our reality but our selves. And the transformation it will bring about at the most basic sensory and instinctual level of our being will compel us, effectively, to inhabit the realm of freedom, the aesthetic realm in other words, as our reality. We do not bring art into our day to day reality - we make it our day to day reality. "Reality is translated into a new aesthetic form."

Marcuse is quick to recognize that were this merely to be an elitist foray into a realm of sensory gratification this would be little more than decadent escapism - either "ornament,

${ }^{183}$ Marcuse, Counter-revolution and Revolt, 103.

${ }^{184}$ Ibid., 107. 
luxury, (or) holiday in an otherwise repressive world." ${ }^{185}$ But he is convinced that we now have the capability to turn the aesthetic dimension into a universal governing principle that encompasses not only our spare time, but "the entire human existence." ${ }^{, 186}$ As we move ourselves into the aesthetic dimension and turn our critical eye upon the realm of material production we have a pleasurable experiential vantage point from which to critique the brutalities that propel the realm of necessity and we will come to experience the transformation of the material reality as a need. Aesthetic experience is not only a sensorial rejection of the realm of necessity: it is a source of vital information that can show us what is at stake in the transformation of the realm of necessity, as well as the form that its transformation needs to take if we are to be liberated from its incessant demands and if $i t$ is to be liberated from its own violence and destruction.

As things stand, for Marcuse, and given the current conditions within the realm of necessity, labour of any kind is deeply problematic: "Necessary labour is a system of essentially inhuman, mechanical, and routine activities." ${ }^{187}$ As he further elaborates, "The realm of necessity, of labour, is one of unfreedom because the human existence in this realm is determined by objectives and functions that are not its own and that do not allow the free play of human faculties and desires." ${ }^{, 188}$ Thus the operating principles of life in the aesthetic dimension "imply not the transformation of labor but its complete subordination to the freely evolving potentialities of man and nature." ${ }^{189}$ Our ability to inhabit the realm of freedom is predicated upon abundance: our sensory liberation might compel us to pole-vault ourselves across the schism between our civilization and our culture and headlong into the aesthetic dimension, but this can become our permanent home only when the fulfillment of need is assured in perpetuity.

\footnotetext{
${ }^{185}$ Marcuse, Eros, 195.

${ }^{186}$ Marcuse, Eros, 188.

${ }^{187}$ Ibid., 195

188 Ibid.

${ }^{189}$ Ibid.
} 
Nonetheless, the basic principle of freedom in Marx's account, and which underscores Marcuse's own, is that freedom is either universal or not at all. Therefore, if nobody is to be left behind, if the aesthetic realm is to avoid becoming an upper-class holiday home that, by its very existence, further entrenches class division and systemic and universal alienation, freedom from need must be universal and the aesthetic realm must become accessible to all. Thus the essential precondition for a universal relocation to the aesthetic dimension is the total automation of need and its fulfillment, with which we are therefore to become fully unconcerned in our aesthetically liberated day to day lives. Therefore, as Marcuse stipulates, "Possession and procurement of the necessities of life are the prerequisite, rather than the content, of a free society, ${ }^{, 190}$ and this is made possible by the technological developments of advanced capitalism, re-directed to support truly rational, life-enhancing, human purpose. So in Marcuse's model we are seeing an extreme shift in the way that our experience of reality as a whole is internally divided - the realm of necessity shrinks to the point where we are fully released from its demands and the realm of freedom expands to encompass our entire experience of our selves and our world.

To some extent this of course resonates clearly with Marx's call to decrease, by whatever means are at our disposal, the demands of the work place and to increase our access to free time. But what of Marcuse's initial concern that Marx himself has lost track of the vital role nature is to play in human liberation? How does Marcuse's account of aesthetic freedom benefit nature in any way whatsoever? What, in other words has happened to nature itself and to Marcuse's outspoken concern for nature in all of this? The starting point for Marcuse's foray into the aesthetic dimension was his own exhortation that it is precisely in linking the liberation of nature to the project of human liberation that Marx's early account is so radically subversive and so remarkably able to point us towards true freedom. But it is most especially over this point that

${ }^{190}$ Marcuse, Eros, 195. 
Marcuse's account begins to fray a little; somewhere along the way, nature seems to have slipped beneath his radar. So whatever concerns we might have about the overall viability of Marcuse's account, the question we need to ask is not whether or to what extent his views on technology are correct, or whether aesthetic exposure is as truly transformative as he believes it to be, since these questions assume and prioritize a human perspective: rather, we need to consider what his account actually means from the point of view of nature as a whole. From the point of view of humans one of the main concerns is the feasibility or practicability of Marcuse's account; but from the point of view of nature the biggest concern by far is surely its desirability.

We have seen that through the free play of the aesthetic imagination our own senses are liberated and, in the process, nature is liberated from the possessive and instrumentalized gaze that dominates the realm of necessity; the resulting sensory or 'biological' transformation gives rise to a new need - the need for universal freedom, to be made real by the total automation of need. Thus human nature - or as Marx might put it, man's organic nature - undergoes a liberating transformation. But, in tangible terms, what does all of this mean for external nature? Marcuse proposes the following:

Nature, the objective world, would then be experienced primarily, neither as dominating man (as in primitive society), nor as being dominated by man (as in the established civilization), but rather as an object of 'contemplation.' With this change in the basic and formative experience, the object of experience itself changes: released from violent domination and exploitation, and instead shaped by the play impulse, nature would also be liberated from its own brutality and would become free to display the wealth of its purposeless forms which express the "inner life" of its objects. ${ }^{191}$

Keeping in mind that in the quotation above is referring to the aesthetic realm, two major problems emerge. The first pertains to Marcuse's original call to embrace nature as our fellow subject - a call to recognize that somehow or other the experience of nature is of equal concern

${ }^{191}$ Marcuse, Eros, 190. 
to our own, that it matters in and of itself, regardless of the instrumental upshot for us. Somehow or other, this thread has been dropped. The most nature seems to be able to hope for, in Marcuse's account, is to be elevated to the status of 'object of our contemplation' and thereby the inspiration for our own further steps towards aesthetic freedom and development. In other words, for nature to be liberated in the aesthetic dimension is for nature to be liberated from our violence towards it (again, in the aesthetic realm) and for it to become, as the 'object of our contemplation,' the impetus for our art, our literature and our music. This is no doubt a marvelous thing for our art, our literature and our music. Yet is this not, also, a form of human appropriation of nature? Is not the aesthetic appropriation of nature domination by another name? The fact that it is non-violent and peaceable is all very well but nature remains very much our object, while the subject/object dialectic that was to doggedly tug at Marx's utopian thinking remains a palpable, if rather more covert, presence in Marcuse's.

But this is not the only problem. Even this shift in our relationship with nature and the object world happens within the aesthetic dimension, which is accessible to us precisely because our needs are fulfilled elsewhere by our exploitation of nature. No matter how small a portion of our day is devoted to the fulfillment of need, no matter how small the effort we expend to survive, no matter by how many degrees we ourselves are removed by our aesthetic dissociation from the processes of extraction upon which our survival depends, nature itself remains both the source of our needs and the means of their fulfillment. That the processes involved is totally automated shrinks the portion of our day devoted to production in the service of need to zero, but does not alter the fact that nature itself continues to be the non-negotiable fulcrum of our very existence.

Of course, automation does have this further benefit to $u s$ : that nature's distress need not 
intrude upon our enjoyment of our new found freedom. Yet precisely because it is automated production is likely to greatly increase the brutality to which nature, overall, is exposed - how marvelously easy to eat meat three times a day if one does not have to risk life and limb in its pursuit - if one does not have to kill it, skin it, disembowel it and hack it to pieces. The more fully automated our life-sustaining processes become the less we are able to truly understand what these processes mean, in the moment of their happening, for their object and the less we are able to understand how the object in its living from might otherwise direct $i t s$ own life-process. This is most especially true of our sensory response and our sensorial understanding of the suffering of nature, which is the level at which we must respond, according to Marcuse, if we are to change our selves and our world. Automation and the distance it creates between the individual whose needs are fulfilled and the original source of that fulfillment is quite possibly one of the greatest obstacles to our capacity to relate ethically to the world we inhabit. Yet the call to recognize nature as a fellow subject seems meaningless unless it is a call to recognize the ethical demands that the subjectivity of the other, of the object, places upon us - a call that is experienced sensorially through contact with, rather than removal from our own life processes. As Roszak has argued at length, the failure to recognize the fundamental importance of the ethical dimension of our relationship with nature to our own well-being is an extremely recent development in the history of human affairs and one, moreover, that has immense significance for human well-being. Describing the way that this plays out within more traditional cultures, he continues:

What Martin Buber called the You-and-I relationship is not restricted to people, or to a transcendent deity. The human must establish a transactional bond with the natural; there must be give and take, courtesy and respect. One bargains with nature, apologises for intruding upon it, begs pardon of the animals one hunts and kills, tries to make good the losses one has brought about, offers sacrifice and compensation. Sanity is just such a matter of balance and reciprocity between the human and the non-human...the connection 
between the two is not simply a matter of survival but of moral and spiritual well-being. Relations with the environment are understood to be ethical, as much as one's relations with a fellow human. ${ }^{192}$

In other words, the property of subjectivity, of being a subject, is not a part time occupation with contract hours to be determined according to the needs of another. It would certainly be convenient if the subjectivity of nature were to bow out gracefully when the next meal of the day calls for a quick spot of domination, but, arguably, domination itself is a problem precisely because subjectivity does not do this. To the extent that nature has subjectivity it retains it even under the conditions we impose upon it as our object, and Roszak's work suggests that this is something that for thousands of years was recognized and embedded within our life sustaining activities. But in Marcuse's account the price nature pays for its privileged position in the aesthetic realm is its total domination by our technology elsewhere.

In the meantime, it is hard to conceive of a society that fulfills its own freedom through the total technological domination of nature while simultaneously maintaining that nature is liberated as a 'subject in its own right,' as being anything other than delusional. Nature, let us not forget, is the vital thread that connects the realm of necessity to the realm of freedom and the aesthetic dimension. Shifting the relative roles and the proportions that these two dimensions play in the human experience does nothing to alter the fact that until such time that our science and technology can produce something out of nothing it is the self same material world that ultimately supports them both. Marcuse is not insensitive to these issues but, perhaps rather oddly, does not seem unduly troubled by them: "In the face of the terrible suffering inflicted by man on man, it seems terribly premature to campaign for universal vegetarianism or synthetic

\footnotetext{
192 Theodore Roszak, The Voice of the Earth, (Grand Rapids: Phanes Press, 2001), 79-80.
} 
foodstuffs; as the world is, the priority must be on human solidarity among human beings. ${ }^{, 193} \mathrm{He}$ recognizes that there is a need to make constant and concerted efforts to reduce the suffering imposed upon animals by our society, ${ }^{194}$ yet sees that the way forwards is to prioritize the rehabilitation of human life.

There is something perplexing and altogether unsatisfactory about the emphasis Marcuse places on the need for the mutual liberation of mankind and nature, while proposing an order of operations that begins with human well-being at the expense of nature leaving the liberation of nature as a whole as a future project for the aesthetically liberated society to address by means that remain largely unarticulated. To the extent that he offers any genuine resolution to this problem it is with the vague suggestion that our current understanding of nature is an 'historical a priori,' which might change within the free society: "A free society may well have a very different a priori and a very different object; the development of the scientific concepts may be grounded in an experience of nature as a totality of life to be protected and 'cultivated.' "195 The vague possibility that the society of the future may find a way to be less exploitative of the natural world is not entirely reassuring, especially given the absence of any plausible account of how the underlying dialectical tension between subject and object might, at that point, be overcome rather than further exacerbated by our own move into the aesthetic dimension and the dissociation that this entails, within Marcuse's account, from our life-processes in a realm apart.

Returning now to the starting point of this discussion, Marcuse has shown us a possible locus of freedom and self-actualization with his account of the aesthetic realm. He has shown us how we might find it and what kind of experience we might expect. But although he does not leave us entirely stranded in its unreality it remains unclear whether the aesthetic experience as

\footnotetext{
${ }^{193}$ Marcuse, Counter-Revolution and Revolt, 68.

${ }^{194}$ Ibid.

${ }^{195}$ Ibid., 61.
} 
he articulates it will gives us the tools we need to effect a radical transformation for the better rather than the worse of our material reality. 


\section{Chapter 3}

It is a fact of experience, and one that is only seemingly paradoxical, that we find freedom in a strict submission to the object.

(Igor Stravinsky, Poetics of Music)

\section{Introduction}

Both Marx and Marcuse situate human freedom, and therefore self-actualization and the overcoming of alienation, in relation to the fulfillment of need. In both accounts freedom itself becomes a 'vital need' but one that is only available to us when the organization of our material production is undertaken in such a way as to make the realm of freedom beyond need universally available. For Marcuse, who argues that work towards the fulfillment of need is 'inhuman,' this entails a radical and - although there is an irony here - repressive technological control and the total automation of the processes of production and basic need fulfillment, in a realm that is not merely differentiated from but fully divorced from the 'unreality' of the aesthetic realm in which our freedom unfolds. Marx however, reaching a compromise within his own model, locates the possibility for freedom within the time that is available to us when our working day is over. ${ }^{196}$ The liberating possibilities of free-time gradually changes us in ways that have the potential to change our relationship with our working lives and our methods of production. Production never abates, so freedom, which rests upon the reconciliation of mankind as subject with nature as our object, can never be fully or permanently attained. Nonetheless, Marx proposes that the lessons we learn from our productive activities in our approximate freedom enable us to turn production as a whole into something that furthers our self-actualization and becomes integral, therefore to our freedom.

\footnotetext{
${ }^{196}$ Schmidt, Concept of Nature, 144-45.
} 
Meanwhile, for Marcuse, external nature in the realm of freedom is the object of our contemplation, while for Marx it is the object of our production. In neither Marx nor Marcuse's account of freedom is there a resolution to the underlying tension between subject and object, leaving little hope that the realm of necessity can be transformed for the good of nature since it is precisely from the troubled relationship between subject and object that mankind's most egregious violations of nature arise.

What is curiously absent from both Marx and Marcuse's accounts is any insight as to creative production as it unfolds in the doing, as opposed to its manifestation as an end result. Yet if we bring aesthetic experience into focus for a moment and try to analyze it as a way of doing rather than as an encounter of the human subject with a different kind of object; or, if we start to think of art as a creative process rather than as body of work, something starts to shift and a different relationship between the subject and object begins to emerge. Robert Morris, in his remarkable essay Anti Form points out that 'the process of 'making itself' has hardly been examined. ${ }^{, 197}$ It is to this process that I now want to turn in the final part of this project.

In what follows I will be drawing on some of my own life experiences for two reasons. The first is that I find them to be a useful way of illustrating the points I am hoping to make. The second is that there is something buried in these experiences that continues to pique my curiosity; but while the texts I have stumbled upon in my researches for this project seem to orbit whatever this thing is, on their own they do not bring it into a sharp focus, so in this final chapter I am hoping that by bringing the two together something useful will happen.

${ }^{197}$ Robert Morris, “Anti Form”, in Continuous Project Altered Daily, (Cambridge Massachusetts: MIT Press, 1993), accessed at https://sculptureatpratt.files.wordpress.com/2015/07/robert-morriscontinuous-project-altered-daily-the-writings-of-robert-morris-1.pdf 


\subsection{On Engagement}

There is a state of being, which I call engagement and which I suspect many or most of us have experienced at some point or another, in which our familiar patterns of interaction with the external world give way to a more fluid and dynamic process. As our project (whatever it happens to be) and its materials start to shift to the foreground of our experience and we find ourselves increasingly immersed in their possibilities, unexpected things start to happen: as our self-awareness fades beneath our sightlines our materials begin to suggest their own direction and to exert themselves upon us as we gradually lose all sense of anything except the unfolding of the matter in hand. As our goals and our habitual orientation towards the future begin to recede and we find ourselves inhabiting the pure present tense our project begins to change, to draw attention to aspects of itself that we had not previously recognized and to spur us towards outcomes that we could not otherwise have imagined.

In my other life as a concert violinist this is an altogether familiar experience, but one that, when I was younger, I had tended to take entirely for granted not only as a normal part of doing what one loves but as the very reason for doing it. Sooner or later, though, if we are fortunate, we will be confronted with the unexpected, and, if we are particularly fortunate the confrontation will be so confounding that we can no longer carry on as before, but must stop and recalibrate our understanding of what we are doing and why. The critical moment for me came about half way through my night watch in the Umfalozi wilderness, camping rough in the bush with some of my south African relatives, with the realization that the hairs on my arm and the sweat rolling down the back of my neck knew all about the hyena prowling close by long before I did, and had already swung into action on my behalf minutes before the unmistakable and cadaverous stench came floating by - an experience that has long served as a reminder that my 
rational and analytical mind sits a few frames out of sync with the reality my body inhabits. As a busy musician in London I had always considered myself an irredeemable urbanite, but my return to London, after months in Southern Africa and the raw, unmediated and urgent sensory engagement with the African bush, was an experience of withdrawal - of sensory retreat from the environment in which I had chosen to live. It was the experience of dissociation from the world and of a shrunken self.

My challenge, then, was to find a point of reconciliation between my experience in the bush and my life in the city - to find a way to re-integrate myself with the world to which I belong. Music and performance, I soon discovered, have the capacity to do precisely that - both can be encountered as a wilderness waiting to be explored, a place of total connection, mind and body, senses and intuitions, perfectly synchronized in their negotiation of uncharted terrain; and when fully engaged, the undiluted exhilaration and uninhibited exploration of the new that can rise spontaneously in a performance can overturn every previous idea one had about the piece one is playing and about one's own musical understanding and capabilities.

In the African bush we listen to nature with every pore of our body, every follicle - and indeed our very survival depends upon it. But nature also has the good grace to listen to us - a quick signal to the hyena, a flick of the wrist to show that we are well and alive is enough to send it on its way. So quick and so thorough is the infusion of the bush into one's entire being that within a matter of days of inhaling the smells of the dry grass and feeling the soft earth beneath me, I could no longer tell where the bush ended and I began. And as a performer, these are the moments for which one lives - the moment when one can no longer tell the difference between the notes on the page, the sound of the instrument, and the feeling of one's fingers on the string. 
What I discovered, as I began to think about some of the many similarities between such remarkably different experiences - one in the heat and the dust of the African bush, one on the concert platform, one driven by urgent necessity and the imperative of survival, the other driven by a highly rarified, aesthetic endeavor, is that the experience of engagement is unrestricted by the boundaries of any one discipline or activity. It is a latent possibility of the given reality that lurks behind almost any corner we turn. Nonetheless, what the two experiences also showed me is that the overwhelming desire to stay in Africa and to abandon city life for life in the bush would be a denial of the modern urban creature that I am. It would be a reversion to a 'naive immediacy' that would necessitate an abandonment of other things - of other parts of my modern being that matter to me.

As I began to think about this a little further I began to realize that the absolutely critical aspect of music that enables it to be such a full and complete experience is that there is absolutely no way of avoiding practice; and practice entails the intellect, it entails reason, it entails detailed analysis and it entails the ability to project a long, long way into the future and to inch one's way slowly forwards. To be a musician is to pull everything that you are doing to the forefront of your vision and to look at it and work at it and to reconfigure it consciously and systematically. And if one does this long enough and well enough then eventually the thing that one has been working on settles itself back into the interior - it becomes, as Marcuse might put it, part of one's biology. Each new piece and each skill gradually reverts to the musical unconscious where it seamlessly interacts with all the others and this is the point at which one is ready to perform. So although the performance has the capacity to be as raw and as vital as the experience of the bush, it differs in that it is also an expression of every part of who we are certainly as creatures of nature, but also as creatures of reason and discipline and foresight and 
planning. And the more we study and practice and think about the music, the higher the level at which we can engage with it when we perform - the more it reveals itself to us.

When a performance goes well the distinction between oneself and the music dissolves and the experience, in the moment, is of the music directing itself - telling the performer what it needs to do, where it needs to go and how it needs to get there, and in ways that can astonish us. The piece develops in ways we had not anticipated and the experience of this ongoing transformation and discovery is the experience of an intense and almost overwhelming freedom. But this is not the freedom to do what one wants - to steer the forces of the external towards a destination of one's own choosing: this freedom is the freedom of a willing and headlong submission to the demands of the music itself as the music responds to one's own. And as the music begins to infuse our instincts and our intentions with its own our ability to respond is, in itself, an unmitigated joy. It is the dissolution of boundaries, the melding of the intellect, the body and the senses, an unmediated fusion of subject and object and it is at the heart of some of our most headlong, spontaneous, creative and transformative experiences of our selves and our world. When we are engaged we flourish.

We might imagine then that engagement would be an essential ingredient for any plausible account of human nature and human well-being and for any social, political or economic system that holds some notion of the good life as its end. Yet it is in fact conspicuous more or less by its absence in the political and philosophical discourse. But engagement is as elusive as it is unstable: it is a state of being that, by its very nature, lies beneath our conscious radar, which might go at least part way to explaining its neglect within the canon. When we are engaged with what we are doing we lose all conscious awareness of almost everything except the 
thing we are working on, and so when we are engaged we cannot be aware of being engaged. As Stravinsky once observed:

The study of the creative process is an extremely delicate one. In truth, it is impossible to observe the inner workings of this process from the outside. It is futile to try and follow its successive phases in some-one else's work. It is likewise very difficult to observe one's self. ${ }^{198}$

No easy task, then, to try and apprehend something that, by its very will-o'-the wisp nature, is gone the moment we try to catch a glimpse. So by virtue of its invisibility in the moment, engagement is accessible to us only through recollection, or to introspection after the fact. Nonetheless, both of these yield certain insights: we lose awareness of our self when we are engaged - we also seem to lose awareness of a whole host of concerns ranging from the minor irritation to the monstrous worry; we lose track of time - we might feel suspended in the intrigue of a moment, an idea, a sound or a brushstroke, only to realize upon re-emerging that several hours have somehow blown by. And, most importantly, we also lose track of our goals.

This last point, I think, is absolutely critical to the way in which we come to understand engagement and its relationship with the creative process. If we examine the end result - the art, the book, the particular performance, the meal even - there is a great temptation to reconstruct and analyze its process in light of its outcome. This, of course, is precisely what our instrumentalized reasoning does extremely well, but in reverse: we have become remarkably good, one way or another, at developing processes finely honed to achieve a pre-determined and reproducible outcome - this is what modern technological production is all about. So when confronted with an outstanding example of something or other (it doesn't matter for these purposes what the thing actually is) it seems perfectly reasonable to assume that its form and its every detail were fully intended and that the working process was simply the process of realizing

${ }^{198}$ Igor Stravinsky, Poetics of Music: In the Form of Six Lectures (Cambridge: Harvard University Press, 1947), 49-50. 
this intention. Intention, in fact, seems to be embedded in the structures of the object itself. Like other forms of production, the qualities and characteristics of the outcome seem to be the very purpose of its production processes, which are valuable to us in so far as they produce the intended result - it is the destination and not the journey that is the goal. But the underlying presupposition, then, is that the production of the work of art (or whatever it happens to be) is like any other, but with an aesthetically inspired end point rather than an economically or pragmatically constructed goal. We are proceeding in our analysis, then, as if there is a goal that is clearly defined and is the very thing that steers the creative process, so that each moment of the process is being controlled by a projection into the future - the present moment, as it is lived, is dictated by the demands of the future. What is is being directed by what is yet to be. But when a specific future is prioritized, then the possibilities of the present are constrained and subordinated in such a way that only those specific aspects of the present that serve the needs of the future are fully embraced - everything else is peripheral, if it is even visible at all encountered as a distraction, an indulgence or maybe an obstacle or temptation to be overcome. In this way it is what we already know and what we have already experienced, or in other words the past, that confronts the project as its own future.

Creative production, reconstructed backwards from the object, seems to be no different to any other kind of production; and the creative person or the artist seems to differ from others not in the way in which he subordinates the present to the future, (and, thereby the future to the past,) but in the type of future that he draws upon with which to channel the present and the skills he brings to the task. The artist, then, seems to be a person with some kind of aesthetic image in mind (in their aesthetic imagination, perhaps) and the talent and the tenacity to turn their vision into a precise and honed physical reproduction of itself. If we pursue this line of thinking then we 
find that the aesthetic future can be neither free nor open, but must be a fixed point, determined and therefore constrained by what is already known. No matter in which part of the mind the image first arose its material realization is the product of that conscious, analytical, rational part of our mind that, as I discovered in the bush, needs to work backwards in its reconstruction of reality, since it is draws its information from what has already happened. When this part of our mind is left to draft up our future for us it can only proceed with what it already knows. In this way the working process and its end result are affirmative - they affirm the given and consolidate the known.

Now there is clearly more than a large grain of truth connecting production as a whole to analytic and instrumental reason, but this can be translated to creative 'production' or processes to a much more limited extent than, I suspect, is generally supposed, because when we look at what many artists and writers and composers and musicians have to say about their work it becomes quickly clear that the certain aspects of the working process itself tend to be overlooked or misunderstood. Stravinsky has this to say on the subject: "All creation presupposes at its origin a sort of appetite that is brought on by the foretaste of discovery. This foretaste of the creative act accompanies the intuitive grasp of an unknown entity already possessed but not yet intelligible..."199 The following brief excerpt from David Hare's autobiography offers this further insight:

I am not sure how quickly I apprehended what would turn out to be my most important discovery about playwriting: fundamentally, I had no control. Whatever the clarity of my intentions, the actual writing of Slag only glancingly resembled my original conception. It's a cliche to say that while you're writing a play the characters take over. They appropriate the action and head off in unforeseen directions. What would be both truer and more interesting to say is that it's not only the characters: every line of dialogue, every exit and entry, every development of the story, every deliberate change of mood on the stage pleases or displeases the author for reasons they would be at a loss to explain. I could, if necessary, make the action more deft. I was perfectly capable of saying, "That

${ }^{199}$ Igor Stravinsky, The Poetics of Music, 51. 
scene's working, but that one isn't. That joke's working, but that one isn't." But to the basic question "Why is the play the way it is?" I had no answer at all. ${ }^{200}$

So while there is some sort of initial intention or intuition that motivates the project and serves as its launch-pad, this seems to be in the form of a more-or-less inchoate suggestion - a shadowy glimpse of something that cannot be cleanly or clearly grasped at the beginning. What we are not seeing is any suggestion of a finished form that makes itself known from the outset.

If we turn to the essays and musings of an artist such as Robert Morris, or read the Gutai Manifesto, or even look at a facsimilie of a Beethoven sonata, let alone turn to works of indeterminacy by a composer such as Lutoslawski or John Cage we start to see, further, that the creative process is one of constant interaction with and response to the materials, in which the materials themselves have what can best be described, I think, as a creative agency: the work as it gathers its own momentum begins to direct and to explore itself. From the viewpoint of the artist, the project and the materials are directing their own processes. We see a suggestion of this creative agency at work in the following excerpt by Robert Morris: "Chance is accepted and indeterminacy is implied. Disengagement with preconceived enduring forms and orders for things is a positive assertion. It is part of the work's refusal (my emphasis) to continue estheticizing the form by dealing with it as a prescribed end." ${ }^{201}$ Jackson Pollock's work, as Morris further comments, is a direct manifestation of this:

Pollock was able to recover process and hold on to it as part of the end form of the work. Pollock's recovery of process involved a profound rethinking of the role of both material and tools in making. The stick that drips paint is a tool that acknowledges the nature of the fluidity of paint. Like any other tool, it is still one that controls and transforms matter. But unlike the brush, it is in far greater sympathy with matter because it acknowledges the inherent tendencies and properties of that matter. ${ }^{202}$

${ }^{200}$ David Hare, The Blue Touch Paper, quoted in the Guardian online edition, accessed Aug.21

2015: https://www.theguardian.com/books/2015/aug/21/david-hare-v-establishment-memoir

${ }^{201}$ Robert Morris, "Anti Form," in Continuous Project Altered Daily

(Cambridge MA: MIT Press, 1993), 46.

${ }^{202}$ Robert Morris, Anti Form, 45. 
The idea that the stick and the paint are somehow "in sympathy" might suggest a romanticized anthropomorphism at work. But, one doesn't have to look very far in any direction to find artists, musicians, choreographers and writers who insist that the working process is one in which things change at every step of the way in direct response to the properties of the material itself, be it the human body, viscosity of the clay, the words on the page, the curvature of the grain, as they reveal and exert themselves and interact with one another through the process; and in such a way that the particularity of the outcome itself - the performance, the script, the book, the painting could have been neither micro-managed nor clearly imagined ahead of the fact. As Stravinsky tells us,

It is a collaboration which is immanently bound up with the inertia of the creative process and is heavy with possibilities which are unsolicited and come most appositely to temper the inevitable over-rigorousness of the naked will. ${ }^{203}$

Without this collaboration, one of two things happens. The first is that the music remains a mere fantasy, trapped in the imagination so that the project never comes to fruition:

Invention presupposes imagination but should not be confused with it. For the act of invention implies the necessity of a lucky find and of achieving full realization of this find. What we imagine does not necessarily take on a concrete form and may remain in a state of virtuality, whereas invention is not conceivable apart from its actual being worked out. Thus, what concerns us here is not imagination in itself, but rather creative imagination: the faculty that helps us to pass from the level of conception to the level of realization. $^{204}$

Alternatively, as Stravinsky continues, the music comes into being but in such a way that it has cheated itself of the very processes that allow it to express itself, in which case he suggests that there is some kind of trickery or a deception at work - but it is a deception that works against us all and against the known reality, for it denies us the possibility to find out what else there may

\footnotetext{
${ }^{203}$ Igor Stravinsky, the Poetics of Music, 54.

${ }^{204}$ Ibid., 53.
} 
be. The 'what if' and the 'what might be' are ever subordinated to what we already know about the 'what is.'

The idea of work to be done is for me so closely bound up with the idea of the arranging of materials and of the pleasure that the actual doing of the work affords us that, should the impossible happen and my work suddenly be given to me in a perfectly completed form, I should be embarrassed and nonplussed by it, as by a hoax. We have a duty towards music, namely, to invent it. ${ }^{205}$

Or as the Gutai artists insist, framing the issue a little differently,

Matter never compromises itself with the spirit; the spirit never dominates matter. When matter remains intact and exposes its characteristics, it starts telling a story and even cries out. To make the fullest use of matter is to make use of the spirit. By enhancing the spirit, matter is brought to the height of the spirit. ${ }^{206}$

In other words through the creative process the future is allowed to emerge from possibilities of the present that are concealed or only partly exposed to the artists until the moment that the working process began. The creative process thereby brings us into intimate contact with the given - intimate exploration of its problems, its possibilities and latent potentials: to create is, above all, a willingness to change; to commit oneself absolutely to the given and to engage with it, to listen to the voice of our object and allow ourselves to change direction in response. But absolutely key to this process is the state of engagement and the shift in focus and in priority that it engenders. So long as we keep our eye firmly on the pre-determined outcome we are insensible to the voice of our object and the further possibilities it might reveal.

Hans Keller, the great music critic and teacher, would tell his students that when playing chamber music the other person is always right. In other words we immerse ourselves in what the other player is doing and listen and respond and support it unreservedly as it is happening to the extent that it sometimes feels that our own hands are playing the other player's part. This

\footnotetext{
${ }^{205}$ Ibid., 53.

${ }^{206}$ Yoshiharo Jiro, Gutai Art Manifesto, accessed August 3, 2017 at: http://web.guggenheim.org/exhibitions/gutai/data/manifesto.html
} 
works because the other player is doing the same - we are both free because we give each other total freedom. There is a loss of self-awareness and an abandonment of self, but this is not an act of self-sacrifice - it is a vital act of self-retrieval, without which the greater part of who we are and of what we are capable remains forever hidden from view, buried beneath the known and the habitual. So where the production of an outcome that cannot be known in advance is the essence of creativity, part of the unknown outcome is the transformation, whether it be subtle of substantial, of the subject. In the creative moment we commit ourselves to the object as our fellow subject and move together headlong to an open future. As Simone de Beauvoir once wrote,

"It is not a matter of approaching a fixed limit; absolute knowledge or the happiness of man or the perfection of beauty; all human effort would then be doomed to failure, for with each step forward the horizon recedes a step; for man it is a matter of pursuing the expansion of his existence and of retrieving this very effort as an absolute. ${ }^{207,}$

And here, de Beauvoir has caught the most important aspect of the creative process, which is that it is an end in itself - it is the point where ends and means meet. Above all the processes themselves and the state of engagement they engender are of intrinsic value - in and of themselves they are the very reason we play music, or perform or make or write or dance or sing, regardless of what - if anything at all - is to come of it.

What this means then, is that to create is not to be possessed of an extraordinary genius or vision - it is to be able to immerse oneself in the present tense and thereby head off into the future without a map; in other words it is to trust the object, trust the external and trust the uncertainty of the future to which they lead and trust in a process that defies and provokes and disrupts and challenges the known. And when we have discovered how to trust in the present moment we find that we can engage in even the most mundane of activities - if we unplug

${ }^{207}$ De Beauvoir, Simone, The Ethics of Ambiguity, (New York: Citadel Press, 1976), 79. 
ourselves from the outcomes we think we want and from the endless cultural distractions that blind and deafen us to anything else, a walk around the block becomes an adventure.

So to summarize the creative process and the experience of engagement we can say that:

1) The particularity of the work of art, art object or artefact is not a goal or an aim - it is the byproduct of the processes by which it came into being.

2) For the artist, it is these very processes themselves - the processes of engagement, that are of intrinsic value, such that means and ends meet in the creative act. Art is not a product, it is not an object, it is way of doing.

3) The creative process shows us that while there is no iron law binding any one form to any one material, materials are in fact (and despite what Marx has to say on the subject) ${ }^{208}$ very far from indifferent to their own form - they guide and suggest and reveal and they also they resist and protest as we work with them.

4) We discover this at the point at which we are engaged and submerged within the creative process itself - the greater our level of engagement the more clearly our materials make their own inclinations known to us.

5) To become engaged and to be fully receptive to the materials we have to let go of our own goals and future orientation, meaning that instrumental reasoning has to bow out; to the extent that we remain focused on our own aims for the project and insist on steering our materials to an end that is predetermined by us, we remain insensible to the other possibilities contained within the present moment and within our materials - at which point we are involved with not the creative process but with production. The creative

${ }^{208}$ See chapter 1 , section 6 . 
processes themselves demand an intimacy with the materials themselves that is undermined by the instrumentalization of the determinate outcome. But, and this is of tremendous importance, we have to do the work ourselves. Intimacy cannot be delegated - it does not work by proxy.

\section{Marx, Marcuse and the Creative Process}

Now that we have seen something of the creative processes I want to turn back first to Marx and then, with a little help from Horkheimer and Adorno, to Marcuse, in order to show that there is a way to draw upon the experience of creative engagement that enables us to approach the problem of freedom and the subject/object relationship from a fresh vantage point.

\section{A. Marx}

In contrast to the creative process, production as we might typically think of it and as it described by Marx (or 'prescriptive production,' as Ursula Franklin has called it, wherein the outcome is tightly controlled and known ahead of the fact $)^{209}$ seems to be an attempt to dispel the unknown and to dispel uncertainty, revealing an underlying desire to control. It has every appearance, therefore, of being motivated by a distrust of the present moment and of the unknown future to which it might lead.

What I hope to have shown in the first chapter is that Marx finds exchange economy to be grounded in a fundamental distrust of the other person, which in turn furnishes a distrust in one's own ability to survive without subordinating oneself to the demands of a system that is fuelled by these relations of distrust. In Marx's account, distrust in humanity oils the wheels of capitalism. Yet in Marx's model of production we find a similar distrust, albeit a distrust of the external, which must likewise, be outmaneuvered for the sake of the desired outcome:

\footnotetext{
${ }^{209}$ Ursula Franklin, The Real World of Technology, (Canada: House of Anansi, 2004), 17.
} 
What distinguishes the worst architect from the best of bees is that the architect builds the cell in his mind before he constructs it in wax. At the end of every labour process, a result emerges which had already been conceived by the worker at the beginning, hence existed ideally. Man not only effects a change of form in the materials of nature; he also realizes his own purpose in those materials. And this is a purpose he is conscious of, it determines the mode of his activity with the rigidity of a law, and he must subordinate his will to it. This subordination is no momentary act. Apart from the exertion of the working organs, a purposeful will is required for the entire duration of the work. ${ }^{210}$

Marx presents this as an entirely a-historical account of human production, "independently of any specific social formation" ${ }^{211}$ from which we can infer that this is true also of his views on the free and universal production that is the basis of our self-actualization. So even in the realm of freedom, production, as it appears in Marx's account, bypasses the creative processes and obviates engagement - it is goal-oriented, objectifying and instrumentalizing, and insists on knowing its own results precisely and ahead of the fact. Production, no matter what form it takes, is a manifestation of the very one-sided instrumentalizing relationship with the world that must be overcome for the sake of our sensory liberation and our freedom and self-actualization; yet Marx wants us to overcome this instrumentalizing orientation to the world through more production. For Marx, this is how we differentiate ourselves from the animals to assert and express our humanity and our freedom. And here, I think we have come to the heart of the problem in Marx's account in a way that enables us to understand why his view of human nature is incompatible with his understanding of freedom. To the extent that production is undertaken as Marx suggests, then even when free from the restraints and distortions of exchange economy and even when universal and in accordance with all the laws of beauty, production is, at its heart, a fundamental expression of our distrust of our own reality - of nature, in other words.

\footnotetext{
${ }^{210}$ Marx, Capital, vol I, 284.
}

${ }^{211}$ Ibid., 283. 
Now, we have already seen Marcuse's suggestion that Marx relates to nature as it appears in his own historical moment and therefore as "that which capitalism has made of nature.,"212 We might now start to consider the possibility that production itself, as Marx understands it, is also 'that which capitalism has made of production.' This is speculation. But if we recall Marx's views on the relationship between matter and form, and, in particular, materials and the forms through which they pass in the metabolic processes of labour and production, we find relationships of indifference: indifference of the materials to their various forms and indifference of the human form to the stuff of nature. Such is the nature of this indifference that the human as subject is reconciled with nature as its object only in a form that remains external to them both. Yet what the previous investigation into engagement seems to show is that materials are very far from indifferent to their form and so too are we when we begin to engage with them: in the creative process, when we are engaged, materials suggest their own transformation, while the human subject and nature seem to intersect in mutual subjectivity, rather than in the externality of the object. But we have to be prepared to let go of our goals and future orientation to discover this. In other words, the view that materials are indifferent to their form is a view that is particular to production itself as Marx understands it to be. The more automated the production methods are, the harder it is to have access to the types of encounter with the materials that would challenge this view.

What we seem to be seeing is that in Marx's account there is a sensory dissociation from the materials of production that carries with it heavy overtones of the sensory dislocation from the world; in turn, as he argues, this dislocation distorts and diminishes human nature under capitalism. Yet production, for Marx, is our non-negotiable, trans-historical defining

${ }^{212}$ Marcuse, Counter-Revolution and Revolt, 62. 
characteristic. Perhaps, then, our insatiable drive to produce is in fact 'that which capitalism has made of human nature.'

Marx's account is so strongly suggestive of alienation from the creative processes themselves that I think it is worth considering the possibility that Marx's account of human nature and production in their trans-historical form is mistaken in its most foundational element.

By way of testing this hypothesis, I want to turn back to Marx's account of the speciesbeing and substitute the idea of 'doing' for that of 'producing.' Marx holds us, above all else, to be creatures that produce beyond need. Yet production itself is very far from being an irreducible concept - it is a form of doing. Now, if we consider the possibility that we might be creatures defined by 'doing' instead of 'producing;' and that in freedom from need we 'do' rather than 'produce', then this would allow within his account for the possibility of true engagement to play a foundational role in our relationship with the external. This would influence the ways in which we fulfill need, but would most especially alter the use to which we put our freedom.

The ongoing productive transformation and objectification of nature according to human purpose and self-understanding can now give way to a non-exploitative interaction with nature; one that is open-ended and unfolds in response to nature's materials and the forms through which they pass and that therefore no longer reflects an image of domination and subjugation back at us. Where other creatures merge with their life-activities in need, we merge with them, at least from time to time, in freedom; and in this freedom we experience the creative agency of nature as our fellow subject, thereby collapsing the tension between species being and world being. Engagement shows us a way to begin to detoxify Marx's dialectic of nature and its metabolic processes. 
This is just a brief sketch. Clearly our world being and our species being would still have rather a lot of work to do to find themselves on an equal and non-destructive footing with one another, but re-working Marx's ideas this way, I propose, gives us an insight as to where and how this work might begin, while preserving the critical centrality of creativity to his account of human nature, of human flourishing and of their relationship with the external.

Finally, before leaving Marx, the notion of engagement highlights a specific problem that arises from the division of labour. Certainly under division of labor human development becomes lop-sided, in ways that have ramifications for society as a whole; and certainly the horizon of possibility is arrested when the majority of the population is unable to fulfill their own greater potential; but we can now see why this matters so much. When one person determines the goals and another is required to fulfill them to the very letter, no-one can engage. The more that every thing we do is broken up into more and more specific and self-contained tasks, each its own specialization, the more prescriptive the working process must be and the more tightly controlled their outcomes, lest they fail to be operable within the whole. A truly engaged workforce would undermine and destabilize the productivity of the work-place and the viability of the end product. But the less engaged we are the less chance there is that any of the things in our lives that most desperately need to change will ever be able to, for we will gradually lose touch with the kind of experience that can show us how else to be.

\section{B) Marcuse}

Marcuse finds freedom in the aesthetic imagination and the way in which we encounter the object therein. But art, for Marcuse, is mistaken for its own canon and remains an object external to our own being. No matter how highly prized the object, no matter its aesthetic properties or its radical expression, it can never lose its quality of being an object, even in the 
unreality of the aesthetic imagination: it can never be our fellow subject. There is a mystification - an enchantment: we are bewitched by properties in the object that we cannot make our own they remain embedded and beyond reach, and while their provocations and dissatisfactions arouse our imaginations, they are contained within their own unreality. Marcuse never loses the utopian faith that our experience of art as the object of our contemplation will somehow lead us to the radical transformation of the given social and material reality: "that art as art expresses a truth, an experience, a necessity which, although not in the domain of radical praxis, are nevertheless essential components of revolution. ${ }^{, 213}$ However, this leads him to seek out an answer to the wrong question:

The question as to whether there are qualities of art which transcend specific social conditions and how these qualities are related to the particular social conditions remains open. Marxist aesthetics has yet to ask: What are the specific qualities of art which transcend the specific social content and form...? $?^{214}$

The question itself obscures the more important matter of the qualities of the human being which enable us to transcend the specific social conditions, and, instead keeps our attention focused on the art object rather than on the way in which it was brought about. The question Marcuse is asking thereby seems to exclude the human being from the possibility of being a causal element of his own liberation.

Meanwhile, as Marcuse himself is all too well aware, under conditions of alienation reality itself has come to be construed as an endless cycle of false need and false fulfillment through manufacture, acquisition and consumption of the object. Insofar as something is part of reality it is inextricably bound by this cycle. So art itself, one way or another, is encountered as an object - a finished item, ready to be consumed. Thus the tendency of art when understood as a body of work or a cultural output is to collapse and affirm the instrumentalizing cycles of

\footnotetext{
${ }^{213}$ Marcuse, The Aesthetic Dimension, 1.

${ }^{214}$ Ibid., 14-15.
} 
capitalism where it is swiftly disarmed as mass culture. Marcuse is abundantly aware of this problem, but does not see an immediate solution. Here again, although Marcuse is right that art communicates a truth, in viewing it as an object he is seeing it through the lens of capitalism and production. The partial truth that is concealed by the encounter with art as an object is that of art as $a$ doing, as the immersive processes of engagement. The object itself is a deception that conceals its own existence as a mere result or happenstance, by assuming the status of a goal not the undetermined result of a creative unfolding but the ultimate end point that is itself the author of its own process. Yet, as Horkheimer and Adorno have argued, the subtle imperfections of even the greatest works of art, the friction between its stylistic elements and its surfaces, reveals the reality of art to be one of constant confrontation with its own shortcomings. ${ }^{215}$ The work itself reveals an ongoing working out of the tension between the given and the possible, between existence and potential. So through its qualities the art object reveals itself as a contingency whose visible surfaces are the by-product of its own process - as a mere punctuation in an unfolding that is, by its very nature, a journey unconstrained by destination. So, most especially under conditions of late capitalism, the processes of art seems to be a form of freedom. This freedom, the highly subversive freedom of art to surrender to its own becoming, is, ultimately the freedom to negate the given reality and, thereby, to negate itself. Through its processes art not only transcends or surpasses the given, but recognizes it, confronts it, and renounces it; and in the process it thereby affirms its own latency, and reveals its further possibilities.

Yet even here there is a deception - a reification that conceals both the human nature of this process that is art, and the necessity of this process to human freedom. The freedom that is concealed by art as an object, by art as it appears to us under capitalism, is the freedom of the

${ }^{215}$ Horkheimer and Adorno, Dialectic of Enlightenment, 103. 
human being to transform and to be transformed. This is the central freedom that any totalizing system must conceal at all costs, for it is upon such concealment, above all else, that the very survival of the system depends. At the same time, the instrumentalization and commodification that drives the market mechanism denies the reality of anything that cannot be instrumentalized or that cannot be commodified - everything is to be encountered as an object, including the self. So where reality is a state of total instrumentalization, engagement - the seamless dissolution of the very distinction between subject and object - is, in itself pure negation. Engagement, within our reality, is pure subversion and so if, as Marcuse argues, we must as a matter of urgency, find a way to understand the revolutionary qualities of art, it is not to the art itself we must turn but to those very human processes, this very human doing, by which art happens to come into being.

And here we find the further 'truth of art' - perhaps its most tightly held secret - and one that is entirely overlooked by Marcuse, which is that the kind of doing that art involves need not be specific to art and nor is it the solitary purview of the artistically talented. It can infuse our day to day lives and what would, otherwise, be the most mundane of tasks - in other words it can infuse the realm of necessity. It shows us that feeding ourselves need not be an onerous task: food can be an intense pleasure in the growing, and preparation as well as in the eating, when we can do it in our own time and our own way - when we can engage with the process and immerse ourselves in what we are doing and not be beholden to a specific outcome. To the extent that we understand the aesthetic dimension as creative process, engagement seems to offer a bridge with which to connect the aesthetic experience to the experience of our own day to day reality.

Nonetheless, many things are likely to prevent this from happening within our present reality, some of which are outlined in the next brief section. 


\subsection{Some Problems With Engagement as a Way to Change the World}

3A) The experience of engagement is easy to overlook. It is elusive, and lies more or less beneath our conscious radar, partly as a result of the instrumentalizing world-view that has been so long and systematically inculcated in our society, and partly due to the very nature of the experience itself.

3B) It does not fit within the framework of our self-understanding. The experience of engagement arises spontaneously and sometimes when one is least expecting it; like an unreliable guest it often show up late and sometimes never at all, no matter the importance of the event - and when it does put in an appearance it tends to outstay its welcome. In other words engagement does not work to rule and cannot be summoned at will - in fact it often defies our will, and is unresponsive to even the most well-reasoned argument; yet seems to work very much to our benefit. So engagement raises important questions as to who or what is in charge at these times, which are frequently when we find ourselves functioning at our best.

The simple answer is that no one is in charge - by its very nature it is a non-hierarchical structure wherein the subject, object, senses, intuitions, mind, body all do what needs to be done in the moment according the needs and suggest and power-sharing unfolds spontaneously and seamlessly among them. So engagement is an anarchic state of being that we negotiate effortlessly. But this places an important area of our well-being and our self-understanding beyond the scope of the standard enlightenment narrative that tells us that not only are we in charge of our every action, masters of our own destiny, but that our continued well-being and prosperity depend upon it. So engagement poses a considerable challenge to the selfunderstanding of modernity and the idea that reason must at all times be in control and in so doing it also furnishes the highly subversive possibility that centralized governance may not be 
to our best advantage at all times and might even work against it. (David Graeber has commented that "anarchist social relations are all around us, and this is critical because it already shows that anarchism is, already, and has already been one of the bases for human interaction. ${ }^{216}$ This brief account of engagement rather seems to suggest that the basis for anarchism itself might well be human creativity, or at least one, rather marginalized corner of it.) In any case, these findings suggest that engagement will tend to remain considerably marginalized, theoretically and experientially, within the modern liberal democracy.

3C) Engagement does not guarantee its own outcomes. Engagement is not in the business of making promises or predictions and certainly offers us nothing in the way of a guarantee as to what will come of it. It is, instead, something of value to us as the very thing that it is. To instrumental reason the intrinsic is intrinsically worthless, so within our own society an experience that is of irreducible value in its own right still needs to justify itself in terms of future benefits, which engagement cannot, by its very nature do. The intrinsic is vanishing from our lives and we are losing a vocabulary with which to express it - there is no deficit column for it on our balance sheet. This is clearly borne out by the extent to which discussions in the media concerning the value of music, for example, are devoted to its impact on tourism and the GDP, with occasional mention of benefits to the IQ and children's sleeping habits - we are at a loss to know how to discuss it in any other terms let alone justify it as a life's work. So as the intrinsic slips away from us our capacity for engagement is rendered meaningless. Music is not the only victim, as even the briefest glance at modern childhood shows: playgrounds are being auctioned off to the highest bidder, children's theatre, drama, art, even cooking and their ongoing contact with nature have been privatized and vestigialized within the extra-curricular. As the opportunity for open-ended doing and true engagement vanishes from the classroom, we go to school to

\footnotetext{
${ }^{216}$ David Graeber, Fragments, 76.
} 
become useful members of a society in which education is being replaced by job training. And as we lose our connection with the doing and with the intrinsic - as we gradually become more and more dis-engaged - we lose our intimacy with our own material reality, and in ways that profoundly threaten our well-being and that of the planet we inhabit. Nonetheless, even when we see the problems with which we are confronted and recognize the need for change, this comes hand in hand with a desire for results, which engagement simply cannot guarantee.

3D) Engagement does not conform with the notion of freedom that prevails within market society. From within the mind-set of market society, choosing to follow a path that affords us the possibility of engagement appears to be a form of flight from reality or of dropping out - of disengaging from the world we inhabit, for the entrenched understanding of freedom within a consumer society is the freedom to choose among the existing options afforded us by the given. Freedom is thereby substantially undifferentiated from a trip to the supermarket, while the thankless choices with which we are now endlessly confronted and that we are required to make in order to be able to function within our given reality ensure that there is no time available for anything else. And crucially, many of these choices confront us as urgent while squeezing out any space for the important. So although we sense somewhere that we are missing the point, and many of us sense that we might in fact be missing out on life itself, our sense of what is important remains inchoate and ever at arms length within an economic system that is predicated upon the perpetual invisibility of our most genuine needs and the endless postponement of their fulfillment.

3E) A population of highly engaged people would undermine our economic system. This last point more or less sums up all the others. Engagement shows clearly that homo economicus not only has another side to him, but that this side threatens to undermine his 
productivity and his market-oriented, utility maximizing, self-interest and a world view based upon rational calculation. Engagement draws us into the realm of the intrinsic, but in so doing it threatens to draw a system predicated on the instrumental to a halt. So it seems to be something of a serendipitous happenstance for our current world order that engagement is so easily swept to the margins.

So, the overarching problem with trying to build a case for the notion that engagement is a source of freedom and well-being, with a built-in capacity to transform ourselves and our world, is that engagement is fundamentally at odds with our current understanding of freedom and it challenges our present perception of who we are and what our own best interests happen to be. But this is not all. The instant gratification of whatever is perceived to be our most urgent need strongly precludes the possibility for engagement. We cannot be engaged when needs are pressing and outcomes must be swift, reproducible and certain. Yet the cycle of constant and urgent need fulfillment and the endless postponement of freedom and wellbeing that this entails, is grounded in a myth - the myth that freedom and necessity are incompatible with one another and that in order to be free our needs must first be fulfilled.

Working away behind the scenes of this myth is a profound resistance to doing things for ourselves - in fact the history of western civilization is, arguably, a history of people believing that the less they are involved with the immediate processes of their own need fulfillment themselves the more human they become. So although we pride ourselves on being productive, we pride ourselves even more when our production moves us away from the realm of biological necessity and into the abstract world of high finance, consultancy, academe, management of one kind or another - pretty much anything that can be done while sitting at a desk. This is one of the 
mainstays of the division of labour. Epicurus stands out, perhaps, for his views that selfsufficiency (which for Epicurus is a fully social affair) ${ }^{217}$ is essential for a life well-lived and that freedom and well-being must enfold needs into their very structures: if we are to avoid being coerced and manipulated by need we must engage with our needs, recognize them for what they are and give them the space in our lives that they require - only then can we differentiate between false needs whose fulfillment creates cycles of anxiety and unhealthy dependence and true needs whose fulfillment bring pleasure.

Now clearly when one's own ability to eat depends upon being paid to make six thousand identical burgers each day to a precise set of instructions, cooking quickly becomes utterly mechanical and fully alienating - the pickle goes under the ketchup and over the lettuce each and every time; and the possibility that the entire thing might be reworked and turned into a deconstructed pie, or bronzed and made into a hat, is not a idea one can entertain if one wants a pay cheque at the end of the day; meanwhile making one's own supper after feeding other people identical meals all day long, seven days a week, would be something of a last straw. Feeding oneself can clearly, in the wrong conditions, be a misery and a humiliation. Engagement suggests that the solution is for all of us to cook - for all of us, and most especially for those whose lives tend to shelter them from such things, to be involved with the processes of our basic needs and to discover that it can be a pleasure and a freedom to do so; it suggests that this discovery would itself lead us to transform the way we relate to nature - we could not help but choose less damaging and less violent ways of feeding ourselves; and in so doing a different social order would necessarily emerge. But much like Marx and Marcuse, we are typically more inclined to see solutions in terms of further mechanization - if the job is humiliating, soul-destroying, mind-

${ }^{217}$ Epicurus, “ The Leading Doctrines”, in The Philosophy of Epicurus, ed. George K. Strodach, Chicago: Northwestern University Press, 1963), 196-203. 
sapping and crushing to the human spirit then outsource it to technology and get a machine to deal with the precise positioning of the pickle. And, as we have already seen, we are then trapped, once again, within the same old cycle of domination and subjugation of the external with all the problems that come with it.

\subsection{Odysseus and the Brand New Shiny Motorboat}

In these last few pages I want to sum up my thoughts on all of this by paying a visit to Horkheiemer and Adorno's discussion in Dialectic of Enlightenment of Odysseus and his adventures with the Lotus Eaters and the Sirens in order to try and grasp more fully the price we pay for our modernity and the endless postponement of the intrinsic, of engagement, and of true flourishing, to which it blinds us, and that has become our modern day disease.

Horkheimer and Adorno argue that as man hurtles towards his enlightenment with consciousness and self-awareness, the knowledge embedded within the ancient myths is subverted and manipulated for political gain. Yet, as they continue, if we cast an eye over the myths themselves, we will find that among the various riches they have to offer is the almost universally expressed notion that "everything that happens must atone for the fact of having happened." ${ }^{, 218}$ And so Horkheimer and Adorno alert us to a tremendous tension between man's power to manipulate myth and belief to his own ends through calculating goal driven reasoning, and the universal message of the myths themselves: we may reason and calculate all we want, the myths tell us, we may set whatever goals we want for ourselves, but there will always be a price to pay. Meanwhile, our belief that the very notion of atonement is just a myth blinds us to such a degree that we fail to see the greater truth at work within our own lives. Far from being creatures of true enlightenment we have simply replaced one myth with another, but, since we

\footnotetext{
${ }^{218}$ Horkheimer and Adorno, Dialectic of Enlightenment, 8.
} 
believe that we are fully rational and that superstition and myth play no role in our modern scientific lives, we fail to recognize the belief systems under which we operate. We have not yet fully grasped that beliefs have a devious habit of appearing to the believer as immutable and universal facts of nature, and so we fail to see the price we are paying for the simple reason that we do not believe there is one.

Turning now to Odysseus we can start to see how this tension plays itself out.

Among the many terrors that beset Odysseus on his journey home the first, and one of the more intriguing, is his encounter with the Lotus Eaters. Anyone who eats their food falls immediately under their spell. There is no malevolence at work here but only the gentle enchantment of "forgetfulness and loss of will." ${ }^{, 219}$ Losing all thoughts of returning home, Odysseus' men wish for nothing more than to stay with the Lotus-eaters, grazing on the fruits of the lotus and a perfectly pleasant life of "dull aimless vegetating." 220 To extricate them from the clutches of this false idyll, ${ }^{221}$ Odysseus had to seize his men by force and clamp them, weeping, in irons on board his ship.

The danger, here, for Odysseus and his men, seems to be the total loss of creative engagement. In their uncritical acceptance of the primal state - of the quintessential state of nature as given - they are subsumed within it. Here too, as in our own society, the capacity to negate or resist is undermined, but the terms and conditions of this flattened primal unity are set by nature; and life is reduced to mere and unquestioning existence. And yet, being wrenched back on board, even as their full humanity is restored they weep. For Adorno and Horkheimer life with the Lotus-eaters "bears the promise of a state in which the reproduction of life is

\footnotetext{
${ }^{219}$ Ibid., 49.

${ }^{220}$ Ibid.

${ }^{221}$ Ibid.
} 
independent of conscious self-preservation...."222 But notice, here, that life with the Lotus eaters is not the production of life - it is mere reproduction, each iteration to be enacted in the image of the last. And, as such, is itself an irremediable negation of creativity - not the creative immersion of engagement but the absorption back into nature and a state of total alienation from that which makes us human. To stay with the Lotus-eaters is to recover the unity of the self as a stagnant remnant. But to leave, as they must, is to tear apart this false - but blissful - unity.

Like the Lotus-eaters the Sirens' merciless charms unfailingly pull all who succumb to them into their perilous orbit. More than anything, Odysseus wants to hear their song. But Odysseus has ambitions, he has goals, and he has a destination - he already knows precisely where he wants to go. He is also aware that no-one can hear the Sirens and hope to withstand their "powers of dissolution." ${ }^{223}$ Nonetheless, Odysseus manages to escape the overwhelming seductions of the Sirens by stuffing wax in the ears of his men and ordering them to row on, full steam ahead. His path to his chosen future is secured for him through the labours of his men, who are now oblivious to the beauty of the Siren's song. Meanwhile, having ordered his men to bind him to the mast of his own ship, Odysseus can safely listen to the Sirens without losing either his life or his grip on his further plans and ambitions. Odysseus's cunning is to sacrifice himself to the Sirens by listening to their song, while at the same time cheating the Sirens of their share of the bargain. ${ }^{224}$ And in so doing, as he sails on to his destiny he appears to have sacrificed nothing whatsoever.

But what is actually happening here? For Horkheimer and Adorno, the "allurement of the

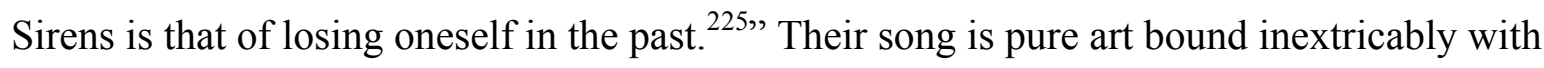
${ }^{222}$ Ibid., 50.
${ }^{223}$ Ibid., 26.
${ }^{224}$ Ibid, 48.
${ }^{225}$ Ibid, 25. 
knowledge of all that has ever happened. Odysseus, strapped to his mast is unable to give in to the pure self-abandonment that the song elicits. He is severed from his own creative self and the knowledge of total engagement and all that this encompasses, which, if unleashed, would send him straight to the Sirens. As for Odysseus' men, they are oblivious to the harm that has been done to them: deafened to the Sirens they have no means by which to comprehend what it is they are missing, or to realize that they are missing anything at all. And so in his resistance to the Sirens, and in his obstinate insistence on his chosen destiny, Odysseus is performing an act of extreme violence towards himself, and an even greater one to his men, whose very senses have been amputated. The price we pay for insisting upon our own destiny and for barring our creative selves from the helm of our own ship is, as Adorno puts it, mutilation. ${ }^{226}$

Now for Horkheimner and Adorno one of the primary concerns is the social dimension of Odysseus's actions. Odysseus secures his own access to music, through division of labour. This division of labour is itself made possible by the deliberate exclusion of the music and the sensibilities it fosters from the lives of Odysseus's men. The suggestion is that art by its very existence affirms and validates the divisive and exploitative society that make art and culture possible in the first place. These same concerns resonate loudly throughout Marcuse's work: "at stake is the 'affirmative character' of bourgeois culture, by virtue of which art serves to beautify and justify the established order." ${ }^{227}$ But equally, through Marcuse's lens, Odysseus's actions militate strongly against his own freedom, for despite his excursion to the aesthetic realm, freedom is only possible for the individual when it is possible for all - and for Marcuse, freedom for all entails automation. So let's give Odysseus some technology: let's air-lift Odysseus and his men out of their trireme and put them into a shiny new motor boat. Now Odysseus can set the

226 Ibid, 27.

${ }^{227}$ Marcuse, Counter-Revolution and Revolt, 92. 
tiller and turn the engines on full blast, they can all strap each other to the railings, they can charge ahead full steam to Ithaca and they can all listen to the Sirens. The social divisions have collapsed and there is universal access to the aesthetic experience.

But what of the music itself? In their refusal to engage with it, or to submit themselves to its demands, Odysseus and his men are denying the music its creative agency. They have, in effect, mutilated the music as well as themselves, by severing it from the possibility of its own further development. No longer a roaring, sensorial subjectivity, no longer a living, vital, transformative force, the music of the Sirens is just a well sung accompaniment - a song about things that have already happened. It is a thing, an externality, and object of consumption - the theme tune for the next leg of a journey to a destination that is already known. And now, neither the music nor its considerably expanded audience will change. The transformative power of the music is disarmed, it is still just a good tune played somewhere by someone, while everyone else heads home and no-one discovers what it is to be truly engaged. Everything will stay just exactly as it was before, and the great thing is that nobody can ever know what has been lost, for what has been lost has not yet come into being: it is not a thing, but a potential, a possibility.

In both escapades, be it the Lotus-eaters or the Sirens, the natural world is understood by Odysseus to be profoundly hostile. Where the danger of the Lotus-eaters is that of being subsumed by nature as pure existence, the danger of the sirens is that of being subsumed by nature as an elemental creative force. In both instances nature itself is the adversary - not only nature as an externality but our own very human nature. But, recalling Marx once again: "That man's physical and spiritual life is linked to nature means simply that nature is linked to itself, for man is a part of nature. ${ }^{, 228}$ Self-alienation then is, at its heart, nothing other than alienation from nature. And so it might seem that we, ourselves cannot be other than alienated, since the

\footnotetext{
${ }^{228}$ Marx, 1844, 76.
} 
creativity that defines human nature necessarily drives us to negate both ourselves and the natural world as we find it and understand it. But to accept this position is to fail to recognize that it is only through this creative act that we are able to discover and explore our greater potential - and to the extent that it is nature itself that compels us to do this (since human nature is nature) nature is not our adversary but an ally to whom we can commit and with whom we can engage. And where we allow ourselves to engage and to let go of the future we have at least a chance, no matter how small and unstable and unpredictable it may be, to overcome our appalling and excessive violence towards the natural world and to embrace nature as our fellow subject. But to do so is not only to trust nature, but to trust ourselves fully to the present and to relinquish control of our destination - the very thing that Odysseus could not do, since not only could he not put his trust in nature, but nor would he forsake his goals.

There is a biting irony in this story: in the violence of rupture, as we prize ourselves away from the unconscious state of nature that is the life of the Lotus-eater so as to fulfill the possibilities of our now self-aware and more fully human and creative selves, we pit ourselves against nature as our adversary; and in this new adversarial state we feel compelled to suppress our creativity and the possibilities of self discovery and development and thereby deny the possibility for true freedom. As Horkheimer and Adorno point out, "Odysseus lives according to the ancient principle which originally constituted bourgeois society. One had to choose between cheating and going under." ${ }^{229}$ Odysseus chooses to cheat nature, and the untruth of his sacrifice deflects attention away from the real sacrifice that defines existence according to the terms of market society, which is the endless postponement of true creative experience for the sake of attaining mere goals. As Horkheimer and Adorno further elaborate, "human beings have always

${ }^{229}$ Horkheimer and Adorno, Dialectic of Enlightenment, 49. 
had to choose between their subjugation to nature and its subjugation to the self,", ${ }^{, 30}$ but this false disjunctive only appears exhaustive because we have not yet found away to come to terms with nature as our fellow subject.

\section{Conclusion}

We may uphold our modern way of life as proof of our flourishing, and see our ability to harness nature to our purposes as a testament to our various successes, but in so doing we may in fact be missing the greater point: so long as we believe these things to be essential to our continued survival (be it biological or social), so long as they are expressions of selfpreservation, so long as we are afraid to explore the full possibilities of the present and let go of the constraints we place upon the future, then we are not free and we are not truly living - we are merely existing. Odysseus disarmed the Sirens by cheating them. But there is another way to disarm them, which is to drop in and pay them a visit. We would forfeit any sense of certainty about the future - itself a questionable security at best. But, if we were truly engaged, then we would all swim to the Sirens.

Which really brings me to my final point. Our lives are not defined by the objects we gaze upon and the things we listen to, but by the things that we do: the real knowledge scintillating in the Sirens' song is revealed to the singer as he sings. Meanwhile, in a society that was primarily concerned with human well-being it would indeed be possible as a normal part of life to swim to the Sirens, to sing with them and to not only survive somehow but to flourish. For, as creatures of reason and intellect as well as creativity, we do not need to distrust and cheat nature and nor do we need to be consumed by our own singing - we can hurl ourselves into it our song and then we can go home and practice. In a free society based on trust of ourselves and of

\footnotetext{
${ }^{230}$ Ibid., 25.
} 
each other and of nature we would be able to engage without engagement being an act of suicide, and in this we would finally discover a form of true freedom.

But, as things stand right now, the market is adversarial and it is bigger than us and so all endeavor must, necessarily, be diverted not to of our chosen future - although this of course is the myth upon which the market depends - but to the insatiable appetites of the market itself. So we genuflect - we sacrifice our health, our environment, our education, our creativity, and our future, while "the nimble-witted man survives only at the cost of his own dream....he can never have the whole, he must always be able to wait, to be patient, to renounce.." ${ }^{231}$ And since freedom remains, as it has always been in market society, "the freedom of the stupid to starve, in art as elsewhere, ${ }^{, 232}$ our creativity bides its time and earns its keep stuffing pretty, plastic baubles in the ears of the multitudes: brightly colored little bombs of mass culture to drown out the brutal reality of the world we have created for ourselves.

${ }^{231}$ Ibid., 45.

232 Ibid., 104. 


\section{Bibliography}

Adorno, Theodor W., and Max Horkheimer. "Culture Industry." In Dialectic of Enlightenment: Philosophical Fragments. Translated by Edmund Jeffcott.

Stanford University Press, 2002.

Aristotle. Nichomachean Ethics. Translated by Terence Irwin. Indianapolis: Hackett, 1999.

Beauvoir, Simone De. The Ethics of Ambiguity. Translated by Bernard Frechtman. New York: Citadel Press, 1976.

Epicurus, "The Leading Doctrines", in The Philosophy of Epicurus, ed. George K. Strodach, Chicago: Northwestern University Press, 1963), 196-203.

Franklin, Ursula M. The Real World of Technology. Toronto, Ont.: House of Anansi Press, 2004.

Graeber, David. Fragments of an Anarchist Anthropology. Chicago: Prickly Paradigm Press, 2004.

Hare, David. The Blue Touch Paper: A Memoir. London: Faber \& Faber, 2016. Quoted in the Guardian online edition, Web.theguardian.com. Accessed Aug.21 2015: https://www.theguardian.com/books/2015/aug/21/david-hare-v-establishment-memoir

Horkheimer, Max. Eclipse of Reason. Eastford Connecticut: Martino Publishing, 2013.

Jiro, Yoshiharo. "Gutai Art Manifesto." Web.guggenheim.org. Accessed April 17, 2015. http://web.guggenheim.org/exhibitions/gutai/data/manifesto.html

Kingsnorth, Paul, and Dougald Hine. Uncivilisation: The Dark Mountain Manifesto. Croydon, England: Dark Mountain Project, 2014.

Latour, Bruno. "Facing Gaia: A New Enquiry Into Natural Religion." Web.giffordlectures.org. June 27, 2015. Accessed December 15, 2014. https://www.giffordlectures.org/lectures/facing-gaia-new-enquiry-natural-religion

Marcuse, Herbert. The Aesthetic Dimension: Toward a Critique of Marxist Aesthetics. Boston: Beacon Press, 2003.

- Counter-Revolution and Revolt. Boston: Beacon Press, 1972. Eros and Civilization: A Philosophical Inquiry Into Freud. Boston: Beacon Press, 1966. An Essay on Liberation. Boston: Beacon Press, 1969. 
The Essential Marcuse: Selected Writings of Philosopher and Social Critic Herbert Marcuse. Edited by Andrew Feenberg and William Leiss.

Boston: Beacon Press, 2007.

Marx, Karl, and Friedrich Engels. The German Ideology. New York: Prometheus Books, 1998.

Marx, Karl. Capital. Translated by Ben Fowkes. Vol. 1. (London): Penguin Books, 1976.s

_Economic and Philosophical Manuscripts of 1844. Translated by Martin Milligan. New York: Prometheus Books, 1988.

- Grundrisse. Foundations of the Critique of Political Economy. Translated by Martin Nicolaus. New York: Vintage Books, 1973.

Karl Marx: A Reader. Edited by Jon Elster. Cambridge: Cambridge University Press, 1986.

_ Marx: Later Political Writings. Edited by Terrell Carver. Cambridge: Cambridge University Press, 2012.

Morris, Robert. "Anti Form." In Continuous Project Altered Daily. Cambridge MA: Mit Press, 1993. Web.Sculptureatprat.wordpress.com. Accessed at https://sculptureatpratt.files.wordpress.com/2015/07/robert-morris-continuous-projectaltered-daily-the-writings-of-robert-morris-1.pdf

Nguyen, Duy Lap. "The Angel of History and the Commodity Fetish: Walter Benjamin and the Marxian Critique of Political Economy." Constellations 22, no. 3 (2015): 341-53.

Roszak, Theodore. The Voice of the Earth. Grand Rapids MI: Phanes Press, 2001.

Schmidt, Alfred. The Concept of Nature in Marx. London: Verso, 2014.

Stravinsky, Igor, and Robert Craft. Expositions and Developments. Oakland CA: University of California Press, 1981.

- Poetics of Music: In the Form of Six Lectures. Cambridge: Harvard University Press, 1947.accessed July 252017 https://monoskop.org/images/6/64/Stravinsky_Igor_Poetics_of_Music_in_the_Form_of_ Six_Lessons.pdf

Wohlleben, Peter. The Hidden Life of Trees: What They Feel, How They Communicate: Discoveries from a Secret World. Translated by Jane Billinghurst. Vancouver: Greystone Books, 2016. 